\title{
NIST Leak Calibration Service
}

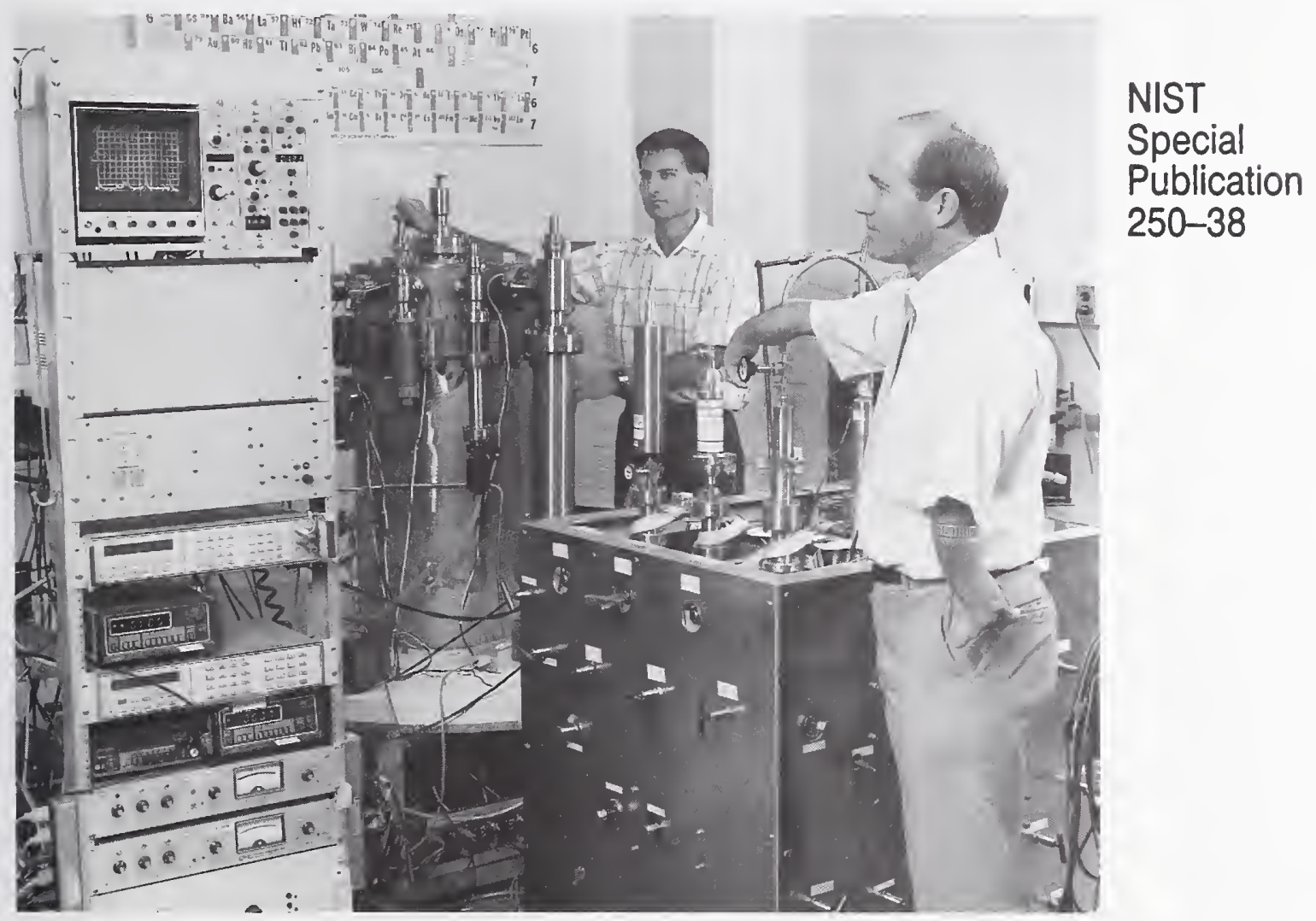

Charles D. Ehrlich and Stuart A. Tison 


\section{NIST MEASUREMENT SERVICES: NIST Leak Calibration Service}

Charles D. Ehrlich and Stuart A. Tison

Thermophysics Division

Chemical Science and Technology Laboratory National Institute of Standards and Technology

Gaithersburg, MD 20899

January 1992

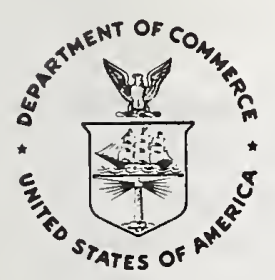

U.S. DEPARTMENT OF COMMERCE, Robert A. Mosbacher, Secretary TECHNOLOGY ADMINISTRATION

Robert M. White, Under Secretary for Technology

NATIONAL INSTITUTE OF STANDARDS AND TECHNOLOGY John W. Lyons, Director 
National Institute of Standards and Technology Special Publication 250-38 Natl. Inst. Stand. Technol. Spec. Publ. 250-38, 89 pages (Jan. 1992) CODEN: NSPUE2 
Calibrations and related measurement services of the National Institute of Standards and Technology provide the means for makers and users of measuring tools to achieve levels of measurement accuracy that are necessary to attain quality, productivity and competitiveness. These requirements include the highest levels of accuracy that are possible on the basis of the most modern advances in science and technology as well as the levels of accuracy that are necessary in the routine production of goods and services. More than 300 different calibrations, measurement assurance services and special tests are available from NIST to support the activities of public and private organizations. These services enable users to link their measurements to the reference standards maintained by NIST and, thereby, to the measurement systems of other countries throughout the world. NIST Special Publication 250, NIST Calibration Services Users Guide, describes the calibrations and related services that are offered, provides essential information for placing orders for these services and identifies expert persons to be contacted for technical assistance.

NIST Special Publication 250 has recently been expanded by the addition of supplementary publications that provide detailed technical descriptions of specific NIST calibration services and, together with the NIST Calibration Services Users Guide, they constitute a topical series. Each technical supplement (NIST SP 250- ) on a particular calibration service includes:
- specifications for the service
- design philosophy and theory
- description of the NIST measurement system
- NIST operational procedures
- measurement uncertainty assessment
- NIST internal quality control procedures

The new publications will present more technical detail than the information that can be included in NIST Reports of Calibration. In general they will also provide more detail than past publications in the scientific and technical literature; such publications, when they exist, tend to focus upon a particular element of the topic and other elements may have been published in different places at different times. The new series will integrate the description of NIST calibration technologies in a form that is more readily accessible and more useful to the technical user.

The present publication, SP 250-38, NIST Leak Calibration Service, by Charles D. Ehrlich and Stuart A. Tison, describes calibration technology and procedures utilized in connection with NIST Service Identification Number 30060 S listed in the NIST Calibration 
Services Users Guide 1989, pages 49 to 51 . Inquiries concerning the contents of these documents may be directed to the author(s) or to one of the technical contact persons identified in the Users Guide.

Suggestions for improving the effectiveness and usefulness of the new series would be very much appreciated at NIST. Likewise, suggestions concerning the need for new calibration services, special tests, and measurement assurance programs are always welcome.

Joe D. Simmons, Chief

Physical Measurement Services Program 
Preface

1. Introduction 1

2. Description of the NIST Leak Calibration Service 2

3. Design Philosophy and Theory 3

Design Philosophy: Introduction 3

Design Philosophy: NIST Primary Leak Standard 3

Flow into Upper Chamber 4

Extension of Low Flow Rate Measurements: Flow into

Lower Chamber 7

Measurement of Upper to Lower Chamber Flow Ratio 7

Flow into Lower Chamber 10

Design Philosophy: Leak Comparator System 11

4. Description of System and Operational Procedures 14

Primary Leak Standard System Description $\quad 14$

Leak Manifold 14

Main Vacuum Chamber 14

Bellows Flowmeter 15

Calibration of Helium Leaks $\quad 15$

NIST Leak Comparator System Description $\quad 17$

$\begin{array}{lr}\text { Temperature Coefficient Determination } & 18\end{array}$

5. Assessment of Uncertainties 20

$\begin{array}{ll}\text { Primary Leak Standard } & 20\end{array}$

Flowmeters 20

Temperature and Orifice Conductance $\quad 22$

Pumping Speed $\quad 22$

Upper Chamber Pressure Indication 23

Flow into Upper Chamber 24

Upper-to-Lower Chamber Flow Ratio 25

Flow into Lower Chamber 26

Summary Analysis: Calibration of Customer Leaks 27

Leak Comparator System 28

Temperature Coefficient Uncertainty 28

Summary Analysis: Calibration of Customer Leaks 28 
6. Quality Control

Control Charts

Closed-Reservoir Helium Permeation Leaks 30

Upper-to-Lower Chamber Flow Ratio 31

Comparison of Primary Standards $\quad 31$

Flowmeter Intercomparisons 31

Domestic Intercomparisons $\quad 32$

International Intercomparisons 33

7. Future 34

8. Acknowledgments $\quad 35$

9. References $\quad 37$

10. Bibliography 39

11. Appendices

A. Use and Conversion of Units of Flow Rate and Throughput A-1

B. General Theory of Gas Flow in Vacuum Systems B-1

C. A Note on Flow Rate and Leak Rate Units

(reprint of published article)

C-1

*

D. Low-Range Flowmeters for use with Vacuum and Leak

Standards (reprint of published article) D-1

* E. Sample Leak Calibration Report

E-1 


\section{LIST OF TABLES}

Page

1. Conversion of Units for Universal Gas Constant (R) 4

2. Bellows Flowmeter Uncertainties 21

3. Summary of Uncertainties for Flow into the Upper Chamber 25

4. Summary of Uncertainties for Flow into the Lower Chamber 27

A-1. Leak Rate Conversion Chart A-6 


\section{LIST OF FIGURES}

$\underline{\text { Page }}$

1. Simple Schematic of the NIST Primary Leak Standard 40

2. Schematic of the NIST Primary Leak Standard 41

3. Valving Sequence for Leak Calibration Through Upper Chamber 42

4. Valving Sequence for Leak Calibration Through Lower Chamber 43

5. Valving Sequence for Measurement of Upper to Lower Chamber Flow Ratio $\quad 44$

6. Schematic of Leak Comparator System 45

7. Temperature Dependence of Helium Permeation Leak 46

8. Measured vs. Actual Leak Rate Using Leak Comparator System 47

9. Valving Diagram of NIST Primary Leak Standard 48

10. Valving Diagram of Bellows Flowmeter 49

11. Piston Flowmeter Uncertainties 50

12. Bellows Flowmeter Uncertainties 51

13. Leak Control Chart for NBSL22 52

14. Control Chart of Upper to Lower Chamber Flow Ratio 53

15. Linearity of Leak Comparator System 54

16. Schematic Cross Section of NIST Permeation Leak 55

17. Random Uncertainties for Piston and Bellows Flowmeters 56

18. Measured Leak Rate Differences Between Flowmeters 57

19. Comparison Between NIST and Other Laboratories 58

20. Schematic Diagram of simple Gas Flow System: Single Piston 59

21. Schematic Diagram of simple Gas Flow System: Dual Pistons 60 
The industrial need for demonstrated accuracy of low-range gas flow rate or leak rate measurements used to calibrate leak detectors and gas analyzers, traceable to a recognized standards authority, prompted the National Institute of Standards and Technology (then the National Bureau of Standards) to initiate a Leak Standards Program in 1984. As helium leak detection has emerged as the most popular method of detecting even the smallest leaks, the demand for quantifying small flow rates of gaseous helium was quickly identified as the area in which to put the initial emphasis. A Special Test Service for helium permeation (or diffusion) leaks, covering the range of leak rates $10^{-8}$ to $10^{-11} \mathrm{~mol} / \mathrm{s}\left(2 \times 10^{-4}\right.$ to $2 \times 10^{-7} \mathrm{~atm} \mathrm{~cm}^{3} / \mathrm{s}$ ( $\left.0{ }^{\circ} \mathrm{C}\right)$ at room temperature, has been offered since the summer of 1986 . Helium permeation leak artifacts sent to the NIST Special Test Service by customers are calibrated over the temperature range 0 to $50{ }^{\circ} \mathrm{C}$. Presently, estimated total uncertainties $(3 \sigma)$ of the measurements performed on customer artifacts are typically between $\pm 5 \%$ and $\pm 15 \%$ over the range of the Special Test Service. There are small additional uncertainties as the equilibrium temperature varies from the $23^{\circ} \mathrm{C}$ reference temperature.

The overall objective of the NIST Leak Standards Program is to provide a Leak Calibration Service to the user community. This first required the development of a primary leak standard suitable for accurately calibrating a transportable leak artifact (or "transfer leak") over the range of leak rates and gas species required by the users. It also necessitated the characterization of the stability and reproducibility of transfer leaks over the long and short term, under both static and dynamic conditions. All of these types of studies, in conjunction with a leak calibration service, allow the transfer of measurements from NIST standards to the users, with estimable uncertainty levels. In order to help the users make the best use of these capabilities, NIST staff members also participate in instructional seminars and workshops, and provide documentation.

This document describes in detail the Primary Leak Standard and Leak Comparator system (on which the temperature dependence of the leaks is determined), deriving the equations that are used to calculate the leak rate from a leak artifact based on the experimental parameters, and evaluating the uncertainties associated with the measurements. A discussion of the observed behavior of helium permeation leak artifacts will also be provided, as will a discussion of the units that are used (and frequently misused) to describe gas flow rate. It will conclude with a look at outstanding problems in the Leak Standards Program and Leak Calibration Service. 


\section{DESCRIPTION OF THE NIST LEAK CALIBRATION SERVICE}

The Thermophysics Division of the National Institute of Standards and Technology provides a Calibration Service* for helium permeation leak artifacts in the range $10^{-8}$ to $10^{-11} \mathrm{~mol} / \mathrm{s}\left(2 \times 10^{-4}\right.$ to $2 \times 10^{-7}$ atm cc/s @ $\left.0{ }^{\circ} \mathrm{C}\right)$. A Calibration Report, which presents the measured value of leak rate over a nominal temperature range of 0 to $50^{\circ} \mathrm{C}$ is issued for each artifact submitted.

At this time, all leak artifacts submitted for measurement must meet the following specifications:

1) Nominal value of helium leak rate of the artifact at room temperature must be between $10^{-8}$ and $10^{-11} \mathrm{~mol} / \mathrm{s}\left(2 \times 10^{-4}\right.$ and $2 \times 10^{-7} \mathrm{~atm} \mathrm{cc} / \mathrm{s}$ (a $0{ }^{\circ} \mathrm{C}$ ).

2) Construction: all-metal reservoir and tubing, of ultra-high vacuum type design, ending in a standard 2.75" conflat-type flange on the vacuum end, and a helium reservoir.

3) The leak element must be of a sealed glass design, permeable to helium gas, and structurally rugged.

4) An easily observable customer identification number or code must be engraved on the circumference of the $2.75 "$ flange.

This Calibration Service must be scheduled in advance. To obtain a Test Authorization Number and shipping instructions, send a request stating name, organization, mailing address, telephone number, number of leak artifacts to be calibrated (with nominal leak rates, at room temperature, in mol/s), and any other pertinent information to:

Mr. Stuart Tison

Leak Program, Special Test Service

Metrology Building/A55

National Institute of Standards and Technology

Gaithersburg, MD 20899

(301) $975-2857$

For further information, contact Mr. Stuart Tison (301) 975-2857 or Dr. Charles Tilford (301) 975-4828.

*This Calibration Service involves measurement or calibration methods which are continually being perfected. Refer to NBS SP250 for updates on the status of this Service. 


\section{DESIGN PHILOSOPHY AND THEORY}

\section{DESIGN PHILOSOPHY: INTRODUCTION}

The Primary Leak Standard that has been developed at NIST is shown schematically in figure 1. This type of apparatus was chosen over several alternatives because it benefits from considerable development work already completed in the NIST high vacuum standards program [1]. The standard is divided into three major components: the main vacuum system, the constantpressure flowmeter, and the manifold on which the leak is mounted. In the first stage of operation, gas is allowed to flow from the leak into the "upper chamber" of the main vacuum chamber, through an orifice into the "lower chamber" of the main vacuum chamber, where it is subsequently exhausted by the pump. When an equilibrium flow rate has been established, the pressure generated in the upper chamber is recorded. The leak is then valved out of the vacuum system and a flow is subsequently established from the flowmeter and adjusted so that the same pressure indication, measured with either an ionization gage or a partial pressure analyzer (tuned to the gas species being measured), is achieved in the upper chamber. This flow rate is then measured using the flowmeter, and to a first approximation the leak rate would be set equal to the measured flow rate. The details that go into providing a more highly refined analysis will be discussed subsequently. In addition, the use of a flow division technique (also discussed later), where gas from the flowmeter is valved into the lower chamber (not indicated in fig. 1), allows extension of the dynamic range of the system to lower flow rates. To date, this system has been operated and errors evaluated for flow rates between $10^{-6}$ and $10^{-12} \mathrm{~mol} / \mathrm{s} .[2,3]$ (See Appendix A for a discussion of flow rate units.) An overview of the general theory of gas flow as it pertains to the flowmeter and leak geometries can be found in Appendix B.

\section{DESIGN PHILOSOPHY: NIST PRIMARY LEAK STANDARD}

The schematic diagram of the NIST Primary Leak Standard presented earlier in figure 1 is shown in slightly more detail in figure 2, where it can be seen that gas flow from either the leak to be calibrated or either of two constantpressure flowmeters can be directed into the "upper chamber" or "lower chamber" of the main vacuum chamber. In a typical calibration sequence, once background pressure indications in the upper chamber are recorded for various valving configurations with no gas flow, flow from the leak is then directed into the upper chamber. The gas flow is allowed to stabilize (as monitored by recording the upper chamber pressure indications on a strip chart recorder), and equilibrium upper chamber pressure indications and pump speed are then recorded (as are the temperature of the main vacuum chamber and the leak). This process is indicated schematically as step 1 in figures 3 and 4 . In Step 2 , the leak is valved out and gas is introduced into one of the two flowmeters (see Appendices $B$ and D and the next section on Description of System for details on design and operation of the flowmeters), which admits gas into either the upper chamber (fig. 3) or the lower chamber (fig. 4) of the main chamber via a variable leak valve. 
After Step 2 of the calibration process the system is allowed time to equilibrate, at which point the valving in the flowmeter is configured and the flowmeter electronics are activated so that the flow rate of the gas emanating from the variable leak valve is measured. This measurement is accomplished by measuring the rate of change of the volume $(d V / d t)$ of the working reservoir required to maintain a constant pressure $\left(P_{w}\right)$ in the working reservoir, which is at temperature $T_{w}$ (indicated schematically in step 3 of fig. 3 ). The leak rate from the leak can then be calculated according to:

$$
\dot{\mathrm{N}}_{\mathrm{L}}=\frac{\mathrm{P}_{\mathrm{w} 3}(\mathrm{dV} / \mathrm{dt})}{\mathrm{R} \cdot \mathrm{T}_{\mathrm{W} 3}}\left[\frac{\mathrm{P}_{\mathrm{U} 1}}{\mathrm{P}_{\mathrm{U} 3}}\right] \cdot\left[\frac{\mathrm{T}_{03}}{\mathrm{~T}_{01}}\right]^{1 / 2} \cdot\left[\frac{\mathrm{S}_{1}}{\mathrm{~S}_{3}} \cdot \frac{\mathrm{C}_{03}+\mathrm{S}_{3}}{\mathrm{C}_{01}+\mathrm{S}_{1}}\right]
$$

where the subscripts ( 1 or 3 ) refer to the Step Number in figure $3, P_{U}$ is the pressure indication in the upper chamber, $\mathrm{T}_{\mathrm{o}}$ is the temperature of the main vacuum chamber (and orifice), $S$ is the pumping speed of the combination of the turbomolecular pump and entrance plumbing, $C_{\circ}$ is the conductance of the orifice, and $\mathrm{R}$ is the universal gas constant (see table 1).

Table 1. Conversion of Units for Universal Gas Constant ( $R$ )

$$
\begin{array}{rlrl}
R & =8.31441 & & \text { Joule mol-1 } \mathrm{K}^{-1} \\
& =8.31441 & & \mathrm{~Pa} \mathrm{~m} \mathrm{~mol}^{-1} \mathrm{~K}^{-1} \\
& =8.31441 \times 10^{3} & \mathrm{~Pa} \ell \mathrm{mol}^{-1} \mathrm{~K}^{-1} \\
& =8.31441 \times 10^{6} & & \mathrm{~Pa} \mathrm{~cm} \mathrm{~mol}^{-1} \mathrm{~K}^{-1} \\
& =62.3634 & & \text { Torr } \ell \mathrm{mol}^{-1} \mathrm{~K}^{-1} \\
& =62.3634 \times 10^{3} & & \text { Torr cm mol-1 } \mathrm{K}^{-1} \\
& =82.05685 & & \text { atm } \mathrm{cm}^{3} \mathrm{~mol}^{-1} \mathrm{~K}^{-1}
\end{array}
$$

Equation (1) can be derived by using the principles developed in Appendix B as follows. Beginning with figure 3 , Step 1 , once steady state flow is achieved, the conservation of total number of molecules requires that the flow rate of gas leaving the leak $\left(\hat{N}_{\ell}\right)$ be the same as the flow rate of gas passing through the orifice $\left(\dot{\mathrm{N}}_{01}\right)$, which from eq (B5) in Appendix $B$ is: 


$$
\dot{\mathrm{N}}_{\ell}=\dot{\mathrm{N}}_{\mathrm{o} 1}=\frac{\left(\mathrm{P}_{\mathrm{U} 1}-\mathrm{P}_{\mathrm{L} 1}\right) \cdot \mathrm{C}_{\mathrm{o} 1}}{\mathrm{R} \cdot \mathrm{T}_{\mathrm{o} 1}}
$$

where $P_{L_{1}}$ is the pressure in the lower chamber. But this must also equal the flow rate of gas through the pump, which from eq (B12) is

$$
\dot{\mathrm{N}}_{\mathrm{s} 1}=\frac{\mathrm{P}_{\mathrm{L}_{1}} \cdot \mathrm{S}_{1}}{\mathrm{R} \cdot \mathrm{T}_{\mathrm{O} 1}} \text {. }
$$

Equating $\dot{\mathrm{N}}_{\ell}$ with $\dot{\mathrm{N}}_{\mathrm{s} 1}$ then gives

$$
\mathrm{P}_{\mathrm{U}_{1}}=\mathrm{P}_{\mathrm{L}_{1}} \cdot\left[1+\frac{\mathrm{S}_{1}}{\mathrm{C}_{\mathrm{o} 1}}\right] \text {. }
$$

Combining eqs (2) and (4) then gives

$$
\dot{\mathrm{N}}_{\ell}=\mathrm{P}_{\mathrm{U} 1} \cdot\left[\frac{\mathrm{S}_{1} \cdot \mathrm{C}_{\mathrm{o} 1}}{\mathrm{C}_{\mathrm{o} 1}+\mathrm{S}_{1}}\right] /\left(\mathrm{R} \cdot \mathrm{T}_{\mathrm{o} 1}\right)
$$

Turning now to step 3 of figure 3 , arguments similar to those used to derive eq (4) yield

$$
\mathrm{P}_{\mathrm{U} 3}=\mathrm{P}_{\mathrm{L} 3} \cdot\left[1+\frac{\mathrm{S}_{3}}{\mathrm{C}_{\mathrm{o} 3}}\right] \text {. }
$$

Also, the flow rate through the orifice:

$$
\dot{\mathrm{N}}_{03}=\frac{\left(\mathrm{P}_{\mathrm{U} 3}-\mathrm{P}_{\mathrm{L} 3}\right) \cdot \mathrm{C}_{03}}{\mathrm{R} \cdot \mathrm{T}_{03}}
$$

must be equal to the flow rate as measured by the flowmeter:

$$
\dot{\mathrm{N}}_{F M}=\frac{\mathrm{P}_{\mathrm{x} 3}(\Delta \mathrm{V} / \Delta t)}{R \cdot \mathrm{T}_{\mathrm{W} 3}} .
$$


When comparing eq (8) and the corresponding parameters in eq (1), note that $P_{r 3}$ replaces $P_{w 3}$ and that $\Delta V / \Delta t$ replaces $d V / d t$. This is due to the fact that in the flowmeter, it is the reference volume pressure $\left(P_{r}\right)$ and not the working volume pressure $\left(P_{W}\right)$ that is measured experimentally, and the instantaneous volume rate of change of the working volume (dV/dt) is actually determined experimentally as the change in volume $\Delta V$ over a measured time interval $\Delta t$. The temperature of the working volume $\left(T_{w}\right)$ is equal to the temperature of the reservoir volume $\left(T_{r}\right)$. The implications are discussed in the section on Assessment of Uncertainties. Equating the right hand sides of eqs (7) and ( 8 ), solving the resulting equation for $P_{L_{3}}$, and substituting $P_{L_{3}}$ into eq (6) results in

$$
P_{U 3}=\left[\frac{C_{03}+S_{3}}{C_{03} \cdot S_{3}}\right] \cdot P_{x_{3}} \cdot(\Delta V / \Delta t) \cdot\left(T_{03} / T_{r_{3}}\right)
$$

Dividing eq (5) by eq (9) then gives equation (10), where the functional dependence of the conductance $\left(C_{0}\right)$ on temperature $\left(C_{0} \propto \sqrt{ } T_{0}\right)$ for conditions of molecular flow has been incorporated, as have the experimentally derivable quantities $\mathrm{P}_{\mathrm{r}}$ and $\Delta \mathrm{V} / \Delta \mathrm{t}$ :

$$
\dot{\mathrm{N}}_{\mathrm{L}}=\frac{\mathrm{P}_{\mathrm{r} 3}(\Delta \mathrm{V} / \Delta \mathrm{t})}{\mathrm{R} \cdot \mathrm{T}_{\mathrm{r} 3}}\left[\frac{\mathrm{P}_{\mathrm{U} 1}}{\mathrm{P}_{\mathrm{U} 3}}\right] \cdot\left[\frac{\mathrm{T}_{03}}{\mathrm{~T}_{\mathrm{o} 1}}\right]^{\frac{1}{2}} \cdot\left[\frac{\mathrm{S}_{1}}{\mathrm{~S}_{3}} \cdot \frac{\mathrm{C}_{\mathrm{o} 3}+\mathrm{S}_{3}}{\mathrm{C}_{\mathrm{o} 1}+\mathrm{S}_{1}}\right] .
$$

There are several points worth noting about eq (10). First, only the pressure ratio $\mathrm{P}_{U_{1}} / \mathrm{P}_{U_{3}}$ is involved, so that it is not necessary to know the absolute pressures in the upper chamber. What is required is a gage that is stable during the course of the measurement process (typically 6 to $8 \mathrm{~h}$ ), and that is linear over the relatively small $1 \%$ or less of reading that separates $P_{\mathrm{u} 1}$ and $\mathrm{P}_{\mathrm{u} 3}$. If the gage is of the total pressure type, then it is also important that any differential impurities in the gas flows be accounted for. Mass spectra are routinely taken using a quadrupole residual gas analyzer at each stage of the measurement process to monitor for this eventuality. One total pressure ionization gage and two residual gas analyzers tuned to the mass species being measured are typically used to record $P_{U}$. Another noteworthy point is that the orifice conductance in the NIST Primary Leak Standard $\left(\mathrm{C}_{0}\right)$ is on the order of $40 \mathrm{l} / \mathrm{s}$ for helium, while the pumping speed is roughly $2500 \mathrm{l} / \mathrm{s}$, so that the last term in eq (10) is very nearly equal to 1 for any reasonable fluctuation in pumping speed and is usually ignored (note that a similar term is not ignored in the next section, however!). As an example, if the pumping speed differs by $1 \%$ between the two measurements, so that $\mathrm{S}_{3}=2488 \mathrm{l} / \mathrm{s}$ and $\mathrm{S}_{1}=2512 \mathrm{l} / \mathrm{s}$, the last factor in brackets in eq (10) is equal to 1.0002 . While the temperature ratio factor is also very nearly 
equal to 1 for the slight variations in room temperature, it is routinely retained in the data analysis routine. A difference of $1{ }^{\circ} \mathrm{C}$ in the chamber temperature results in a correction factor of 1.002 in eq (10). Further discussion concerning sources of uncertainties associated with this equation is in the Assessment of Uncertainties section.

Another important point concerning eq (10) is that it is an equation representing the measured value of the leak rate for the leak at temperature $\mathrm{T}_{\mathrm{L}}$, as indicated in Step 1 of figure 3. The data analysis routine subsequently determines what the leak rate would have been if the leak had been measured at $23^{\circ} \mathrm{C}$, using the previously determined temperature dependence of the leak (see section on Leak Comparator).

\section{Extension of Low Flow Rate Measurements:} Flow into Lower Chamber

At flow rates of about $10^{-12} \mathrm{~mol} / \mathrm{s}$, the uncertainties associated with the flowmeters approach the $10 \%$ level. To extend the measurement capabilities of the system to lower flow rates while keeping uncertainties at a reasonable level, it is necessary to utilize a flow division technique, as illustrated in figure 4. The principle behind the flow division technique is that, for constant orifice conductance and pumping speed, the ratio of [the flow rate into the upper chamber that gives any upper chamber pressure (that results in molecular flow through the orifice)] to [the flow rate into the lower chamber that results in the same upper chamber pressure] is a constant. This constant can be measured using relatively high flow rates into both chambers, where the uncertainties associated with the flowmeters will be low, and then used at lower flow rates. There are of course additional uncertainties associated with measuring these flow ratios, as will be discussed subsequently.

\section{Measurement of Upper to Lower Chamber Flow Ratio}

Figure 5 illustrates the two main steps involved in measuring the ratio of flows $\left(R_{U / L}\right)$ that give the same upper chamber pressure indication. In Step 1 , gas at pressure $P_{r 1}$ is admitted into the flowmeter and valved into the upper chamber (resulting in an upper chamber pressure of $P_{U 1}$ and a lower chamber pressure of $P_{L_{1}}$ ), the system is allowed to equilibrate, and the flow rate of the gas is measured using the flowmeter. In step 2, gas is again admitted into the flowmeter but now valved into the lower chamber. The gas admitted to the flowmeter is at a pressure $P_{r 2}$ such that the upper chamber pressure $P_{U 2}$ is very nearly equal to the upper chamber pressure $P_{U 1}$ from Step 1 . Since $P_{U 1}$ and $\mathrm{P}_{\mathrm{U} 2}$ are seldom exactly equal, nor are the chamber temperatures or pumping speeds in the two steps usually equal, it is necessary to derive an expression for the ratio $R_{U / L}$ that corrects for these differences and so refers to a single temperature $\left(\mathrm{T}_{0}\right)$ and pumping speed (S). In principle (as will be shown), for a given gas specie and orifice geometry, $R_{U / L}$ is a function of $T_{0}$ and $\mathrm{S}$ only. 
From Step 1, conservation of flow rate $\left(\dot{\mathbb{N}}_{1}\right)$ at the flowmeter, orifice and pump gives:

$$
\dot{\mathrm{N}}_{1}=\frac{\mathrm{P}_{\mathrm{L} 1} \cdot \mathrm{S}_{1}}{\mathrm{R} \cdot \mathrm{T}_{\mathrm{O} 1}}
$$

and

$$
P_{U_{1}}=P_{L_{1}} \cdot\left(1+\frac{S_{1}}{C_{01}}\right) .
$$

In Step 2, under equilibrium conditions, there can be no net flow across the orifice, so that

$$
P_{U 2}=P_{L 2}
$$

and conservation of flow rate $\left(\dot{\mathrm{N}}_{2}\right)$ from the flowmeter to the pump gives

$$
\dot{\mathrm{N}}_{2}=\frac{\mathrm{P}_{\mathrm{L} 2} \cdot \mathrm{S}_{2}}{\mathrm{R} \cdot \mathrm{T}_{\mathrm{o} 2}}
$$

Substituting $P_{L_{1}}$ from eq (12) into eq (11), and $P_{L_{2}}$ from eq (13) into eq (14), and dividing the two resulting equations gives

$$
\mathrm{R}_{\mathrm{L} / \mathrm{U}} \equiv\left(\dot{\mathrm{N}}_{2} / \dot{\mathrm{N}}_{1}\right)=\frac{\mathrm{P}_{\mathrm{U} 2} \cdot \mathrm{S}_{2} \cdot \mathrm{T}_{\mathrm{o} 1}}{\mathrm{P}_{\mathrm{U} 1} \cdot \mathrm{S}_{1} \cdot \mathrm{T}_{\mathrm{o} 2}} \cdot\left(1+\frac{\mathrm{S}_{1}}{\mathrm{C}_{01}}\right) .
$$

Note that if $P_{U}, S$ and $T_{0}$ were not to change from Step 1 to Step 2 , then eq (15) would collapse to the last factor in parentheses, which depends only on $S$ and $C_{o}$ (which is proportional to $\sqrt{T_{0}}$ ). It is the last factor, $1+\left(S_{1} / C_{o}\right)$, that represents the true ratio $\left(\mathrm{R}_{\mathrm{L}} / \mathrm{U}\right)_{\mathrm{t}}$ being sought. However, the pumping speed and orifice conductance are not known, so that eq (15) cannot be used to calculate this ratio. Instead, the experimentally determined ratio comes from the two flowmeter measurements: 


$$
\left(R_{\mathrm{L} / U}\right)_{\mathrm{m}}=\frac{\mathrm{P}_{\mathrm{r} 2} \cdot(\Delta \mathrm{V} / \Delta t)_{2} \cdot \mathrm{T}_{\mathrm{r} 1}}{\mathrm{P}_{\mathrm{r} 1} \cdot(\Delta \mathrm{V} / \Delta t)_{1} \cdot \mathrm{T}_{\mathrm{r} 2}}
$$

where the subscript " $m$ " refers to the measured quantity. Substituting eq (16) into eq (15) and solving for $\left(R_{L / U}\right)_{t}$ (referenced to $S_{1}$ and $T_{o 1}$ ) gives:

$$
\left(R_{\mathrm{L} / \mathrm{U}}\right)_{\mathrm{t}}\left(\mathrm{S}_{1}, \mathrm{~T}_{\mathrm{o} 1}\right)=\frac{\mathrm{P}_{\mathrm{r} 2} \cdot(\Delta \mathrm{V} / \Delta \mathrm{t})_{2} \cdot \mathrm{T}_{\mathrm{r} 1}}{\mathrm{P}_{\mathrm{r} 1} \cdot(\Delta \mathrm{V} / \Delta \mathrm{t})_{1} \cdot \mathrm{T}_{\mathrm{r} 2}} \cdot \frac{\mathrm{P}_{\mathrm{U} 1} \cdot \mathrm{S}_{1} \cdot \mathrm{T}_{\mathrm{o} 2}}{\mathrm{P}_{\mathrm{U} 2} \cdot \mathrm{S}_{2} \cdot \mathrm{T}_{\mathrm{O} 1}} .
$$

Equation (17) represents an individual measurement of lower chamber to upper chamber flow ratio for a specific set of conditions, namely the chamber temperature $T_{01}$ and the pumping speed $S_{1}$. Experimentally, several such measurements are typically performed over a 1 to 2 week period. Since the pumping speeds and chamber temperatures vary over this time period, it is in principle necessary to reference each measurement to a common set of $\mathrm{T}_{\mathrm{ref}}$ and $\mathrm{S}_{\mathrm{ref}}$. This is most easily accomplished by using the 'definition' of $\left(\mathrm{R}_{\mathrm{L} / \mathrm{U}}\right)_{\mathrm{t}}$ :

$$
\begin{aligned}
\left(R_{L / U}\right)_{t}\left(S_{r e f}, T_{r e f}\right) & =\frac{\left[1+\left(S_{r e f} / C_{r e f}\right)\right]}{\left[1+\left(S_{1} / C_{o 1}\right)\right]} \cdot\left(R_{L / U}\right)_{t}\left(S_{1}, T_{o 1}\right) \\
& \approx\left[\frac{S_{r e f}}{S_{1}}\right] \cdot\left[\frac{C_{o 1}}{C_{r e f}}\right] \cdot\left(R_{L / U}\right)_{t}\left(S_{1}, T_{o 1}\right) \\
& =\left[\frac{S_{r e f}}{S_{1}}\right] \cdot\left[\frac{T_{o 1}}{T_{r e f}}\right]^{\frac{1}{2}} \cdot\left(R_{L / U}\right)_{t}\left(S_{1}, T_{o 1}\right) .
\end{aligned}
$$

As will also be discussed in section $V$, the turbomolecular pump speed $S$ has been found to vary linearly with the pump rotational frequency, so the ratio $\mathrm{S}_{\mathrm{ref}} / \mathrm{S}_{1}$ can be replace by $\mathrm{f}_{\mathrm{ref}} / \mathrm{f}_{1}$, where $\mathrm{f}$ is the measured frequency. Although the frequency has varied by as much as $5 \%$ in the past, with regulation of the pump controller input voltage the frequency now varies by less than 0.18 during the course of a day.

The average value (denoted $\mathrm{R}_{\mathrm{L} / \mathrm{U}}\left(\mathrm{S}, \mathrm{T}_{\mathrm{O}}\right)$ ) of the set of measured values from eq (17) or (20) is then referred to as the lower-to-upper flow ratio, and its inverse will be denoted as $\mathrm{R}_{\mathrm{U} / \mathrm{L}}\left(\mathrm{S}, \mathrm{T}_{\mathrm{O}}\right.$ ). In practice, $\mathrm{T}_{\mathrm{o}}$ is $298.15 \mathrm{~K}$ (or 25 ${ }^{\circ} \mathrm{C}$ ), and $\mathrm{f}_{\mathrm{ref}}$ is $577 \mathrm{~Hz}$. Typical fluctuations in the measured flow ratio of helium are as large as $2 \%$ from day to day. A typical control chart showing the measured values is presented in the section on quality control (see fig. 13). 
With the upper-to-lower chamber flow ratio now determined, it is possible to use the technique shown in figure 4 to measure flow rates below $10^{-12} \mathrm{~mol} / \mathrm{s}$ with the flowmeter, or to measure higher flow rates with smaller uncertainties than can be obtained using the direct flow technique of figure 3 . Step 1 of figure 4 shows the leak valved into the upper chamber of the main vacuum chamber. After equilibration, the various parameters are recorded. In Step 2, gas is introduced into the flowmeter, and the valving is such that the gas flows into the lower chamber. The reference reservoir pressure $\left(P_{\mathrm{r} 2}\right)$ is such that the upper chamber pressure $\left(P_{U_{2}}\right)$ is very nearly equal to the upper chamber pressure when gas from the leak flows into the system $\left(\mathrm{P}_{\mathrm{U}_{1}}\right)$. Once the system has equilibrated, the flowmeter is used to measure the flow rate into the lower chamber $\left(\dot{\mathrm{N}}_{3}\right)$, as indicated in step 3 .

To derive an expression for the leak rate $\left(\mathrm{N}_{\mathrm{L}}\right)$ in terms of the measured parameters, we proceed as in the previous sections. From step 1, conservation of flow rate at the leak, orifice and pump gives:

$$
\dot{\mathrm{N}}_{\mathrm{L}}=\frac{\mathrm{P}_{\mathrm{L} 1} \cdot \mathrm{S}_{1}}{\mathrm{R} \cdot \mathrm{T}_{\mathrm{O} 1}}
$$

and

$$
\mathrm{P}_{\mathrm{U}_{1}}=\mathrm{P}_{\mathrm{L}_{1}} \cdot\left(1+\frac{\mathrm{S}_{1}}{\mathrm{C}_{\mathrm{o} 1}}\right)
$$

In Step 3, under equilibrium conditions, there can be no net flow across the orifice, so that

$$
\mathrm{P}_{\mathrm{U} 3}=\mathrm{P}_{\mathrm{L} 3}
$$

and conservation of flow rate $\left(\dot{\mathrm{N}}_{3}\right)$ from the flowmeter to the pump gives

$$
\dot{\mathrm{N}}_{3}=\frac{\mathrm{P}_{\mathrm{L} 3} \cdot \mathrm{S}_{3}}{\mathrm{R} \cdot \mathrm{T}_{\mathrm{0} 3}} \text {. }
$$

Substituting $P_{L_{1}}$ from eq (22) into eq (21), $P_{L_{3}}$ from eq (23) into eq (24), and dividing the two resulting equations by each other gives 


$$
\dot{\mathrm{N}}_{3} / \dot{\mathrm{N}}_{\mathrm{L}}=\frac{\mathrm{P}_{\mathrm{U} 3} \cdot \mathrm{S}_{3} \cdot \mathrm{T}_{\mathrm{o} 1}}{\mathrm{P}_{\mathrm{U} 1} \cdot \mathrm{S}_{1} \cdot \mathrm{T}_{\mathrm{o} 3}} \cdot\left(1+\frac{\mathrm{S}_{1}}{\mathrm{C}_{\mathrm{o} 1}}\right) .
$$

From the discussion in the previous section, the last factor on the right in eq (25), $1+S_{1} / C_{o 1}$, is the theoretical flow rate ratio $\left(R_{L / U}\right)_{t}$ for pump speed $S_{1}$ and orifice conductance $C_{01}$. Its average value is denoted by $\mathrm{R}_{\mathrm{L} / \mathrm{U}}\left(\mathrm{S}_{1}, \mathrm{C}_{\mathrm{O} 1}\right)$, and its inverse as $\mathrm{R}_{\mathrm{U} / \mathrm{L}}\left(\mathrm{S}_{1}, \mathrm{C}_{\mathrm{O}_{1}}\right)$, so that eq (25) can be rewritten as

$$
\begin{aligned}
\stackrel{\mathrm{N}}{\mathrm{L}} & =\mathrm{R}_{\mathrm{U} / \mathrm{L}}\left(\mathrm{S}_{1}, \mathrm{~T}_{\mathrm{O} 1}\right) \cdot \dot{\mathrm{N}}_{3} \cdot \frac{\mathrm{P}_{\mathrm{U} 1} \cdot \mathrm{S}_{1} \cdot \mathrm{T}_{\mathrm{O} 3}}{\mathrm{P}_{\mathrm{U} 3} \cdot \mathrm{S}_{3} \cdot \mathrm{T}_{01}} \\
& =R_{\mathrm{U} / \mathrm{L}}\left(\mathrm{S}_{1}, \mathrm{~T}_{01}\right) \cdot \frac{\mathrm{P}_{\mathrm{r} 3} \cdot(\Delta \mathrm{V} / \Delta \mathrm{t})_{3}}{\mathrm{R} \cdot \mathrm{T}_{\mathrm{r} 3}} \cdot \frac{\mathrm{P}_{\mathrm{U} 1} \cdot \mathrm{S}_{1} \cdot \mathrm{T}_{\mathrm{O} 3}}{\mathrm{P}_{\mathrm{U} 3} \cdot \mathrm{S}_{3} \cdot \mathrm{T}_{01}} .
\end{aligned}
$$

Equation (27) is then the basis for measurement of the leak rate from a leak using the flow division technique, where the upper-to-lower flow ratio $\left(R_{U / L}\right)$ is measured at relatively high flow rates using the method of the previous section. As noted earlier in reference to eq (10), this expression for the leak rate is for the leak at temperature $T_{L}$.

\section{DESIGN PHILOSOPHY: LEAK COMPARATOR SYSTEM}

Once the leak rate from one leak undertest has been measured on the Primary Leak Standard (for the leak referenced to a particular temperature), it is possible to use this "standard" leak to measure other "unknown" leaks by direct comparison. This comparison function can be performed on the Leak Comparator System (LCS). An additional function of the LCS is to measure the temperature dependence of the unknown leak, which is accomplished by varying the temperature of the unknown leak and comparing the resulting leak rate with the leak rate of the standard leak (which is kept near its reference temperature). Both of these functions of the LCS rely on determination of the LCS linearity, which has been investigated experimentally [4].

The Leak Comparator System is shown schematically in figure 6 (a more complete discussion of the system is given in the Description of System section). Basically, a rectangular high vacuum manifold with pneumatically controlled valves on the corners (designated $V_{i}$, where $i=6$ to 9 ) is connected to a commercial helium leak detector (along the leg $V_{6}-V_{7}$ ). The leak to be characterized ("unknown" leak) is connected to the manifold in the $\mathrm{V}_{7}-\mathrm{V}_{9}$ leg, and the leak with which it is to be compared ("standard" leak) is connected to the manifold in the $V_{6}-V_{8}$ leg. A turbomolecular pump $(50 l / s)$ is connected to the manifold along the $V_{8}-V_{9}$ leg. Gas from either the unknown 
leak or standard leak, or both leaks, can be valved into the leak detector. When gas from a leak is not routed to the leak detector, then it is routed to the turbo pump, so that both leaks are continuously pumped. The unknown leak is encased in a temperature-controlled environment, with a controllable temperature range from -10 to $60{ }^{\circ} \mathrm{C}$. The standard leak is thermally insulated, and the temperatures of both leaks are monitored with platinumresistance thermometers (PRTs). The output voltage from the leak detector electrometer and PRTs is converted through an analog to digital converter $(A D C)$ to be read by a computer, which also controls sequencing of the automated data acquisition system. Data is usually taken at $5{ }^{\circ} \mathrm{C}$ increments from 0 to $50^{\circ} \mathrm{C}$.

The equilibrium temperature dependence of leak rates from leaks depends strongly on the type of leak element (through which the gas "leaks") inside the leak. For orifice-type leaks, over a limited but useful temperature range, the temperature dependence can be represented according to:

$$
\mathrm{L}(\mathrm{T})=\mathrm{L}_{\mathrm{o}} \cdot\left[1+\alpha \cdot\left(\mathrm{T}-\mathrm{T}_{\mathrm{o}}\right)\right]
$$

where $\mathrm{L}(\mathrm{T})$ is the leak rate for the leak at temperature $\mathrm{T}, \mathrm{L}_{\circ}$ is the leak rate for the leak at temperature $T_{0}$, and $\alpha$ is referred to as the "linear temperature coefficient" of the leak. For permeation or diffusion leaks, however, the temperature dependence is exponential [2]:

$$
\begin{aligned}
\mathrm{L}(\mathrm{T}) & =A \cdot \mathrm{T} \cdot \mathrm{e}^{-\mathrm{B} / \mathrm{T}} \\
& =\mathrm{L}_{\mathrm{o}} \cdot\left(\mathrm{T} / \mathrm{T}_{\mathrm{o}}\right) \cdot \mathrm{e}^{-\mathrm{B} \cdot\left(\mathrm{T}_{\mathrm{o}}-\mathrm{T}\right) /\left(\mathrm{T} \cdot \mathrm{T}_{\mathrm{o}}\right)}
\end{aligned}
$$

where B is referred to as the "exponential temperature coefficient" of the leak, and $A$ has been solved for explicitly in eq (30) in terms of $L_{0}$ and $T_{0}$. Figure 7 shows data ( + ), obtained using the LCS, and the fitted curve for a helium permeation leak. The data were fit using eq (29), and the resulting curve is arbitrarily normalized to unity at the $\mathrm{T}=0{ }^{\circ} \mathrm{C}$ leak rate value. Note that the leak rate increases by a factor of almost seven over the temperature span used for this leak, not an uncommon result for a permeation leak. The value of $B$ is typically between 2200 and $3500 \mathrm{~K}$, and for many commercial helium permeation leaks is close to $3000 \mathrm{~K}$. It is clear from this figure that the detection system of the LCS must be linear or errors will be introduced when fitting the data. Figure 8 shows a plot of the measured leak rate versus the actual leak rate over one decade of operating range of the LCS, indicating a maximum deviation from linearity of $1 \%$ when using techniques described in Reference [4].

An interesting aspect of the LCS is that it is not necessary to know the absolute value of the leak rate from the standard leak in order to determine the temperature coefficient, either linear or exponential, of the unknown leak. This can be seen more clearly by rewriting eq (28) in the form 


$$
\alpha=\frac{\left[\mathrm{L}(\mathrm{T}) / \mathrm{L}_{0}\right]-1}{\left(\mathrm{~T}-\mathrm{T}_{0}\right)}
$$

and eq (30) in the form

$$
B=\frac{T \cdot T_{0}}{\left(T-T_{0}\right)} \cdot \ln \left[\frac{L(T) \cdot T_{0}}{L_{0} \cdot T}\right] \text {. }
$$

Note that in both eqs (31) and (32) the ratio $\left(\mathrm{L}(\mathrm{T}) / \mathrm{L}_{\circ}\right.$ ) appears, and not $\mathrm{L}_{\circ}$ alone, so that it is not necessary to know the absolute magnitude of the leak rate, but only its relative change with temperature, to determine the respective temperature coefficients. While it would in principle be possible to calculate $B$ as the average of the individual values of a set of data using eq (32), what is done in practice is to use eq (29) and fit the data (using linear regression) according to

$$
\ln [\mathrm{L}(\mathrm{T}) / \mathrm{T}]=\ln (\mathrm{A})-(\mathrm{B} / \mathrm{T})
$$

obtaining $B$ as the slope of $\ln [\mathrm{L}(\mathrm{T}) / \mathrm{T}]$ vs. 1/T. It can also be seen in this equation that only the relative value of $\mathrm{L}(\mathrm{T})$ needs to be known to determine $B$, since the term $(\ell n(A))$, representing the absolute magnitude of the leak rate, enters only as the $y$-intercept of the line, and does not effect the slope (-B). 


\section{PRIMARY LEAK STANDARD SYSTEM DESCRIPTION}

The NIST Primary Leak Standard (PLS) is composed of three main components; the main vacuum chamber, the leak manifold, and a flowmeter. The PLS may be used with either the piston or bellows flowmeter but is primarily used with the latter. Calibration of a customer leak is performed by [comparing the partial pressure of the test gas generated in the upper chamber of the vacuum chamber by the gas flowing from the leak] to [the upper chamber partial pressure generated by the gas flowing from the flowmeter]. Although this system is capable of calibrating leaks for a wide variety of gas species, the calibration service is limited to calibration of helium leaks at the present time. The following paragraphs detail the salient characteristics of the Primary Leak Standard and the steps taken to calibrate a helium leak. The reader should refer to figures 9 and 10 for identification and placement of components of the PLS referred to hereafter.

\section{Leak Manifold}

The primary purpose of the leak manifold is to provide a means of installing a leak in such a way that the measurement of the leak rate of the leak can be accomplished in a minimum amount of time and without the introduction of additional errors to the measurement process due to the installation configuration. The leak manifold has provisions for installation of up to six leaks simultaneously. The manifold is composed of stainless steel tubing and other high vacuum hardware and connected with all-metal seals, which eliminates outgassing which can occur with elastomer seals. The leak manifold uses two $50 \mathrm{l} / \mathrm{s}$ turbomolecular pumps to achieve a high vacuum and maintain pumping of the helium gas emitted from the installed leaks. A quadrupole mass spectrometer is connected to the system at port (P6) and is used to monitor gas purity from the installed leaks as well as other contaminants which can be emitted from leaks which have been manufactured with substandard materials or have been used in contaminated environments. For open-reservoir leaks three pressure gages are used to measure reservoir pressures. This is primarily for research on the conductance properties of leak elements.

\section{Main Vacuum Chamber}

The main vacuum chamber is used for measurement of the partial pressure generated by the flow of gas from either a leak or the flowmeter. The main vacuum chamber is divided into two sections which are separated by a $1 \mathrm{~cm}$ diameter orifice. The volume above the orifice is referred to as the upper chamber and the volume below the orifice is referred to as the lower chamber. Pressure measurements in the upper chamber are accomplished using three quadrupole mass spectrometers, and three "nude" type ionization gages. The system vacuum pump connected to the chamber with a 10 inch flange is a 2000 $\ell / s$ turbomolecular pump, which is backed by a mechanical pump for evacuation of pumped gases. For accurate measurement of the leakage rate from a test leak the system must be able to achieve, maintain, and measure helium partial 
pressures ranging from $1 \times 10^{-4}$ to $1 \times 10^{-8} \mathrm{~Pa}$. This requires that the turbomolecular pump have the capacity and stability over the corresponding flow rates to achieve pumping speed stabilities of less than 0.18 per hour. It is also necessary that the quadrupole mass spectrometers have the necessary sensitivities and stabilities to measure helium partial pressures over this range with a $3 \sigma$ random error of less than 18 per hour. Since changes in the valving configurations also change the background partial pressure, most notably hydrogen, it is also desirous that the quadrupole mass spectrometers be insensitive to changes in the hydrogen background pressure. Changes in the normal hydrogen background pressures encountered while calibrating leaks result in changes in the helium sensitivity of the quadrupole mass spectrometers of less than 0.28 .

\section{Bellows Flowmeter}

The bellows flowmeter is composed of a reference volume, variable volume, two pistons, piston advance control system and pressure measurement devices as indicated schematically in figure 10. The bellows flowmeter generates and measures a flow of gas by changing the volume of the variable volume at a measured rate such that the pressure in the variable volume remains constant. The pressure in the variable volume is determined using capacitance diaphragm gages (CDGs) in the reference volume to measure the pressure, and a differential CDG is used between the reference and variable volumes to measure the pressure difference between these two volumes. The reference and variable volumes are filled to the same pressure and then isolated from each other by closing valves $B 1$ and $B 2$. The pressure in the variable volume decreases due to the gas escaping through the leak valve which produces a change in the differential CDG (D5) signal. The differential CDG signal activates a servo control system which controls the rate of advance of the piston to maintain a zero differential pressure between the two volumes. The flow from the flowmeter can then be calculated using the methods of section 3 .

\section{CALIBRATION OF HELIUM LEAKS}

To calibrate a helium leak, the leak is first installed on the leak manifold (leak ports $\mathrm{P} 1-\mathrm{P} 6$ ) using $23 / 4$ inch conflat-type fittings which utilize allmetal seals. This is accomplished by first isolating the turbomolecular pumps (turbo 1 and turbo 2) from the leak manifold by closing valves L9, L16, L17, and L18. Argon gas is then introduced at a pressure slightly above atmospheric by opening valve $\mathrm{L} 4$ and one of the leak isolation valves (L30L35). A positive flow of argon gas through the system during installation of the helium leak minimizes the amount of water vapor which enters the system when exposed to the atmosphere. The leak is then installed on one of the six leak ports (P1-P6) as stated earlier. The argon gas is then evacuated by an exterior roughing pump through valve $L 4$ after which valve $L 4$ is closed. Valves L16-L18 are then reopened to the turbomolecular pumps to re-establish a high vacuum. The helium leak is continually pumped on the leak manifold until its leak rate reaches equilibrium, which usually occurs in $24 \mathrm{~h}$.

The day before a calibration on an unknown leak is performed, the flow from the leak is diverted from the leak manifold to the main vacuum chamber by 
closing valve L30 and opening valve L24 if the unknown leak is installed on port P1. The gas then flows through valves L21 and L36 and enters the upper chamber of the main vacuum system, and is ultimately evacuated through the orifice into a turbomolecular pump. When the upper chamber helium partial pressure reaches equilibrium (usually $30 \mathrm{~min}$ ) as measured by quadruple mass spectrometers QMS1, QMS2 and QMS3, the mass spectrometer ranges are adjusted to the proper scales. The composition of the flowing gas is examined using QMS1 to identify if there are significant levels of contaminants which could compromise the integrity of the measurement. Since quadrupole mass spectrometers are somewhat sensitive to the total pressure and composition of the measured gas, contaminant gases (gases other than helium flowing from the leak or elsewhere) may introduce instabilities and changes in the sensitivities of the mass spectrometers (Reference [5]). If the contaminant gases do reach a level which may compromise the calibration, the leak will not be calibrated. The flow from the leak is then diverted back to the leak stand by reversing the described process.

On the day of the calibration, the partial pressure of helium is measured in the main vacuum chamber with valve L37 opened and with valves L36 and L38 closed while the flow from the leak is still being evacuated by the leak manifold. The values obtained for the helium partial pressure are termed the baseline of the lower chamber. The process is repeated with valves L37 and L38 closed and valve L36 open. The data obtained is termed the baseline of the upper chamber. This data corresponds to zero data taken for the specific valving configuration and is later subtracted from the values obtained while the leak is flowing with the same valving configuration. With valve L36 open and valve L37 and L38 closed, the flow from the leak is diverted from the leak manifold into the upper chamber of the main vacuum system. Sufficient time is then allowed for the helium partial pressure in the upper chamber to reach equilibrium, after which the helium partial pressure is recorded for mass spectrometers QMS2 and QMS3. QMS1 is usually used to examine the gas purity emitted from the leak and is not tuned to helium but scans from 1 to 100 AMU. The total pressure in the upper chamber is also recorded using three "nude type" ionization gages (N1, N2 and N3). The flow from the leak is then diverted back to the leak manifold.

The flowmeter is then set up to generate approximately the same flowrate into the upper chamber of the main vacuum chamber in the following way. The capacitance diaphragm gages (D1-D4 in fig. 10) used to measure to the fill pressure of the reference volume are zeroed while being exposed to a high vacuum $\left(<10^{-4} \mathrm{~Pa}\right)$ as measured by the ionization gage (I1). The ionization gage is then shut off and the turbomolecular pump is isolated from the flowmeter by closing valve B17. Helium gas is then introduced with valves B1 and B2 open into the flowmeter by opening valve B14 until the desired pressure is attained. Helium then flows through the loak valve to the upper chamber of the main vacuum system, which generates a partial pressure of helium proportional to the flowmeter fill pressure. The pressure in the flowmeter is then adjusted so that the equilibrium flow from the flowmeter gives the same helium partial pressure, to within $0.1 \%$, as that recorded while the leak was flowing into the upper chamber. 
The flow from the flowmeter is measured in the following manner. The 1 Torr differential CDG (D5) is zeroed and the variable and reservoir volumes are isolated by closing valves B1 and B2. The piston is then set in motion by pushing the enable button on the controller and the advance of the piston is controlled by the feedback circuitry which maintains a constant pressure in the variable volume. The time elapsed for the piston to displace consecutive $5 \%$ intervals of the total piston volume is recorded by the computer controlled data acquisition system until the piston reaches its total displaced volume. After this has been completed the variable and reservoir volumes are valved back into the flowmeter system by opening valves B1 and B2. The leak rate of the leak can then be calculated using the methods described in section III.

The leak rate of the leak can also be measured using a flow division technique, described previously in section 3 , by flowing gas from the flowmeter into the lower chamber of the main vacuum system. This is accomplished in the following manner. The flow of gas from the flowmeter is first diverted from the upper to the lower chamber by closing valve L36 and opening valve L37. The helium pressure in the flowmeter is adjusted so that the equilibrium flow from the flowmeter into the lower chamber gives the same helium partial pressure in the upper chamber as that recorded while the leak was flowing into the upper chamber, to within $0.1 \%$. The steps of the preceding paragraph are then repeated. The leak rate of the leak can then be calculated using the methods described in section 3 .

\section{NIST LEAK COMPARATOR SYSTEM DESCRIPTION}

The Leak Comparator System (LCS), shown in figure 6, was originally designed and provided by the Sandia Primary Standards Laboratory and was subsequently modified at NIST. The LCS is composed of three main components: the leak detector, the leak manifold, and the control systems. The leak manifold provides a way of introducing gas flow from two leaks simultaneously or individually, without requiring venting of the system. The control system operates the valving and controls the temperature of the leak under test. The leak detector is used to measure the partial pressure of helium generated by the flow of helium from the leaks on the manifold and is described in more detail in the following paragraph.

The helium leak detector used in the LCS is a commercially available "tuned" magnetic-sector mass spectrometer. The term "tuned" in this case means that the instrument only measures partial pressures of molecules with molecular weight of 4 AMU. The mass spectrometer consists of an ion source with a thoria coated tungsten filament, a magnet and an ion collector. Gas entering the mass spectrometer is ionized and then separated by its mass/charge ratio so that only helium ions strike the collector. The signal originating from the collector is then converted to a proportional voltage which is measured using a digital voltmeter. The leak detector has the following characteristics which are necessary for leak rate measurements over the range of the NIST calibration service: a response time of $5 \mathrm{~s}$, a minimal detectable leak rate of $1 \times 10^{-14} \mathrm{~mol} / \mathrm{s}$, and an ion-current drift rate of 18 of full scale per hour. 
The LCS control system uses an IBM-compatible computer to control the data acquisition and analysis of the data. Its main functions include the following: control of the temperature bath to within $0.02{ }^{\circ} \mathrm{C}$ of the set point temperature, control of the valving of the LCS leak manifold, monitoring of the temperatures of the standard and unknown leaks installed on the LCS, collection of the ion signal data from the system digital voltmeter, and least squares curve fitting to the functional temperature dependence of permeation leaks given in section 3. The program to accomplish these functions is written in a Basic language and uses corresponding instrument drivers for IEEE-488 communications.

\section{TEMPERATURE COEFFICIENT DETERMINATION}

The temperature dependence of the leak rate of a helium permeation leak is determined by measuring the leak rate of the leak at temperatures over a range of 0 to $50{ }^{\circ} \mathrm{C}$. The temperature coefficient is then determined by performing a least squares curve fit to the functional temperature dependence given by eq (33) in section 3. The data collection is collected using the following procedure.

A helium permeation leak for which the temperature dependence is to be measured is installed on the Unknown port of the LCS. A standard leak with approximately the same leak rate is installed on the Standard port of the LCS. The leaks are pumped by a turbomolecular pump until the leak rates reach equilibrium, usually within $24 \mathrm{~h}$. The leak detector is also turned on (according to the manufacturer's procedures) and allowed to warm up for a $24 \mathrm{~h}$ period. The program is then loaded and run, and the user specifies the sequence and number of temperatures for which the leak rates will be measured for the unknown leak. The user also specifies the number of data points to be taken at each individual temperature. It is common practice to take 5 data points at each of the following temperatures $\left({ }^{\circ} \mathrm{C}\right)$ in the given sequence: 25 , $35,50,40,30,20,10,0,15,25$.

The program then executes the following data control and acquisition routine. The temperature bath is controlled to obtain a temperature stability of the unknown leak to within $0.02{ }^{\circ} \mathrm{C}$. Thermal gradients within the unknown leak are then allowed to stabilize by maintaining this temperature for a $2 \mathrm{~h}$ period before the leak rate measurement is performed. After the stability time of $2 \mathrm{~h}$ has elapsed, the background ion current of the leak detector is measured 10 times over a 5-min interval and the average and standard deviations are recorded. The standard leak is then valved into the leak detector and allowed to stabilize for $60 \mathrm{~s}$ before the data is collected. Ion current data are collected over a 5-min period, and the average and standard deviations are calculated based upon the 10 collected readings. The standard leak is then isolated from the leak detector and the unknown leak is valved in and allowed to stabilize for $60 \mathrm{~s}$. The ion current data is then collected over a 5-min interval and the average and standard deviation are calculated. The leak detector is then isolated from both leaks and allowed to stabilize for $60 \mathrm{~s}$ before the background ion current is measured using the same procedure described above. The program then calculates the leak rate of the unknown leak based upon the ratios of the recorded ion signals corrected for 
zero drifts. This process is repeated for the data points at each temperature in the data collection sequence. At the conclusion of the data acquisition the program performs a least square fit to the data using the functional form of eq (33) in section 3. The temperature coefficient and the uncertainty in the temperature coefficient are calculated. The absolute leak rate at $23{ }^{\circ} \mathrm{C}$ is also calculated and compared to the value obtained using the primary leak standard. The difference between the two techniques has historically been no greater than 1.58, and well within the uncertainties of the respective systems. 


\section{ASSESSMENT OF UNCERTAINTIES}

\section{PRIMARY LEAK STANDARD}

\section{Flowmeters}

The fundamental equations relating the measured leakage rate of a leak (at a given temperature) to the measured parameters of the Primary Leak Standard were derived in section 3 (eqs (10), (17) and (27)). At the heart of these equations are the terms arising from the operation of either of the two constant-pressure flowmeters. A thorough discussion of the uncertainties associated with the various flowmeter terms can be found in the article in Appendix D. A brief review is presented here for convenience.

In its simplest form, a constant pressure flowmeter consists of a container of gas, a flow element through which the gas can escape, a gage which monitors the pressure of the gas in the container, and a mechanism for mechanically varying the volume which the gas occupies in a controlled manner. The volume which the gas occupies is referred to as the "variable volume," and in operation the "variable volume" is varied in such fashion as to keep the pressure of the gas in the variable volume essentially constant. The two flowmeters employed in this study utilize electronic feedback circuitry to accomplish this goal.

The 'exact' equation expressing the average flow rate of gas from a constant-pressure flowmeter, over the time interval $\Delta t$, is

$$
[\mathrm{dN} / \mathrm{dt}]_{\mathrm{ave}}=\left[\left(\mathrm{P}_{\mathrm{i}} \mathrm{V}_{\mathrm{i}}\right) /\left(\mathrm{RT}_{\mathrm{i}}\right)-\left(\mathrm{P}_{\mathrm{f}} \mathrm{V}_{\mathrm{f}}\right) /\left(\mathrm{RT}_{\mathrm{f}}\right)\right] / \Delta t
$$

where $P_{i}\left(P_{f}\right)$ is the pressure in the variable volume, $V_{i}\left(V_{f}\right)$ is the volume of the variable volume, and $T_{i}\left(T_{f}\right)$ is the temperature of the gas in the variable volume of the flowmeter at the beginning (end) of the time interval $\Delta t$. This equation is essentially a definition, since the first group of terms in the right-hand bracket is the amount of gas in the variable volume at the beginning of the measurement, and the second group of terms is the amount of gas remaining in the variable volume at the end of the measurement. Thus eq (34) represents the net quantity of gas that has left the variable volume in the time interval $\Delta t$, divided by that time interval. Under ideal conditions the initial and final pressures would be identical, but deviations occur in practice and are therefore explicitly taken into account. Defining $\Delta \mathrm{T}=\mathrm{T}_{\mathrm{f}}-\mathrm{T}_{\mathrm{i}}$, $\Delta \mathrm{P}=\mathrm{P}_{\mathrm{f}}-\mathrm{P}_{\mathrm{i}}$, and $\Delta \mathrm{V}=\mathrm{V}_{i}-\mathrm{V}_{\mathrm{f}}$, eq (34) can be rewritten as

$$
[\mathrm{dN} / \mathrm{dt}]_{\mathrm{ave}}=\left[\left(\mathrm{P}_{\mathrm{i}} \Delta \mathrm{V}\right) /\left(\mathrm{RT}_{\mathrm{i}} \Delta \mathrm{t}\right)\right]\left\{1-\left(\mathrm{V}_{\mathrm{f}} / \Delta \mathrm{V}\right)\left[\left(\Delta \mathrm{P} / \mathrm{P}_{\mathrm{i}}\right)-\left(\Delta \mathrm{T} / \mathrm{T}_{\mathrm{i}}\right)\right]\right\}
$$

to first order in $\Delta \mathrm{P} / \mathrm{P}_{\mathrm{i}}$ and $\Delta \mathrm{T} / \mathrm{T}_{\mathrm{i}}$. This form of the equation provides a convenient way of assessing the uncertainties, and emphasizes the importance of keeping the so-called dead volume ratio $\left(V_{f} / \Delta V\right)$ to a minimum. 


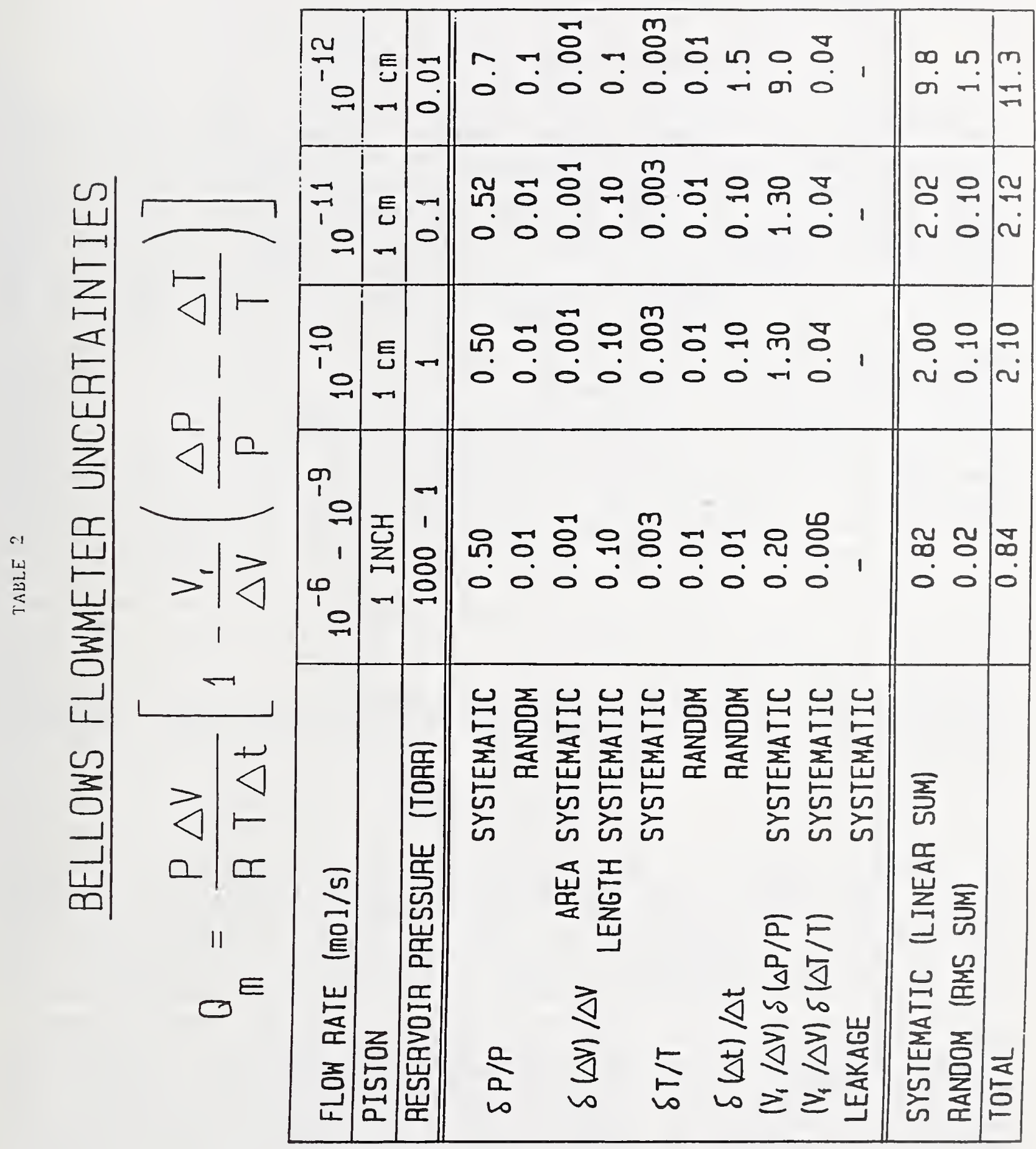


Table 2 gives estimated uncertainties of the individual terms for the "bellows" flowmeter for flow rates which are lower $\left(10^{-12} \mathrm{~mol} / \mathrm{s}\right)$ than those presented in Appendix D for the "piston" flowmeter. This information is presented graphically in figures 11 and 12.

\section{Temperature and Orifice Conductance}

All temperatures, including that of the leak, the main chamber (and orifice), and the flowmeter are obtained using platinum resistance thermometers that are thermally anchored to the individual parts. The systematic uncertainty associated with the calibration of these instruments is on the order of $10 \mathrm{mK}$, which at room temperature is $.003 \%$. The largest contribution to random fluctuations (say over the course of an hour) are variations in room temperature. While the room in which the Primary Leak Standard is located is thermally controlled, variations in room temperature of up to several degrees during a workday are possible. Thus, correcting for temperature-related effects, as is done in the above mentioned equations, can be important. Note, however, that except in the case of the flowmeter temperature (discussed in Appendix C) and leak temperature, all other temperatures appear in the equations as ratios, which reduces the overall uncertainty caused by systematic error (but not random error). Typical three sigma values of the temperature fluctuations of the leak and main chamber (expressed as 8 of reading) over the individual 20-min data-taking sequences using the flowmeter are only .018 (for both). While it is possible that a slight systematic difference may exist between the measured temperature of the leak and the actual temperature of the leak element, which is located inside the leak housing, insulating procedures should limit this difference to well under $0.1{ }^{\circ} \mathrm{C}$. This would amount to a $0.3 \%$ error in the leak rate of a permeation leak having a typical 'linearized' coefficient of $3 \% /{ }^{\circ} \mathrm{C}$. Note also that the orifice conductance appearing in eq (10) is proportional to the square root of the chamber temperature, but contributes less than .02\% to the uncertainty of the flow rate measurement as is described in the example in Section 3.

\section{Pumping Speed}

The pumping speed of the turbomolecular pump is quite difficult to measure directly, so instead we have measured the rotational frequency of the turbine blades, which is obtained from a signal within the pump controller and displayed using a frequency counter. The systematic uncertainty associated with the frequency measurement is entirely insignificant and unimportant, as only ratios of pumping speeds are present in the equations. More important is the uncertainty associated with the assumption that the pumping speed is directly proportional to the rotational frequency, since until recently the rotational frequency would drift and fluctuate uncontrollably. It has been experimentally verified that the observed frequency fluctuations and drift are correlated with similar variations in the ac line voltage powering the pump controller. Attempts to regulate the line voltage without otherwise disturbing operation of the pump proved to be unsuccessful until recently. Before regulation of the power supply voltage, drifts of 5 o or more during the 
course of a workday, particularly in the afternoon, were not uncommon, so that corrections certainly needed to be taken into account.

The assumption that the pumping speed is directly proportional to the rotational frequency is difficult to verify. It can best be determined by observing the change in the upper chamber pressure indication when a presumably constant flow rate of gas is flowing into the lower chamber. If the rotational frequency shifts abruptly, then the corresponding change in the upper chamber pressure indication can be noted, and, assuming linearity of the upper chamber pressure indicator with upper chamber pressure, the linearity of pumping speed with rotational frequency can be measured. Unfortunately, without regulation, the change in the rotational frequency is usually more of a long-term drift (abrupt changes of less than $1 \%$ have been observed, but were erratic), so that the natural time constant of this part of the system (between 10 and $20 \mathrm{~min}$ ) prevents precise measurement of this effect. However, measurements that have been obtained recently by controlling the power line voltage indicate speed/rotational frequency proportionality is within .01\% over the $5 \%$ or so observed range of rotational frequencies.

During the entire 20 min data-taking sequence using the flowmeter, the pump rotational frequency is recorded, and an average value is obtained. With regulation of the pump controller input voltage, three sigma standard deviations of pump rotational frequency, expressed as of of reading, typically range between .05\% and $0.1 \%$. As will be shown below, the contribution to the total uncertainty associated with the uncertainty in pumping speed for flow into the upper chamber is insignificant, while for flow into the lower chamber it is of the same order of magnitude as the values given here.

\section{Upper Chamber Pressure Indication}

Measurement of the upper chamber pressure $\left(P_{u}\right)$ presents several interesting challenges. Good sensitivity, linearity, repeatibility and low zero drift of the pressure measuring instrument over a wide range are important. Monitoring and accounting for gas impurities can be tricky, as different gases move through the vacuum system at different rates, and are not differentiable in total-pressure gages. Opening and closing various portions of the vacuum system from the main chamber at different stages of the data-taking cycle result in varying outgassing rates of hydrogen and other contaminants into the vacuum system, which must be accounted for with separate zero readings depending on whether flow is into the upper or lower chamber. Other more subtle effects, such as the possible slight pumping action of helium by the getter pump in the upper chamber, must sometimes be considered.

As indicated in previous sections, one well-regulated nude Bayard-Alpert type ionization gage (total pressure gage), and two quadrupole-type residual gas analyzers (partial pressure gages), tuned to helium, are used to measure the pressure in the upper chamber. In addition, a third quadrupole residual gas analyzer is used to monitor the background gases. The reason for the redundancy of gages, besides the obvious advantage of multiple measurements of presumably the same quantity, is that gage stability and repeatiblity were 
found to depend strongly on the particular operating range of the quadrupole instruments, and at the lowest pressures $\left(10^{-7} \mathrm{~Pa}\right.$ and below), correcting for the differential hydrogen outgassing rendered the total pressure gage of marginal use. It was found that if either of the residual gas analyzers tuned to helium was also used to scan for background gases, the problems associated with retuning and restabilization of the gage for upper chamber pressure measurements were intractable. While none of these gages is calibrated, it is not necessary to do so since it is the ratio, and not the absolute magnitude, of upper chamber pressures that enters in all of the equations of importance.

What is important is that the gages be linear over the range of use, stable over the time of use, and repeatable in going through the cycling process when gas from the leak and the flowmeters is alternately valved into and out of the system. If in addition the sensitivity of the gage depends on the level or composition of background gas, this effect must be minimized or accounted for. Such an effect has been seen recently in the sensitivity of a gage to helium for varying hydrogen background. For the typical differences in upper chamber residual hydrogen partial pressures seen during a day, the change in sensitivity could account for up to 0.38 change in the helium partial pressure indication.

In order to minimize uncertainties associated with gage linearity, general operating procedure is to achieve an upper chamber partial pressure indication of helium for helium gas flowing from the flowmeter (into either the upper or lower chamber) that is well within 1 of of the upper chamber partial pressure indication when helium gas from the leak is flowing into the upper chamber, as recorded by the most stable gage. In order to minimize uncertainties due to gage instability, the upper chamber partial pressure indication is recorded and averaged ten times for flow from the leak (with nominal three sigma deviations between . $15 \%$ and $0.3 \%$ of reading for the residual gas analyzers, and $0.7 \%$ for the nude ionization gage), and 20 times for flow from the flowmeter (with the same nominal three sigma deviations). In order to minimize uncertainties associated with gage repeatability during the course of the measurement sequence (Steps 1 through 3 in figs. 3 and 4), every effort is made to keep the upper chamber partial pressure as constant as possible during the valving and filling operations, or at least to minimize the time that the upper chamber partial pressure is changing. This presumably minimizes any 'hysteresis' type of effects that may occur when cycling these gages.

A control chart of the measured leak rate (referenced to $23^{\circ} \mathrm{C}$ ) versus time of a check standard is shown in figure 13. This figure illustrates the relative differences in leak rate measurement using the various upper chamber pressure measuring instruments. The pronounced systematic offset between the nude gage data and that taken using the residual gas analyzers is due to changing hydrogen backgrounds during the measurement process, which the nude gage cannot compensate for. This effect is more pronounced at lower flow rates where the hydrogen partial pressure is comparable to the helium partial pressure, as it is for the data in this figure.

\section{Flow into Upper Chamber}

Using the individual uncertainties discussed above, it is now possible to 
discuss an overall uncertainty associated with an individual measurement of flow rate by flow into the upper chamber. The equation which describes this flow rate is reproduced here for convenience:

$$
\dot{\mathrm{N}}_{\mathrm{L}}=\frac{\mathrm{P}_{\mathrm{r} 3}(\Delta \mathrm{V} / \Delta \mathrm{t})}{\mathrm{R} \cdot \mathrm{T}_{\mathrm{r} 3}}\left[\frac{\mathrm{P}_{\mathrm{u} 1}}{\mathrm{P}_{\mathrm{u} 3}}\right] \cdot\left[\frac{\mathrm{T}_{03}}{\mathrm{~T}_{01}}\right]^{\frac{1}{2}} \cdot\left[\frac{\mathrm{S}_{1}}{\mathrm{~S}_{3}} \cdot \frac{\mathrm{C}_{03}+\mathrm{S}_{3}}{\mathrm{C}_{01}+\mathrm{S}_{1}}\right] .
$$

The total uncertainties associated with the flowmeter factors are a function of the actual flow rate, and can be found in Appendix $D$ and table 2. These total uncertainties are predominantly systematic. The uncertainties associated with the ratio of upper chamber pressure indications are also a function of flow rate, and are given as three times the standard deviation of the observed indicated pressures for a specified set of upper chamber gages. These uncertainties are treated as random. Uncertainty in the chamber temperature is primarily due to random fluctuations in room temperature, which results in measured differences in chamber temperature of up to $0.1 \%$ during an $8 \mathrm{~h}$ period. The rightmost factor in brackets shows that, even though the pumping speed and temperature are known to drift, the entire factor is so close to unity that these uncertainties are inconsequential. As evidence, consider a 'worst case' example where $\mathrm{S}_{1}=2500 \ell / \mathrm{s}, \mathrm{T}_{01}=299 \mathrm{~K}, \mathrm{C}_{01}=40 \ell / \mathrm{s}$, $\mathrm{S}_{3}=2375 \mathrm{l} / \mathrm{s}, \mathrm{T}_{03}=293 \mathrm{~K}, \mathrm{C}_{03}=36.6 \mathrm{l} / \mathrm{s}$. The correction term in brackets is calculated to be 0.9994 , so that the correction is only 0.068 . These uncertainties are summarized in table 3 .

\section{TABLE 3. Summary of Uncertainties for Flow into the Upper Chamber}

\begin{tabular}{|c|c|c|c|c|}
\hline & $\mathrm{Fl}$ & $\checkmark$ Rate & $(\mathrm{mol} / \mathrm{s}$ & \\
\hline & $10^{-6}-10^{-9}$ & $10^{-10}$ & $10^{-11}$ & $10^{-12}$ \\
\hline Bellows Flowmeter (sys) & 0.82 & 2.0 & 2.02 & $\overline{9.8}$ \\
\hline Bellows Flowmeter (ran) & 0.02 & 0.1 & 0.1 & 1.5 \\
\hline Upper Chamber Pressure (ran) & 0.3 & 0.3 & 0.3 & 0.3 \\
\hline Chamber Temperature ( $\mathrm{ran}$ ) & 0.1 & 0.1 & 0.1 & 0.1 \\
\hline Pump Speed/Conductance (ran) & 0.06 & 0.06 & 0.06 & 0.06 \\
\hline Total $[($ sys $)+$ rss $(r a n)]$ & $\overline{1.30}$ & $\overline{2.56}$ & $\overline{2.58}$ & $\overline{11.76}$ \\
\hline
\end{tabular}

Note that, at the lowest flow rates, the sum of the random components of uncertainty in this Table is consistent with the observed random uncertainty seen in figure 13. The first two rows of table 3 are described earlier in table 2 .

Upper-to-Lower Chamber Flow Ratio

The equation used to calculate individual measurements of upper-to-lower 
flow ratio is eq (17). A slightly modified form (the reciprocal value) is:

$$
\left(R_{U / L}\right)_{t}\left(S_{1}, T_{o 1}\right)=\frac{P_{r 1} \cdot(\Delta V / \Delta t)_{1} \cdot T_{r 2}}{P_{r 2} \cdot(\Delta V / \Delta t)_{2} \cdot T_{1}} \cdot \frac{P_{U 2} \cdot S_{2} \cdot T_{o 1}}{P_{U 1} \cdot S_{1} \cdot T_{o 2}} .
$$

The first set of factors involving the flowmeter is again a ratio, so that many of the systematic errors associated with the flowmeter cancel. Typically the residual systematic uncertainty of the flow ratio should be less than 18 . Furthermore, both flowmeter runs are usually at relatively high flow rates $\left(10^{-11} \mathrm{~mol} / \mathrm{s}\right.$ and $\left.\mathrm{mid} 10^{-10} \mathrm{~mol} / \mathrm{s}\right)$, so that the random uncertainty due to the flowmeters is on the order of 3\%. Again, at the higher flow rates the random uncertainty in upper chamber pressure indication is small, so that a total uncertainty of $0.3 \%$ due to the pressure ratio term is appropriate. From above, the uncertainty in pumping speed due to fluctuation and linearity assumptions is $0.1 \%$, so that the uncertainty due to the pumping speed ratio is estimated at 0.28 . Finally, the uncertainty in the chamber temperature ratio from above is 0.18 .

The total random uncertainty in each individual measurement of $\left(R_{U / L}\right)_{t}$ will be taken as the square root of the sum of the squares of the individual random uncertainties:

$$
\delta\left(\mathrm{R}_{\mathrm{U} / \mathrm{L}}\right)_{\mathrm{t}}=\sqrt{\left[\delta^{2}(\text { flowmeter })+\delta^{2}\left(\mathrm{P}_{\mathrm{u}}\right)+\delta^{2}(\mathrm{~S})+\delta^{2}\left(\mathrm{~T}_{\mathrm{o}}\right)\right]},
$$

which for the values above gives 38. The total uncertainty would then be 48 .

Figure 14 is a control chart of the measured upper-to-lower chamber flow ratio over a period of $280 \mathrm{~d}$, uncorrected for changes in pumping speed or orifice temperature. Even without these corrections, the three-sigma spread in the data is only \pm 2.38 , which is in good agreement with the predicted random uncertainty. Note in figure 14 that much of the scatter in the data for a given day is due to the variation in the upper chamber pressure indication. However, there is an apparent correlation between the average of the various sets of data and the average turbopump frequency for the day which could also account for some of the observed differences.

\section{Flow into Lower Chamber}

The equation describing leak rate measurement for flow into the lower chamber is:

$$
\dot{\mathrm{N}}_{2}=\mathrm{R}_{\mathrm{U} / \mathrm{L}}\left(\mathrm{S}_{1}, \mathrm{~T}_{\mathrm{o} 1}\right) \cdot \frac{\mathrm{P}_{\mathrm{r} 3} \cdot(\Delta \mathrm{V} / \Delta \mathrm{t})_{3}}{\mathrm{R} \cdot \mathrm{T}_{\mathrm{r} 3}} \cdot \frac{\mathrm{P}_{\mathrm{U} 1} \cdot \mathrm{S}_{1} \cdot \mathrm{T}_{\mathrm{o} 3}}{\mathrm{P}_{\mathrm{U} 3} \cdot \mathrm{S}_{3} \cdot \mathrm{T}_{\mathrm{o} 1}} \text {, }
$$


which contains elements similar to those in both of the sections above. The uncertainties associated with the particular factors are again a function of the flow rate of the flowmeter and are summarized in table 4.

\section{TABLE 4. Summary of Uncertainties for Flow into the Lower Chamber}

\begin{tabular}{|c|c|c|c|c|}
\hline & \multicolumn{4}{|c|}{ Leak Rate $(\mathrm{mol} / \mathrm{s})$} \\
\hline & $10^{-6}-10^{-9}$ & $10^{-10}$ & $10^{-11}$ & $10^{-12}$ \\
\hline Upper/Lower ratio (sys) & & 4.02 & 4.02 & 4.02 \\
\hline Bellows Flowmeter (sys) & & 0.84 & 2.10 & 2.12 \\
\hline Bellows Flowmeter (ran) & & .5 & .5 & 1.0 \\
\hline Upper Chamber Pressure (ran) & & .3 & .3 & .3 \\
\hline Chamber Temperature (ran) & & .1 & .1 & .1 \\
\hline Pump Speed (ran) & & .1 & .1 & .1 \\
\hline Total $[($ sys $)+\operatorname{rss}(\operatorname{ran})]$ & & $\overline{5.46}$ & $\overline{6.72}$ & $\overline{7.19}$ \\
\hline
\end{tabular}

Note that the uncertainties given are for leak rate, not flowmeter flow rate, and reflect the fact that the flowmeter is being operated at a factor of roughly 67 times higher in flow rate than for the corresponding upper chamber flowmeter runs. Thus, while there is an additional uncertainty due to the upper/lower flow ratio for a given measurement of leak rate, this is offset by a corresponding decrease in the uncertainty of the flowmeter. From figure 13 it can be seen that the random scatter in the lower chamber data is consistent with the rss random error value of 1.18 derived from table 4.

\section{Summary Analysis: Calibration of Customer Leaks}

Calibration of a customer leak on the Primary Leak Standard typically involves at least five individual measurement sequences (on five separate days), each sequence including leak rate measurement using the bellows flowmeter valved into first the upper chamber, and usually then the lower chamber (for leaks with leak rates below $10^{-8} \mathrm{~mol} / \mathrm{s}$ ). Uncertainties associated with measurements for flow into both chambers are evaluated using the methods indicated above, and the uncertainty that goes into the calibration report is the smaller of the two, provided that the two average values of leak rate for the two 'methods', plus and minus their respective uncertainties, overlap at the three-sigma level. While there is almost always overlap, the individual three-sigma values are found to vary from fractions of a percent to $5 \%$ or more, and the magnitude is not found to correlate strongly with leak rate. In addition, the differences between the average measured value of leak rate using the two methods is found to vary from fractions of a percent to almost $3 \%$ for leak rates between $5 \times 10^{-12}$ and $7 \times 10^{-11} \mathrm{~mol} / \mathrm{s}$, although again there is not a strong correlation with leak rate, confirming that the flow ratio is not a function of the flow rate. A sample calibration 
report is presented in Appendix $E$.

\section{LEAK COMPARATOR SYSTEM}

As discussed earlier, the exponential temperature coefficient of helium permeation leaks is determined using the Leak Comparator System (LCS). This is done by fitting the relative leak rate vs. temperature data to eq (33) to obtain parameter $B$.

$$
\ln [\mathrm{L}(\mathrm{T}) / \mathrm{T}]=\ln (\mathrm{A})-(\mathrm{B} / \mathrm{T})
$$

The uncertainties associated with this procedure arise from three sources, the systematic uncertainty associated with any nonlinearity in the measured leak rate vs. actual leak rate, the random uncertainties associated with the data acquisition process and errors associated with the linearized fitting procedure.

\section{Temperature Coefficient Uncertainty}

In order to determine the linearity of the system over the normal operating range, a single leak with a variable backpressure reservoir was calibrated on the Primary Leak Standard, at several leak rates, between $2 \times 10^{-12} \mathrm{~mol} / \mathrm{s}$ and $1.4 \times 10^{-11} \mathrm{~mol} / \mathrm{s}$. The leak was then mounted on the LCS in the "unknown" position, and the 'normalized' leak rate was measured over this range, using a constant-reservoir leak (nominal leak rate $1.5 \times 10^{-11} \mathrm{~mol} / \mathrm{s}$ ) in the "standard" position [4]. The results are presented in figure 15, where residuals from the linear fit of the measured leak rate are plotted against actual leak rate. The maximum deviation from linearity was 1.5\%. Solving eq (33) for B and differentiating with respect to L gives the systematic uncertainty of $B$ :

$$
\delta \mathrm{B}_{\text {sys }} / \mathrm{B}=(\mathrm{T} / \mathrm{B})(\delta \mathrm{L} / \mathrm{L}) \text {. }
$$

Using worst-case values of $B=2200 \mathrm{~K}$ and $\mathrm{T}=323 \mathrm{~K}$ gives $\delta \mathrm{B}_{\mathrm{sys}} / \mathrm{B}=.28$. The random component of uncertainty in B (denoted $\delta \mathrm{B}_{\mathrm{ran}}$ ) is taken as three times the standard deviation of the $B$ coefficient obtained by linear regression of the data to eq (33).

\section{Summary Analysis: Calibration of Customer Leaks}

The systematic and random errors in B discussed above can be combined to give an overall uncertainty according to:

$$
\delta \mathrm{B}^{\prime}=\delta \mathrm{B}_{\mathrm{sys}}+\delta \mathrm{B}_{\mathrm{ran}} .
$$


This uncertainty in B must then be translated into an uncertainty in leak rate, which is expressed as an additional uncertainty per ${ }^{\circ} \mathrm{C}$ away from the $23^{\circ} \mathrm{C}$ reference temperature at which the leak was measured on the primary leak standard. Rewriting eq (30) as:

$$
\mathrm{L}(\mathrm{T}) \pm \delta \mathrm{L}=\mathrm{L}_{0} \cdot\left(\mathrm{T} / \mathrm{T}_{0}\right) \cdot \mathrm{e}^{-(\mathrm{B} \pm \delta \mathrm{B}) \cdot\left(\mathrm{T}_{\mathrm{o}}-\mathrm{T}\right) /\left(\mathrm{T} \cdot \mathrm{T}_{0}\right)}
$$

Dividing through by $\mathrm{L}(\mathrm{T})$ :

$$
1 \pm \delta \mathrm{L} / \mathrm{L}=e^{\mp \delta \mathrm{B} \cdot\left(\mathrm{T}_{\mathrm{o}}-\mathrm{T}\right) /\left(\mathrm{T} \cdot \mathrm{T}_{\mathrm{o}}\right)}
$$

Expansion of the exponential term to first order then gives:

$$
\frac{\delta \mathrm{L}}{\mathrm{L}}=\frac{\delta \mathrm{B} \cdot\left|\mathrm{T}_{\mathrm{o}}-\mathrm{T}\right|}{\mathrm{T} \cdot \mathrm{T}_{\mathrm{o}}}
$$

The additional uncertainty in leak rate per degree $C$ from the reference temperature $T_{0}$ is obtained by dividing equation (41) by $\left|T_{0}-T\right|$ :

$$
\frac{\delta \mathrm{L}}{\mathrm{L} \cdot\left|\mathrm{T}_{\mathrm{o}}-\mathrm{T}\right|}=\frac{\delta \mathrm{B}}{\mathrm{T} \cdot \mathrm{T}_{\mathrm{o}}}
$$

Equation (42) is used to assign an additional uncertainty to the calibration of leak rate for calibrations at temperatures $\mathrm{T}$ different than the reference temperature $\mathrm{T}_{0}=23^{\circ} \mathrm{C}$. What is done in the calibration report is to use the worst-case example of $\mathrm{T}=0^{\circ} \mathrm{C}$, so that a constant, worst-case uncertainty is reported (see sample report in Appendix E). A typical value is 0.18 per ${ }^{\circ} \mathrm{C}$. 
Once the operating characteristics and uncertainties of a primary standard have been established, subsequent use of the primary standard at the same level of uncertainty requires periodic verification to ensure that none of the uncertainties have changed with time. This is accomplished most readily by using the standard to measure a quantity of interest, in this case leakage rate from a "reference" leak, which is hopefully stable with time. By maintaining quality control charts (measured leakage rate vs. time) on multiple reference leaks one can minimize the stability concern. Periodic verification of specific critical components internal to the standard is also a good idea to guard against hidden compensating changes which may mask overall changes in uncertainty. Such verification includes annual calibration of the pressure and temperature sensors.

Another consideration that frequently falls under the heading 'quality control' is how well measurements performed using one primary standard compare with similar measurements using other primary standards, of the same or different design, in the same or other laboratories. Comparisons of this sort have been performed, and will be discussed below.

\section{CONTROL CHARTS}

\section{Closed-Reservoir Helium Permeation Leaks}

The leak rate of helium gas coming from a closed-reservoir helium permeation leak is a function of several parameters, the most important being the diffusion coefficient and surface area of the glass leak element, the temperature of the leak and the amount of helium gas in the closed reservoir. Figure 16 shows a schematic cross section of a leak of NIST design, where a valve is connected to the reservoir to allow for initial filling (and possible refilling). While the temperature of the leak can be regulated or monitored, the density of helium gas in the closed reservoir can usually only be surmised, based on the initial filling conditions and the thermal history of the leak. For a leak that is kept at more or less the same temperature after its initial filling, the leak rate from that leak is not constant in time, but decays at a rate that depends on the mechanical properties and geometry of the leak. Without knowing all of these details, it is still possible to calculate the time constant for decay by knowing the initial quantity of gas in the reservoir $(\mathrm{N}(\mathrm{t}=0))$ and the initial leak rate $(\dot{N}(t=0))$, according to

$$
\tau=[N(t=0) / \dot{N}(t=0)] .
$$

$N(t=0)$ can be estimated by estimating the reservoir volume, measuring the initial fill pressure and temperature, and using the ideal gas law (see eq (B1)). $\dot{N}(t=0)$ can be measured after the leak rate equilibrates after initial filling, which usually takes several days. Note that $\tau$ is the amount of time that it takes for the leak rate to decay by a factor of $1 / \mathrm{e}(=.368)$, or 638 . Many leak manufacturers state a value of decay of leakage rate in terms of \%/year, which is not to be confused with, but can be derived from, the value of $\tau$. 
As an example, for a leak rate of $10^{-9} \mathrm{~mol} / \mathrm{s}$, a fill pressure of $145 \mathrm{psi}$ (1 $\mathrm{MPa}$ ), and a reservoir volume of $200 \mathrm{~cm}^{3}$, the time constant $\tau$ is approximately $3 \mathrm{yr}\left(1 \mathrm{yr}=3.1536 \times 10^{7} \mathrm{sec}\right)$. In $1 \mathrm{yr}$, the leak rate will have decayed by $(1-$ $\left.\mathrm{e}^{-1 / 3}\right)$, or 288 . Most leaks sold commercially have yearly decay rates of $10 \%$ or less.

Figure 13, referenced earlier, is a control chart for a closed-reservoir helium permeation leak (NBSL22) of the NIST design, which has been used as a reference standard since the present Primary Leak Standard configuration was first characterized. The leak rate of this leak is in the mid $10^{-12} \mathrm{~mol} / \mathrm{s}$ range, the reservoir volume is roughly $150 \mathrm{~cm}^{3}$, and the initial fill pressure was $73 \mathrm{kPa}$. The estimated time constant is then approximately 35 yr, implying a yearly decay rate of roughly 28 /year, which is borne out by the control chart. The chart also verifies the consistency of performance of the Primary Leak Standard at the corresponding flow rates for both upper and lower chamber flow, at least within the scatter of the data.

\section{Upper-to-Lower Chamber Flow Ratio}

Another test of the performance constancy of the Primary Leak Standard is periodic verification of the upper-to-lower chamber flow ratio. This data was presented earlier in the Control Chart in figure 14. For the period indicated, the flow ratio has remained constant, within the scatter of the data. Additional data taken over a 3 yr period have yielded similar results. Lower scatter has been observed after input voltage regulation has been applied to the turbo pump power supply.

\section{COMPARISON OF PRIMARY STANDARDS}

\section{Flowmeter Intercomparisons}

The piston flowmeter was first used to perform primary calibrations of vacuum gages in 1984. When the bellows flowmeter was brought on-line in 1985, an extensive series of intercomparisons between the two flowmeters was performed, using the Primary Leak Standard, over the range $10^{-12}$ to $10^{-10}$ mol/s. Several fixed-reservoir helium permeation leaks and one sintered silicon carbide leak were used as stable transfer standards for these intercomparisons.

The technique used to compare the flowmeters at a particular flow rate consisted of first using one flowmeter and then the other on the same day to measure the leak rate from a particular leak, repeating the process on subsequent days. This procedure was repeated for several different leaks in order to make the intercomparison at different flow rates. Measurements were made almost exclusively for flow into the upper chamber. Data from this study are summarized in figures 17 and 18 . In figure 17 the $1 \sigma$ random uncertainty in measured leak rate is presented for five different leaks, for measurements using the bellows flowmeter alone, the piston flowmeter alone, and the data 
from both flowmeters combined. The NIST serial number for the leak used at a given flow rate is indicated along the top axis of the figure. The measured random uncertainties are seen to slightly increase with decreasing flow rate. Figure 18 presents the difference in average measured leak rate using the two flowmeters, again as a function of flow rate, using each of the individual upper chamber pressure measuring instruments seperately as well as combined. Here also the difference between measured flow rate using the two flowmeters increases with decreasing flow rate. This is most probably due to observed differences in hydrogen outgassing rates in the variable and reservoir volumes, which has a significant influence on the measured total leak rate at the lower flow rates, and points out the need for going to flow into the lower chamber to measure flow rate at these lower values. Methods for compensating for hydrogen outgassing are being developed. Above $5 \times 10^{-12} \mathrm{~mol} / \mathrm{s}$, the flowmeters agree with each other to better than $1 \%$, providing confidence that systematic uncertainties such as incorrect piston areas or timing errors do not exist.

In a separate study, a leak (NBSL11, leak rate $9.8 \times 10^{-12} \mathrm{~mol} / \mathrm{s}$ ) was used to compare the flowmeters using both pistons on each flowmeter, and several range settings of the differential CDG's used to measure the pressure differentials between the reservoir and variable volumes. This study resulted in a maximum measured difference of $1.7 \%$ between the leak rate values using the two flowmeters. Other data taken using NBSL11 and the bellows flowmeter for flow into the lower chamber, using both the inch and centimeter diameter pistons, gives a difference between average measured leak rate of only 0.38 . Similar small differences were also found in the $10^{-8} \mathrm{~mol} / \mathrm{s}$ range using molecular drag gages as transfer standards on the piston flowmeter[1].

\section{Domestic Intercomparisons}

The NIST leak calibration program began in 1984, with strong collaboration with the Primary Standards Laboratory at Sandia National Laboratories (SNL). A comparison of primary leak standards between laboratories, using two sintered metal leaks as transfer standards, gave agreement at the * $1 \%$ level using helium, nitrogen and argon over the leak rate range from mid $10^{-11}$ to mid $10^{-9} \mathrm{~mol} / \mathrm{s}$ [2]. The primary leak standard used by SNL for this intercomparison was their " $P \triangle V$ " system, which differs in design philosophy from the NIST standard [6]. This data is designated NBSL1 in figure 19.

An additional intercomparison with SNL, using a helium permeation leak (NBSL13) with nominal leak rate $1.3 \times 10^{-12} \mathrm{~mol} / \mathrm{s}$, gave results that differed by 9.3\% (SNL value was higher). While this difference is relatively large, at that low a flow rate the uncertainties asociated with the NIST Primary Leak Standard are also large, and yet the values agree well within their combined uncertainties (the SNL uncertainty is also \pm 108 at this leak rate). This data is presented in figure 19, which summarizes such intercomparisons. 
While there have not been any international round robins for NIST to participate in since the leak program began in 1984, a round robin sponsored by the Commission of the European Communities, Community Bureau of Reference $(B C R)$ in 1982 resulted in the calibration by several European national laboratories of a variety of leaks, including at least two helium permeation leaks[7]. After the round robin, these leaks were put in safe storage, but were made available to the participant laboratories for selected intercomparisons. One of the participant laboratories, which requested anonymity, made these two permeation leaks available to NIST for purposes of intercomparison of the measurement capabilities of the two laboratories. These leaks were assigned NIST identification numbers NBSL2O and NBSL23, and were subsequently calibrated on the NIST Primary Leak Standard. The NIST data, referenced to $23^{\circ} \mathrm{C}$, was compared to the calibrations by the European laboratory. The results are presented in figure 19. The European laboratory calibration of NBSL20, with a nominal leak rate of $3.3 \times 10^{-11} \mathrm{~mol} / \mathrm{s}$, differed from the NIST value by 1.98 , while the calibration of NBSL23, at the lower nominal leak rate of $4.2 \times 10^{-12} \mathrm{~mol} / \mathrm{s}$, differs from the NIST value by 4.08 . Both of these measured differences are well within the combined estimated total uncertainties $(3 \sigma)$ of the two laboratories (approximately \pm 10 for each laboratory). 
There are several areas in which to concentrate future research activities associated with the NIST Leak Calibration Service. First, there is considerable industry interest in having NIST extend the lower end of the service at least another 4 decades, to $10^{-15} \mathrm{~mol} / \mathrm{s}\left(2 \times 10^{-11} \mathrm{std} \mathrm{cc} / \mathrm{s}\right)$ or below, at better than the \pm 10 s uncertainty level. At the other end of the range, there is some outside interest in extending the upper flow rate limit of $10^{-8} \mathrm{~mol} / \mathrm{s}$. While the helium permeation leak remains, by far, the type of leak most requested for calibration, occasional inquiries for services for leaks emitting other gases warrant consideration. Another area which is receiving immediate attention is the Leak Comparator System (LCS), which will be upgraded with a newer version using a stable residual gas analyzer to replace the relatively noisy (electronically) helium leak detector.

The highest priority of the research activities discussed above is the extension of the low flow rate end of the present helium permeation leak calibration service at improved uncertainty levels. The accepted industry norm for the uncertainty associated with a commercially available calibrated leak is $\pm 10 \%$, irrespective of the leak rate. As the uncertainty associated with the calibration of helium permeation leaks using the present NIST equipment reaches this level at $10^{-12} \mathrm{~mol} / \mathrm{s}$, a NIST service offered at this flow rate would not allow manufacturers to transfer the $\pm 10 \%$ uncertainty level to their customers, due to the increased uncertainties that they would have to add as part of their calibration process. While the performance limits of the flowmeters at the lowest flow rates seem to have been reached, it may still be possible to reduce the lowest leak rate offered in the calibration service without constructing a new primary standard. This may best be accomplished by assembling a group of 10 or more helium permeation leaks with leak rates that are very nearly equal (at the $10^{-12} \mathrm{~mol} / \mathrm{s}$ level), and measuring the leak rate of the entire assembly of leaks at one time using the Primary Leak Standard (PLS), as suggested by Rangan [8]. By separately measuring the ratio of leak rates from the various leaks to each other, it would then be possible, with a minimum of additional uncertainty, to ascertain their individual absolute leak rates as the appropriate ratio of the measured total. Such a program is receiving serious consideration.

Providing calibration services for gases other than helium implies calibrating other types of leaks besides permeation, which would require intensive evaluation programs of the stability, repeatability, etc. of these leak types. Some preliminary investigations of sintered and capillary leaks have already been performed $[2,4]$, and further studies are planned.

At present, all customer leaks sent in for calibration are first installed on the LCS to determine the temperature coefficient, and to otherwise check the suitability of the leak before installing it on the PLS. If the "standard" leak against which the customer leak is compared on the LCS were also calibrated, the entire calibration of the customer leak could be completed on the LCS with minimal additional uncertainty, freeing up the PLS for other measurements. With the advent of the new LCS, a goal is to calibrate (on the PLS) either an ensemble of closed-reservoir leaks, or a few variable backpressure leaks, so that the entire customer leak calibration 
service can be performed on the new LCS. This will make the process more efficient in several ways, reducing the cost per calibration of an individual leak.

\section{ACKNOWLEDGMENTS}

The authors would like to acknowledge the major contributions of Drs. K.E. McCulloh and C.R. Tilford in the conception and design of this standard. We also thank Mr. D.F. Martin and Mr. B. Dove for their efforts in the manufacture and assembly of many of the components involved, and Mr. F. Long for his efforts in designing and maintaining the electrical components. Special thanks are extended to Mr. T. Moss of Sandia National Laboratories for permission to reprint his conversion table for leak rate units in Appendix A. 

[1] S. Dittmann, "High Vacuum Standard and Its Use," U.S. Government Printing Office, NIST Special Publication 250-34, 31 (1989)

[2] R.W. Hyland, C.D. Ehrlich, C.R. Tilford and S. Thornberg, "Transfer Leak Studies and Comparisons of Primary Leak Standards at the National Bureau of Standards and Sandia National Laboratories," J.Vac.Sci.Technol. A 4 , 334 (1986)

[3] K.E. McCulloh, C.R. Tilford, C.D. Ehrlich and F.G. Long, "Low-range Flowmeters for Use with Vacuum and Leak Standards," J.Vac.Sci.Technol. A $\underline{5}, 376$ (1987)

[4] C.D. Ehrlich, S.A. Tison, H.Y. Hsiao and D.B. Ward, "A Study of the Linearity of Transfer Leak Standards and a Helium Leak Detector," J.Vac.Sci.Technol. A $\underline{8}, 4086$ (1990)

[5] L. Lieszkovszky, A.R. Filippelli and C.R. Tilford, "Metrological Characteristics of a Group of Quadrupole Partial Pressure Analyzers," J.Vac.Sci.Technol. A $\underline{8}, 3838$ (1990)

[6] M.V. Iverson and J.L. Hartley, "Methods for Calibration of Standard Leaks," J. Vac. Sci. Technol. 20, 982 (1982)

[7] D. Gould, "Intercomparison of the Calibration of Helium Leaks for Use in Leak Detection," Commission of the European Communities EUR 8325 EN, (1982)

[8] K. Rangan, Lockheed Missiles and Space Company, Presented at the Standard Leak Calibration Workshop, Gaithersburg, Maryland, 1987

[9] T.A. Moss, "Conversion Tables for Pressure and Leak Rates," J.Vac.Sci.Technol. A $\underline{5}, 2962$ (1987)

[10] C.D. Ehrlich, "A Note on Flow Rate and Leak Rate Units," J.Vac.Sci.Technol. A 4 , 2384 (1986)

[11] M. Knudsen, "Die Gesetze der Molekularstromung und der inneren Reibungsstromung der Gase durch Rohren," Ann. Physik 28, 75 (1909) and "Die Molekularstromung der Gase durch Offnungen und die Effusion," Ann. Physik 28, 999 (1909)

[12] M. von Smoluchowski, "Zur kinetischen Theorie der Transpiration und Diffusion verdunnter Gase," Ann. Physik 33, 1559 (1910)

[13] S. Dushman, "The Production and Measurement of High Vacua," Gen. Electric Rev. 23, 493 (1920)

[14] P. Clausing, Ann. Physik 12, 961 (1932); English translation appears in "The Flow of Highly Rarefied Gases through Tubes of Arbitrary Length," J. Vac. Sci. Technol. $\underline{8}, 636$ (1971) 
[15] J.H. Dymond and E.B. Smith, "The Virial Coefficients of Gases," Oxford University Press, copyright 1969

[16] J.F. O'Hanlon, "A User's Guide to Vacuum Technology," J. Wiley \& Sons, copyright 1980 


\section{BIBLIOGRAPHY}

In addition to the references cited above, the interested reader may wish to consult the following.

Units:

"Standardization and Temperature Correction of Calibrated Leaks," G.M.

Soloman, J. Vac. Sci. Technol. A 4, 327 (1986)

Leaks:

"The Modeling of Standard Gas Leaks," J.L. Chamberlin, J.Vac.Sci.Technol. A 7 , 2408 (1989)

"Diffusion Leak Artifacts as a Secondary Standard for Gas Flow," W. Jitschin, G. Grosse and D. Wandrey, Vacuum $\underline{38}, 883$ (1988)

Rarefied Gas Flow:

"The Flow of Highly Rarefied Gases," A. Venema, Phillips tech. Rev. $\underline{33}, 43$ (1973)

\section{Texts and Handbooks:}

"Nondestructive Testing Handbook, Second Edition; Volume 1, Leak Testing,"

R.C. McMaster ed., published by American Society for Metals, copyright 1982 by American Society for Nondestructive Testing, Inc.

"Vacuum Manual," L. Holland, W. Steckelmacher, J. Yarwood, E.\&F.N. Spon Ltd., London, copyright 1974

"Scientific Foundations of Vacuum Technique," S. Dushman, John Wiley \& Sons, New York, copyright 1962

"Dictionary of Terms for areas of Science and Technology served by the American Vacuum Society (second edition)," H.G. Tompkins ed., published for the American Vacuum Soiciety by the American Institute of Physics, copyright 1984

"Vacuum Technology (second,revised edition)," A. Roth, North-Holland Publishing Company, copyright 1982

"Ultrahigh Vacuum Practice," G.F. Weston, Butterworth \& Co. Ltd., copyright 1985 


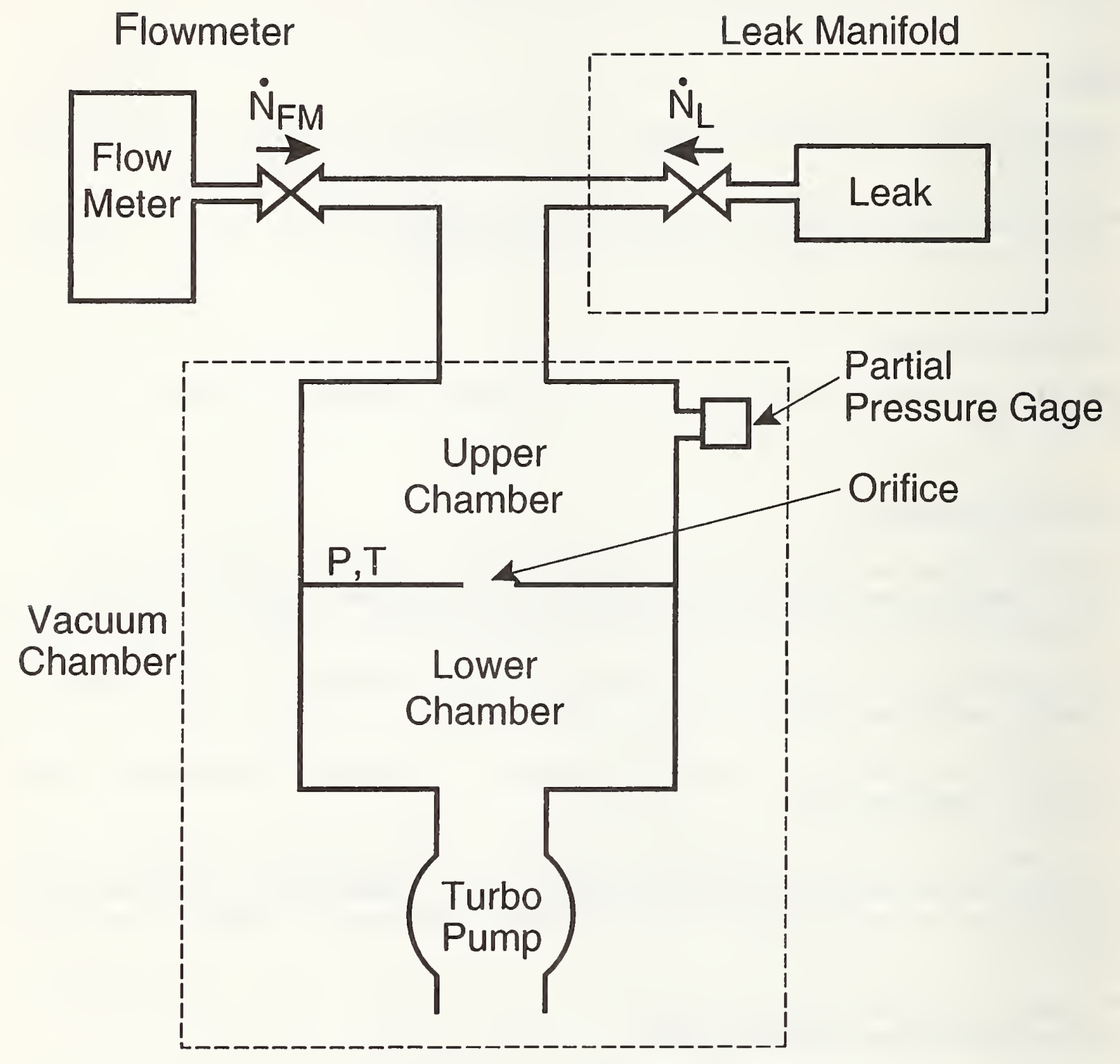

Figure 1. Schematic drawing of the NIST Primary Leak Standard, showing the major components. The pressure indication (P) in the vacuum chamber (at temperature $T$ ) caused by gas flow (rate $\dot{N}_{L}$ ) from the leak is matched by flow (rate $\dot{\mathrm{N}}_{\mathrm{FM}}$ ) from the flowmeter. The flow rate $\dot{\mathrm{N}}_{\mathrm{FM}}$ is then measured using the flowmeter. 


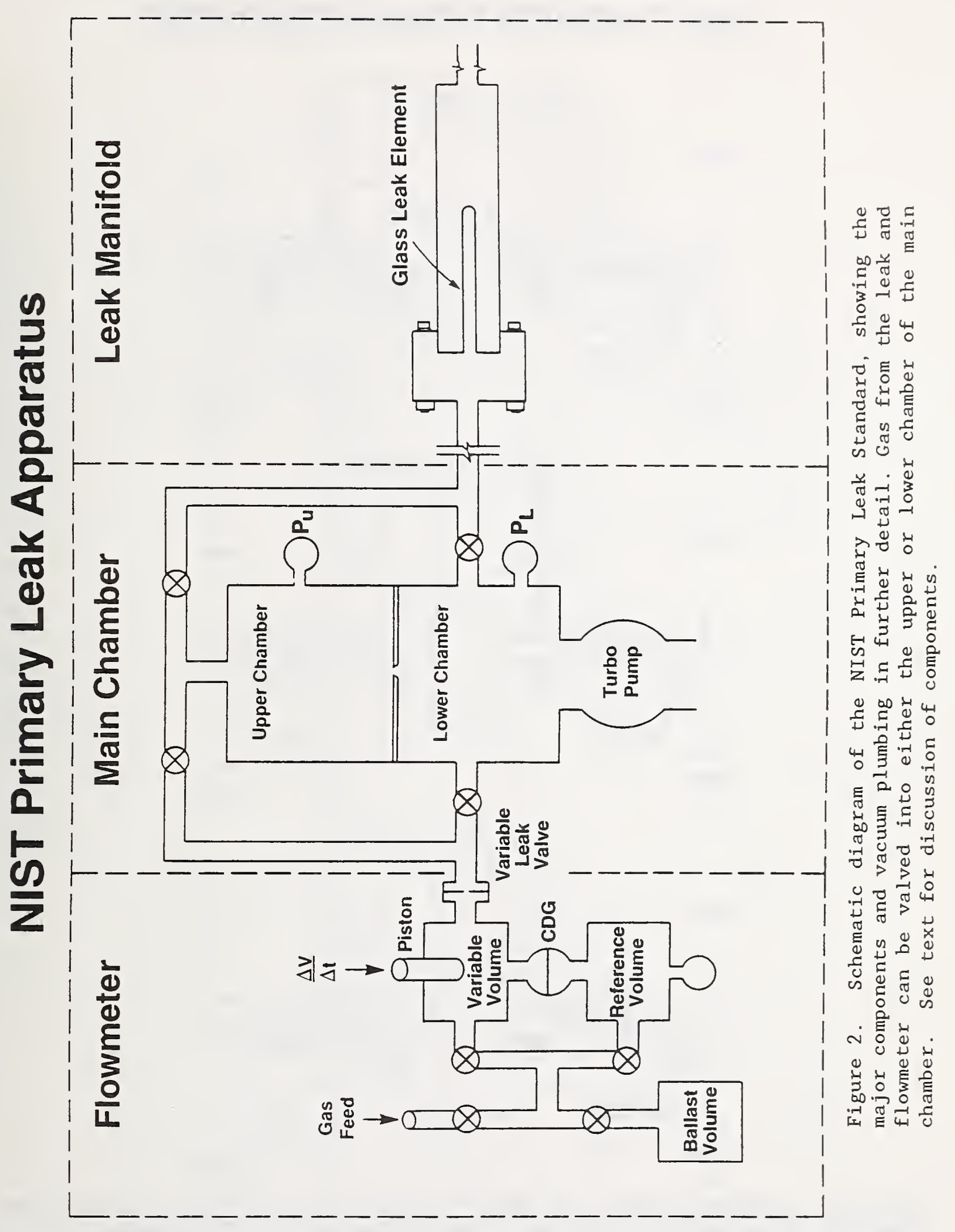




\section{LEAK CALIBRATION THROUGH UPPER CHAMBER .}
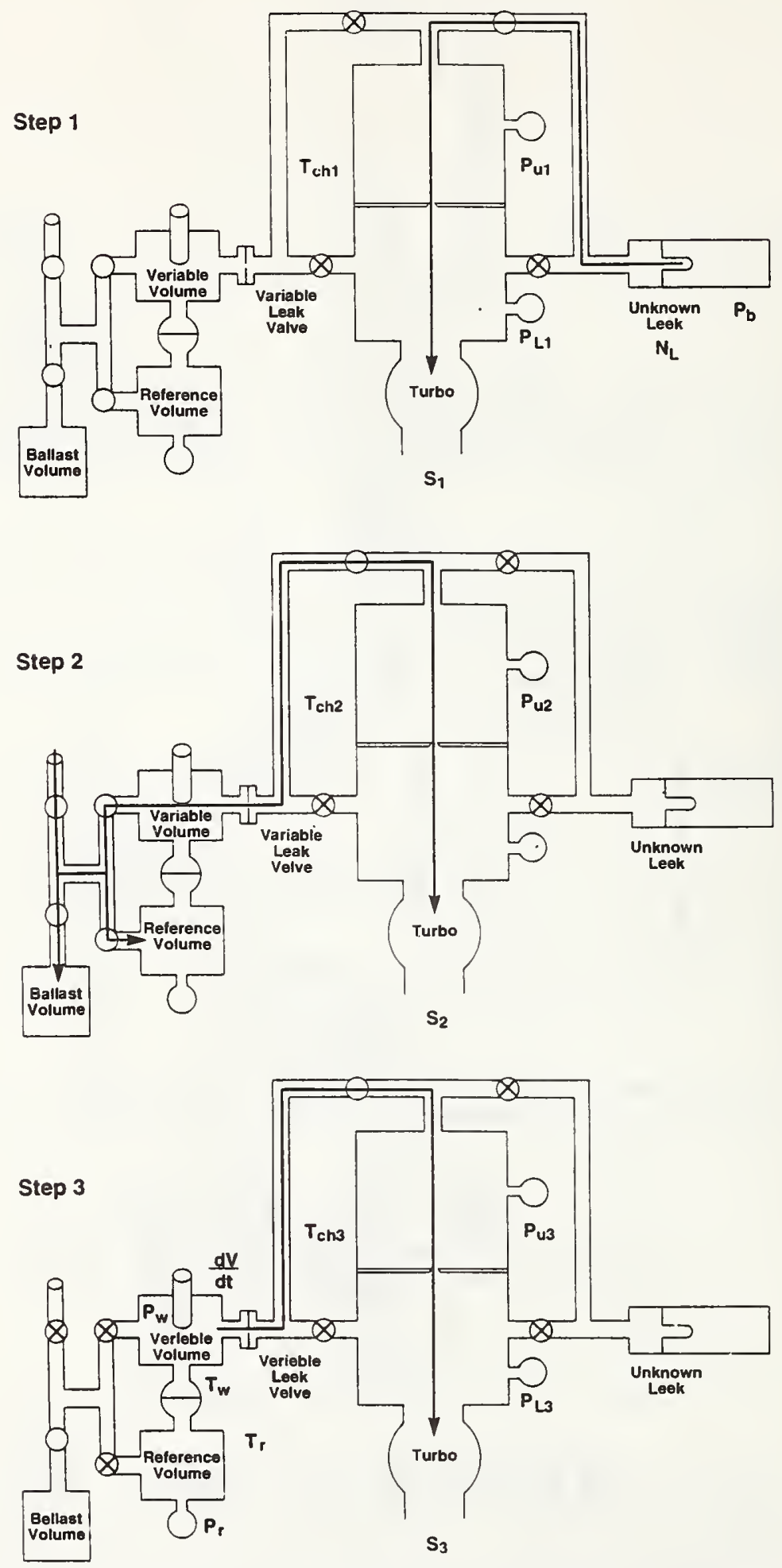

Figure 3. Valving sequence for measuring leak rate of unknown leak by flowing gas from flowmeter into the upper chamber of the main vacuum chamber. 


\section{LEAK CALIBRATION THROUGH LOWER CHAMBER}
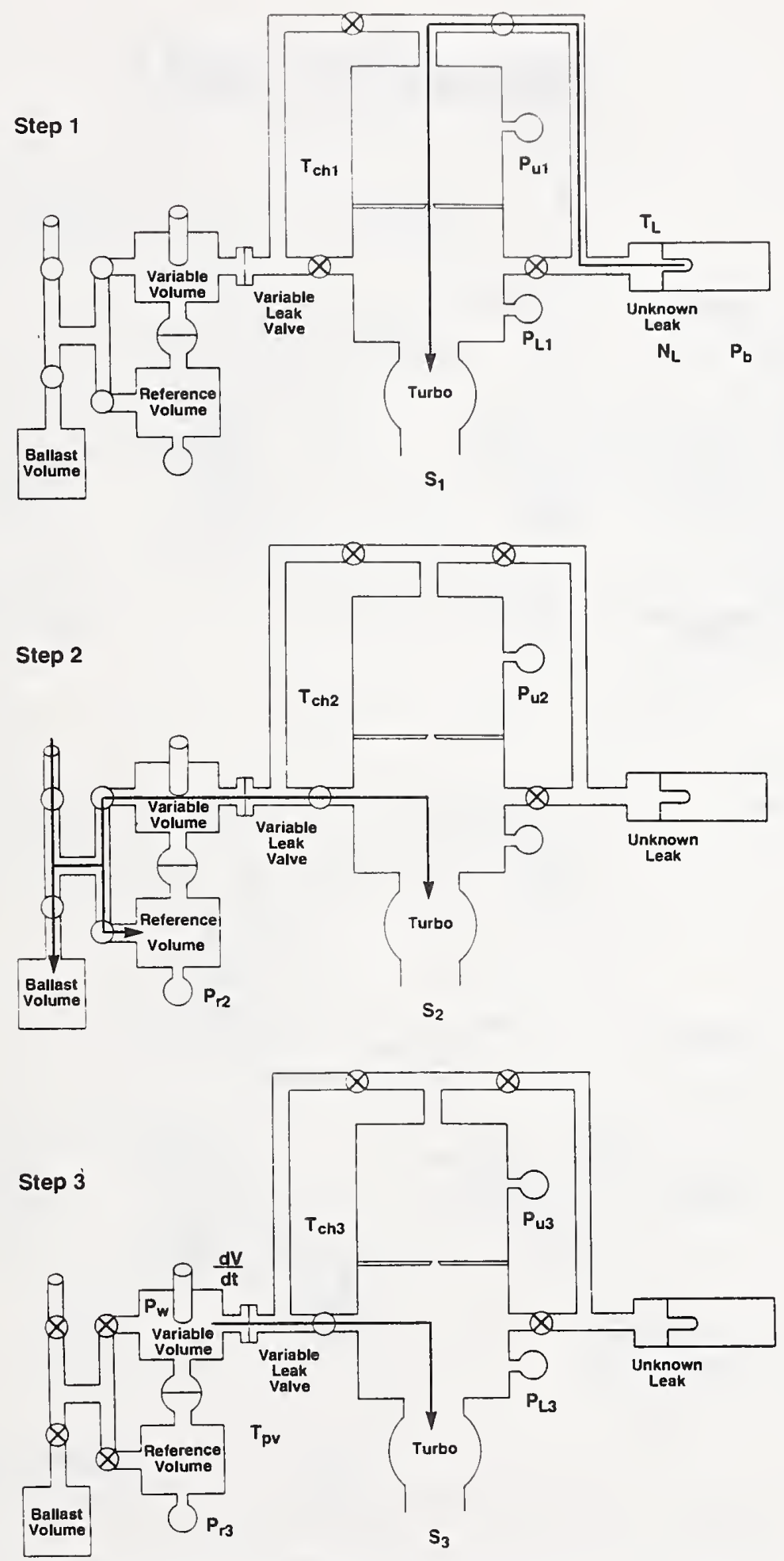

Figure 4. Valving sequence for measuring leak rate of unknown leak by flowing gas from flowmeter into the lower chamber of the main vacuum chamber. 

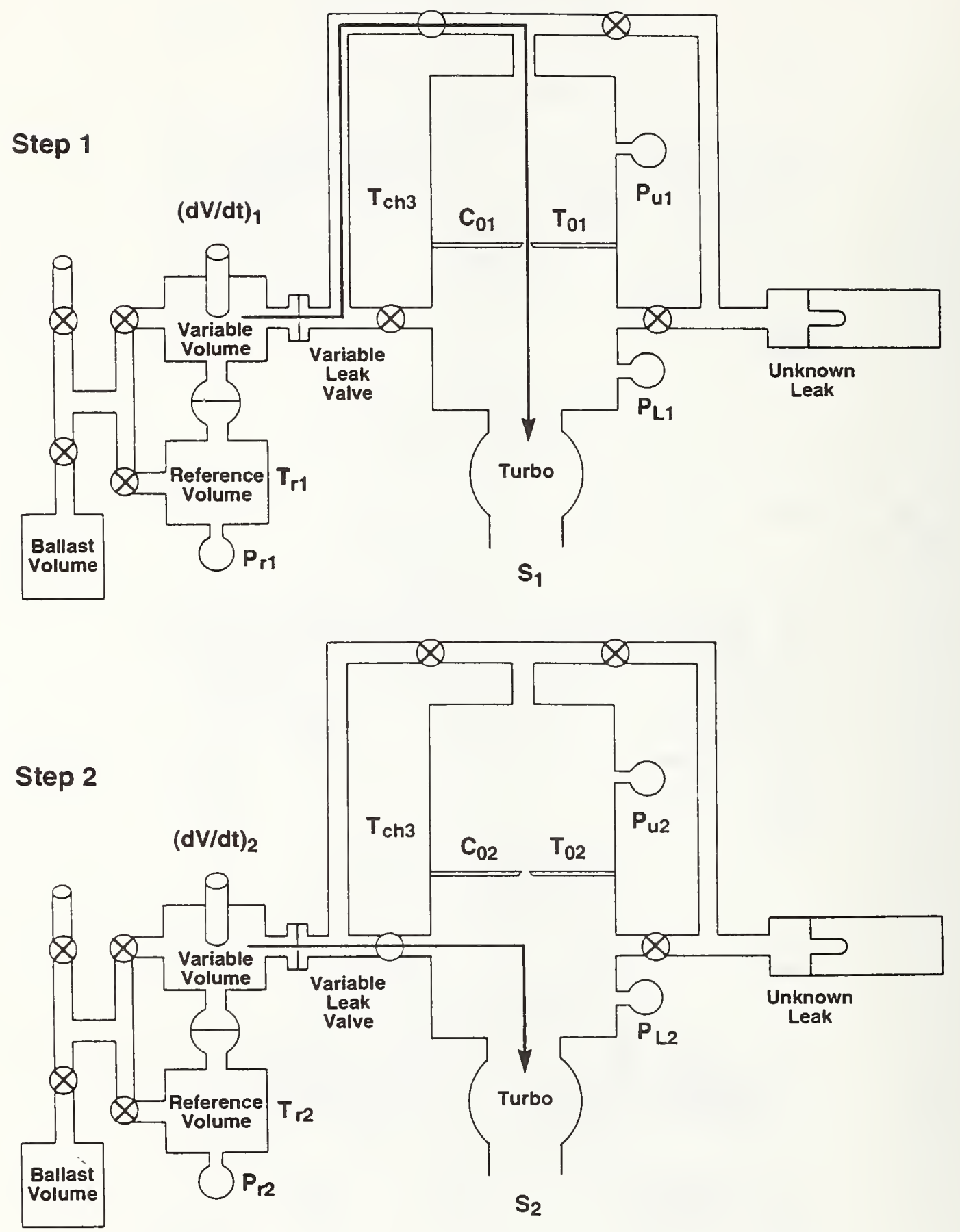

Figure 5. Valving sequence for measuring flow rate ratio. 


\section{Leak Comparator}

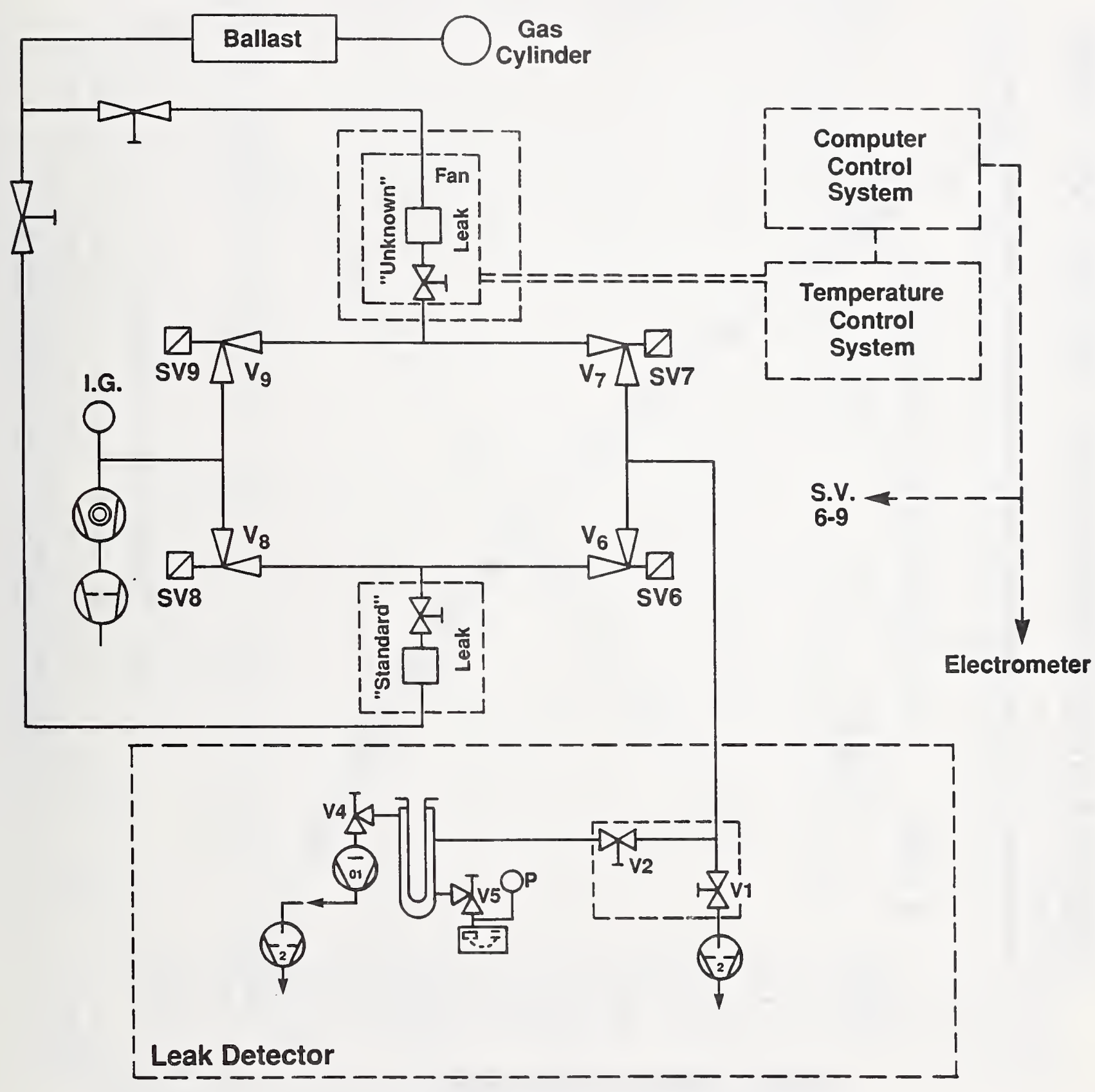

Figure 6. Schematic diagram of the Leak Comparator System. 


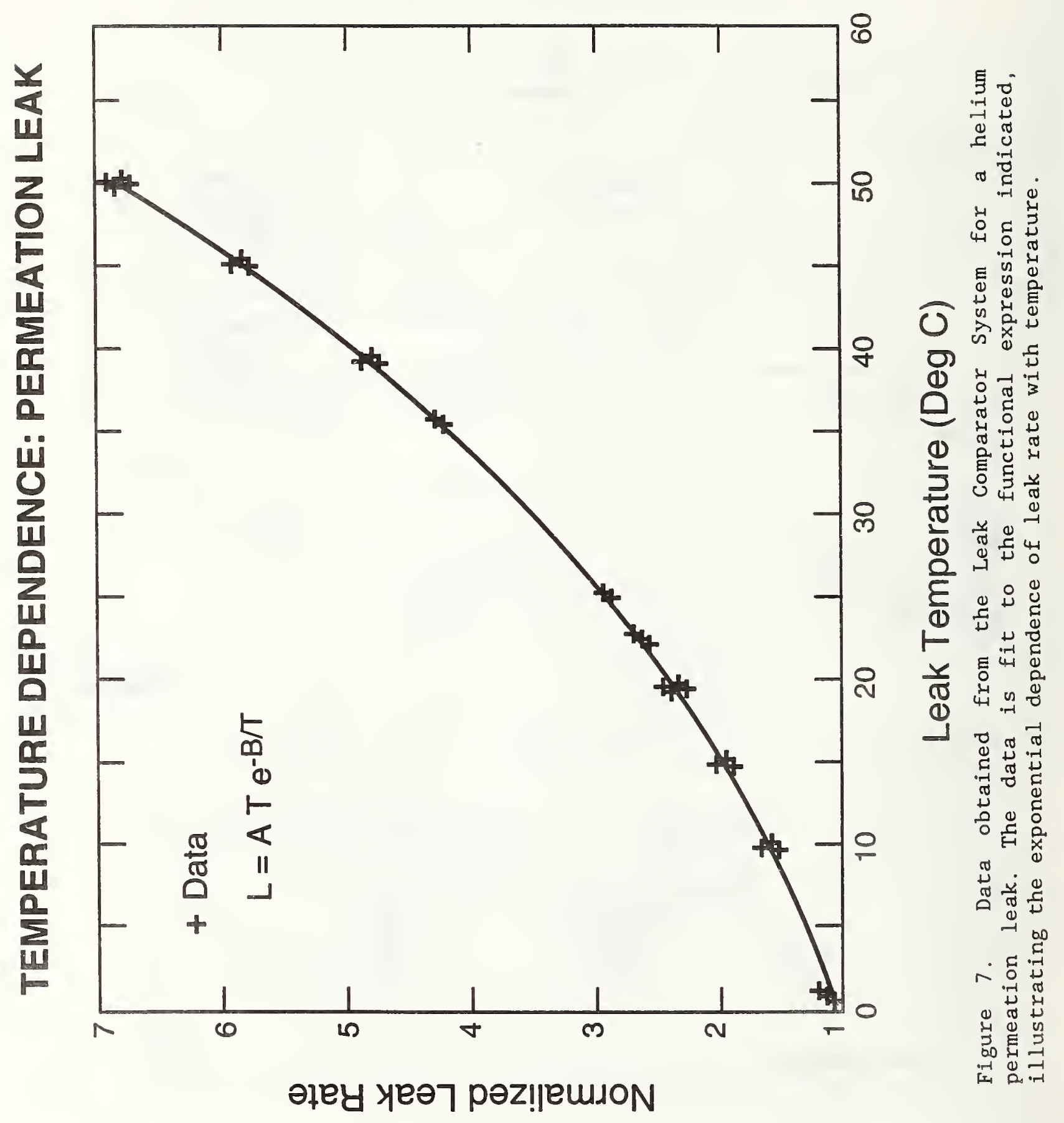




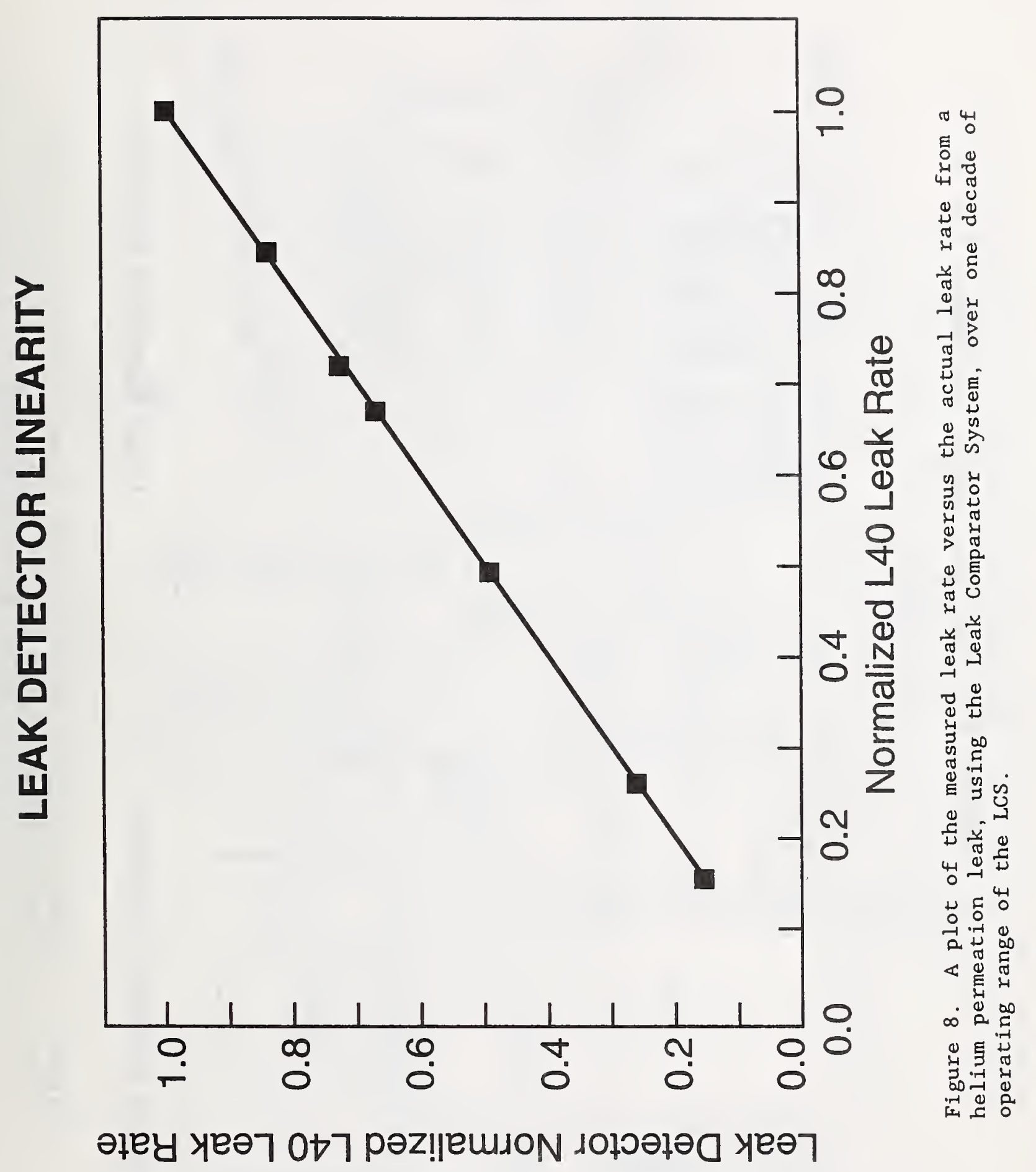




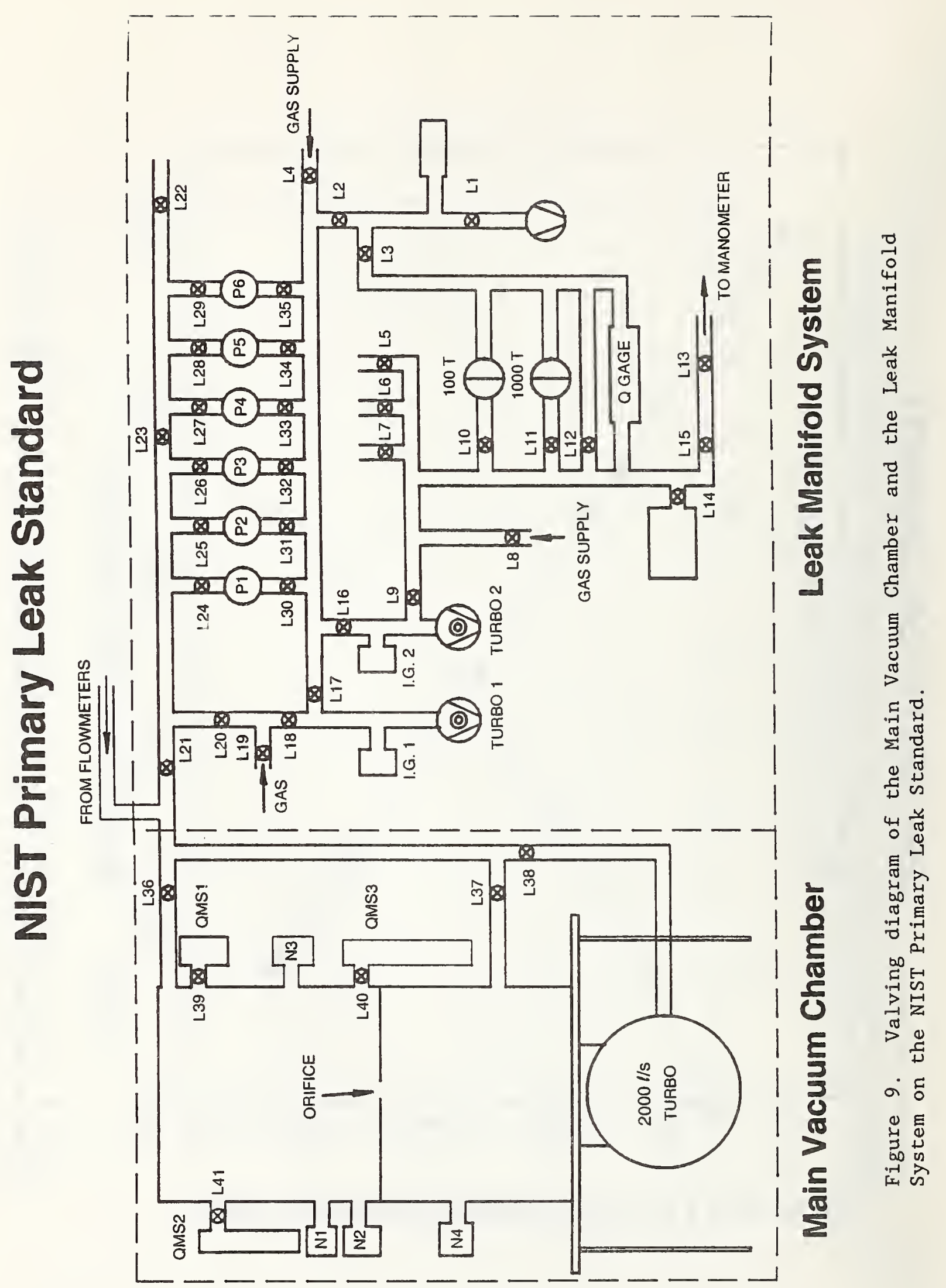




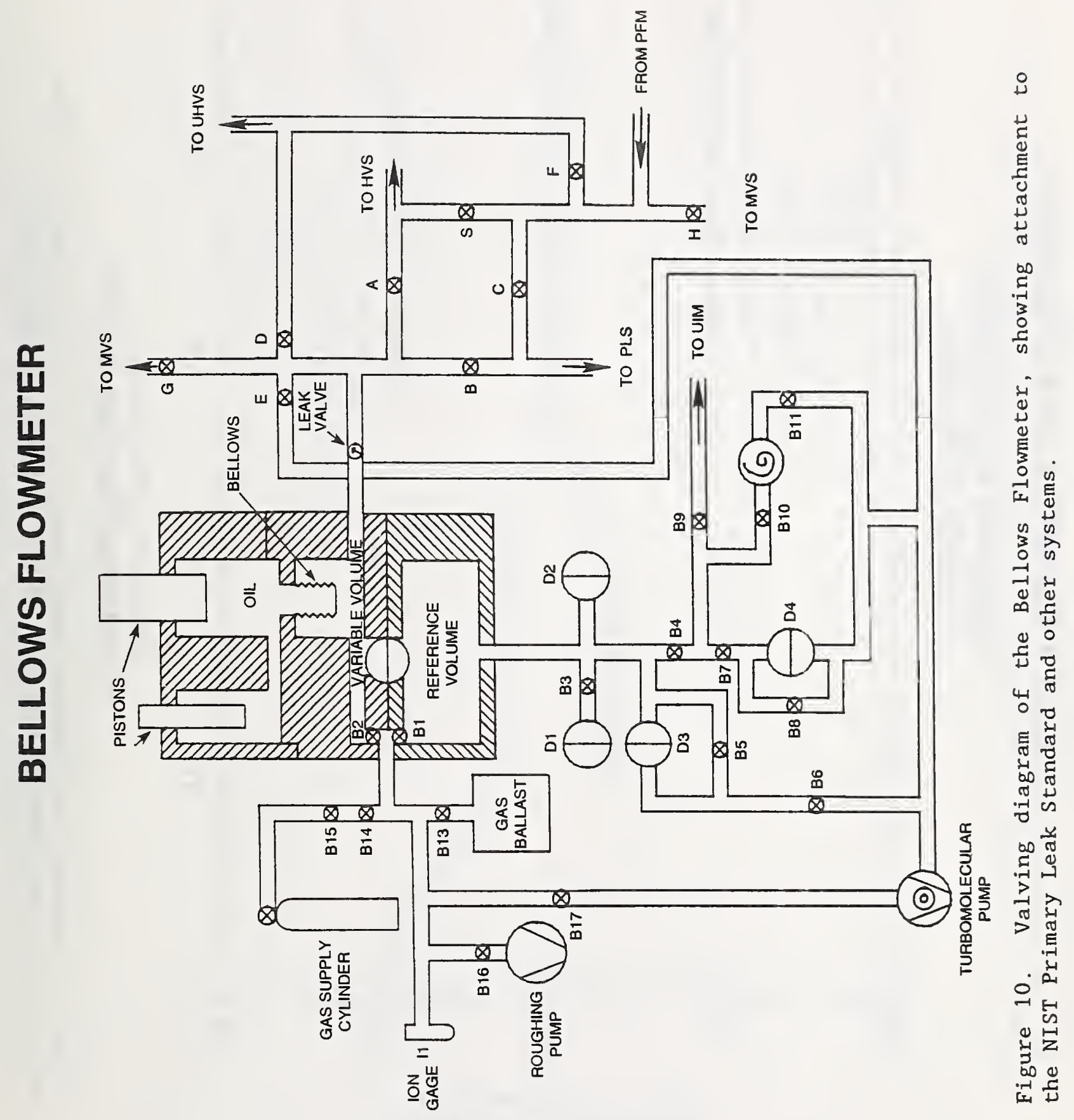




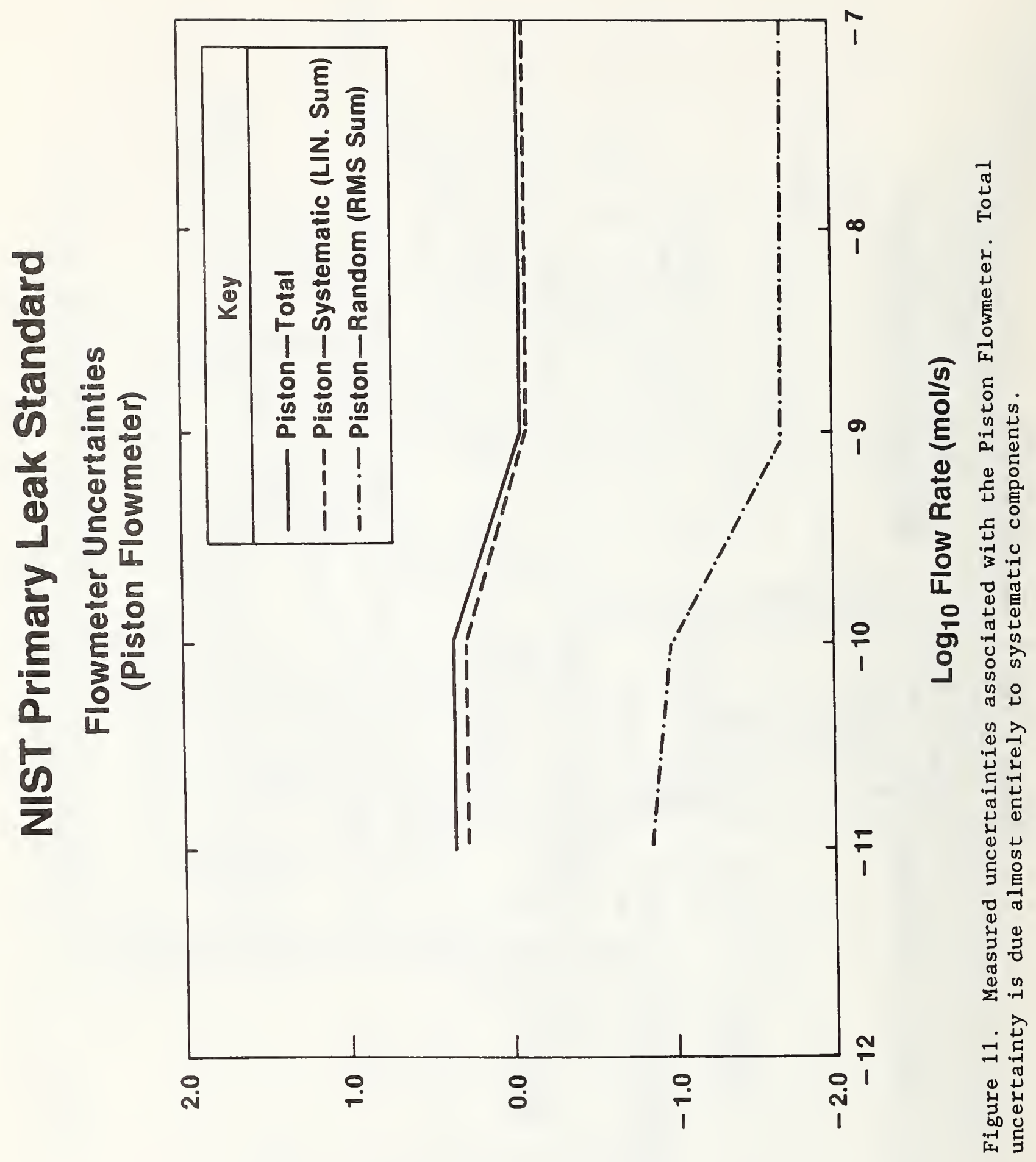

Kłu!efrəoun \% 0เ60า 


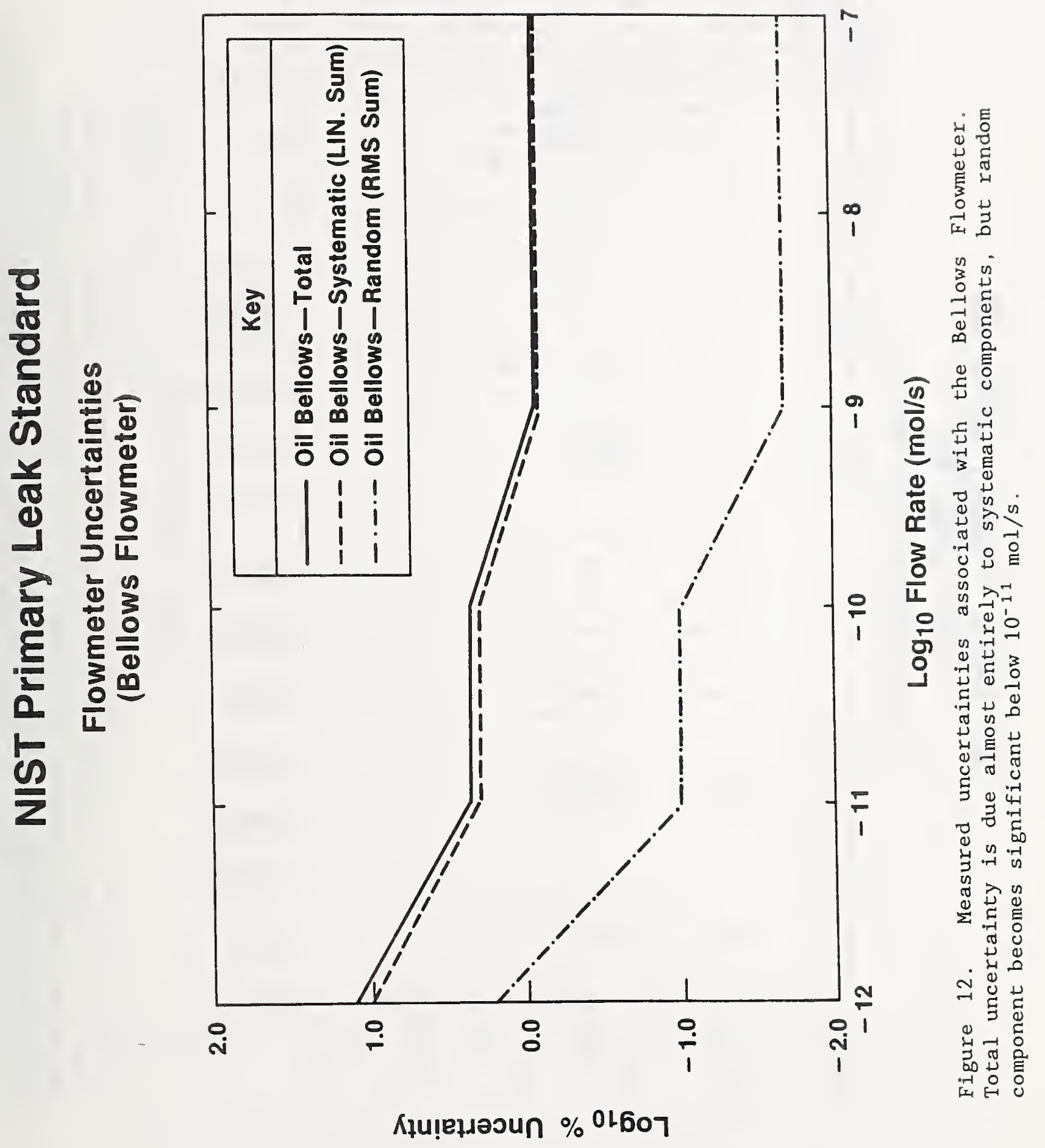




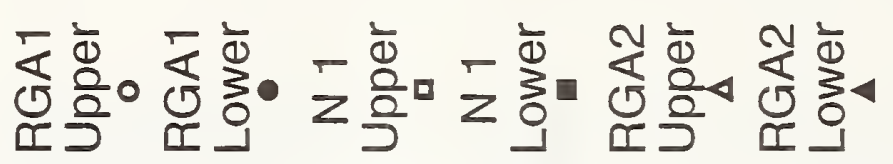

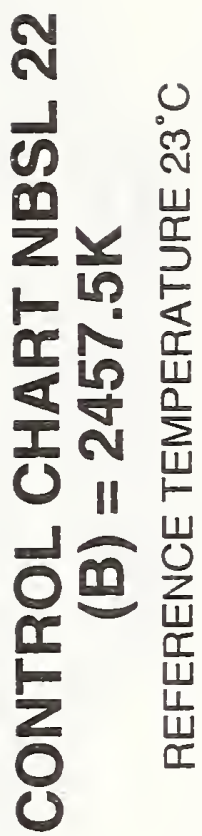

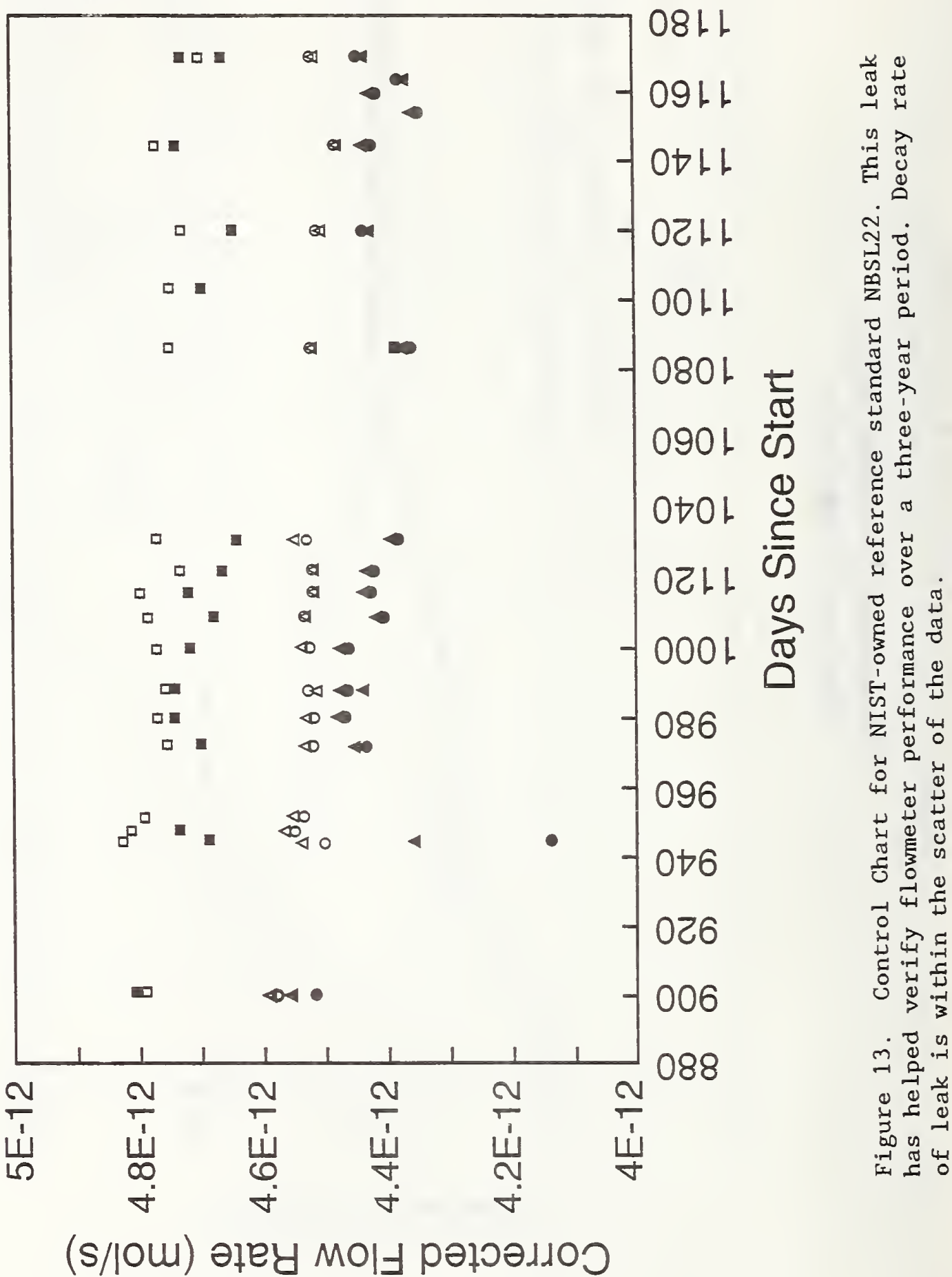




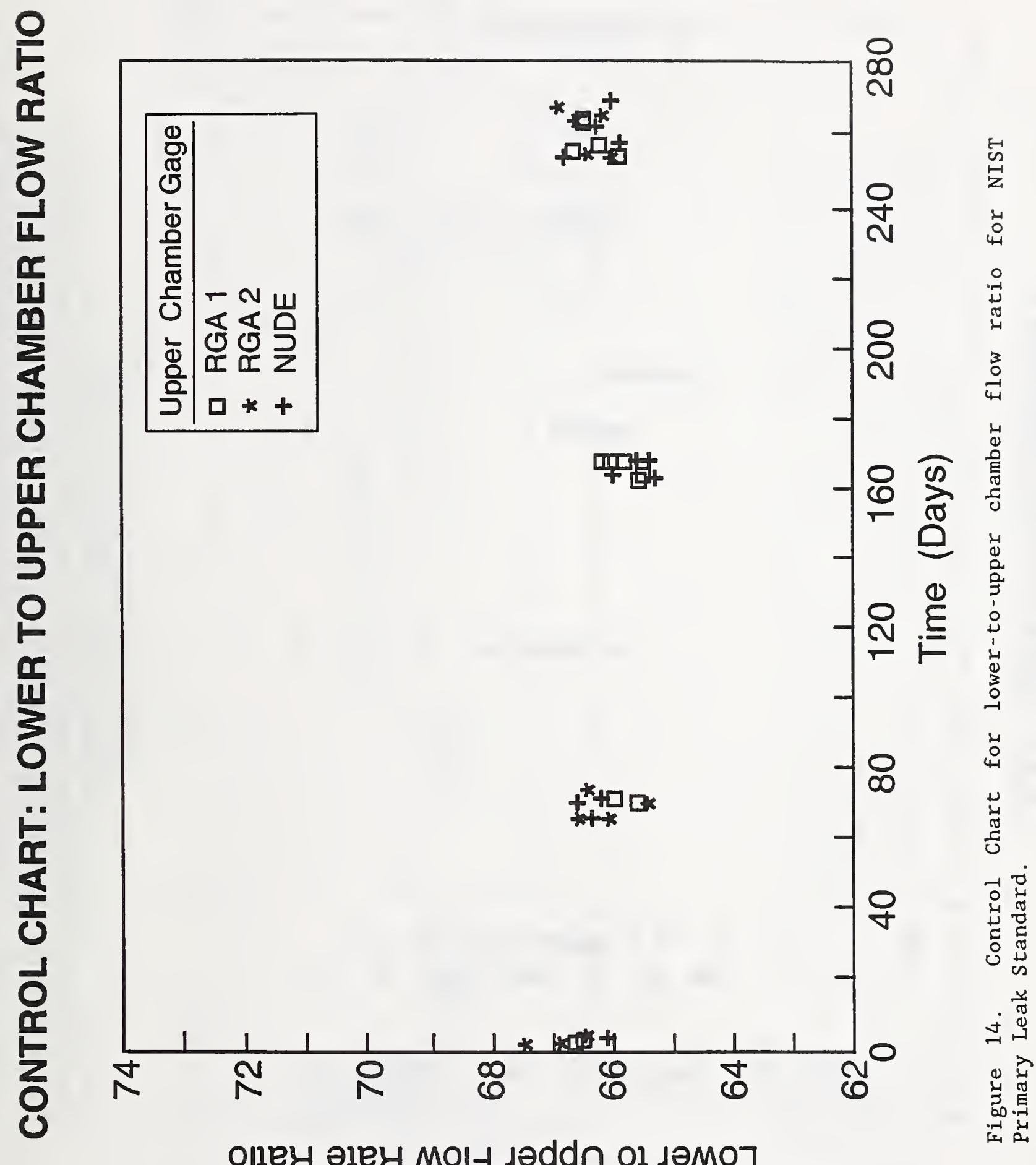




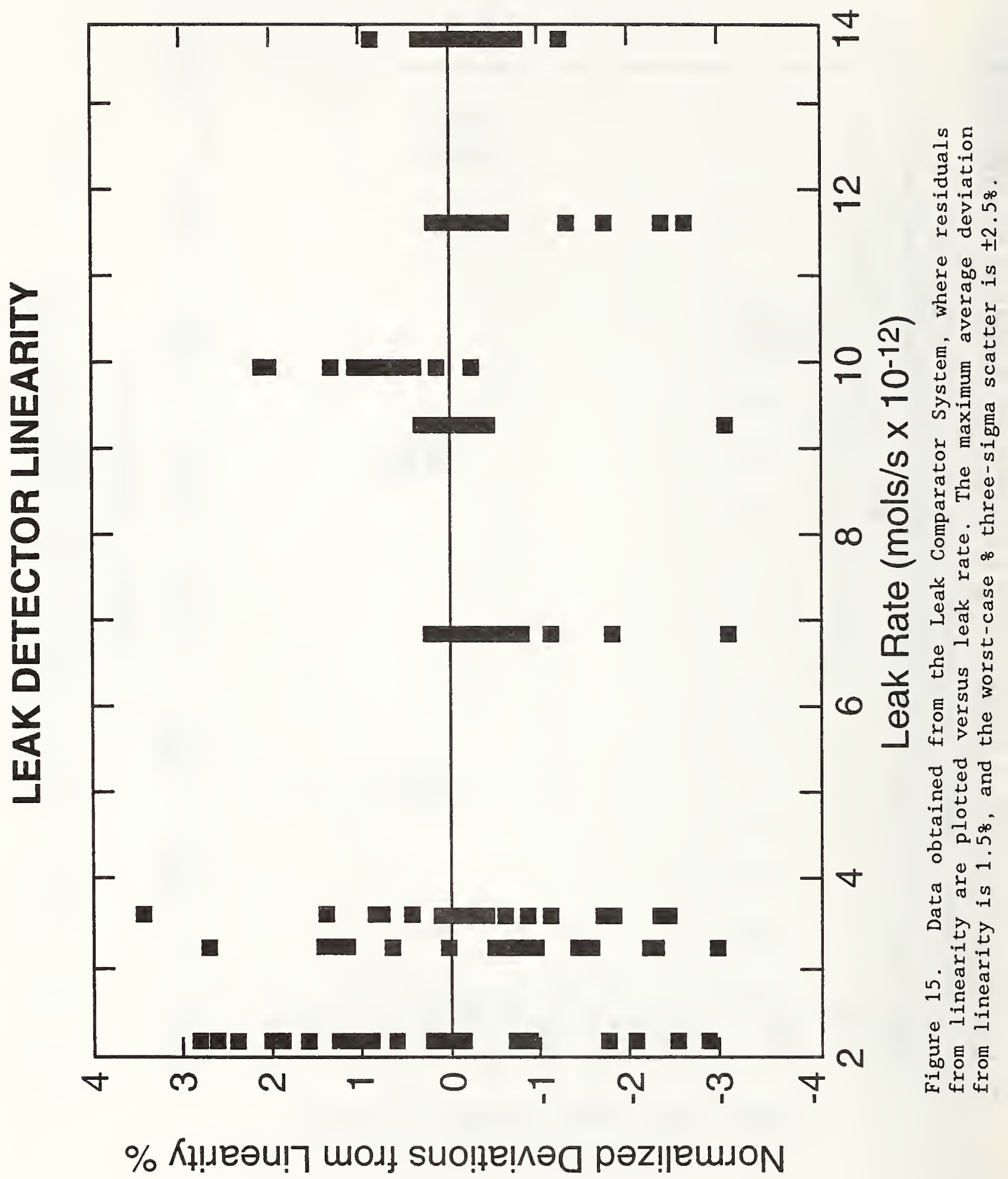




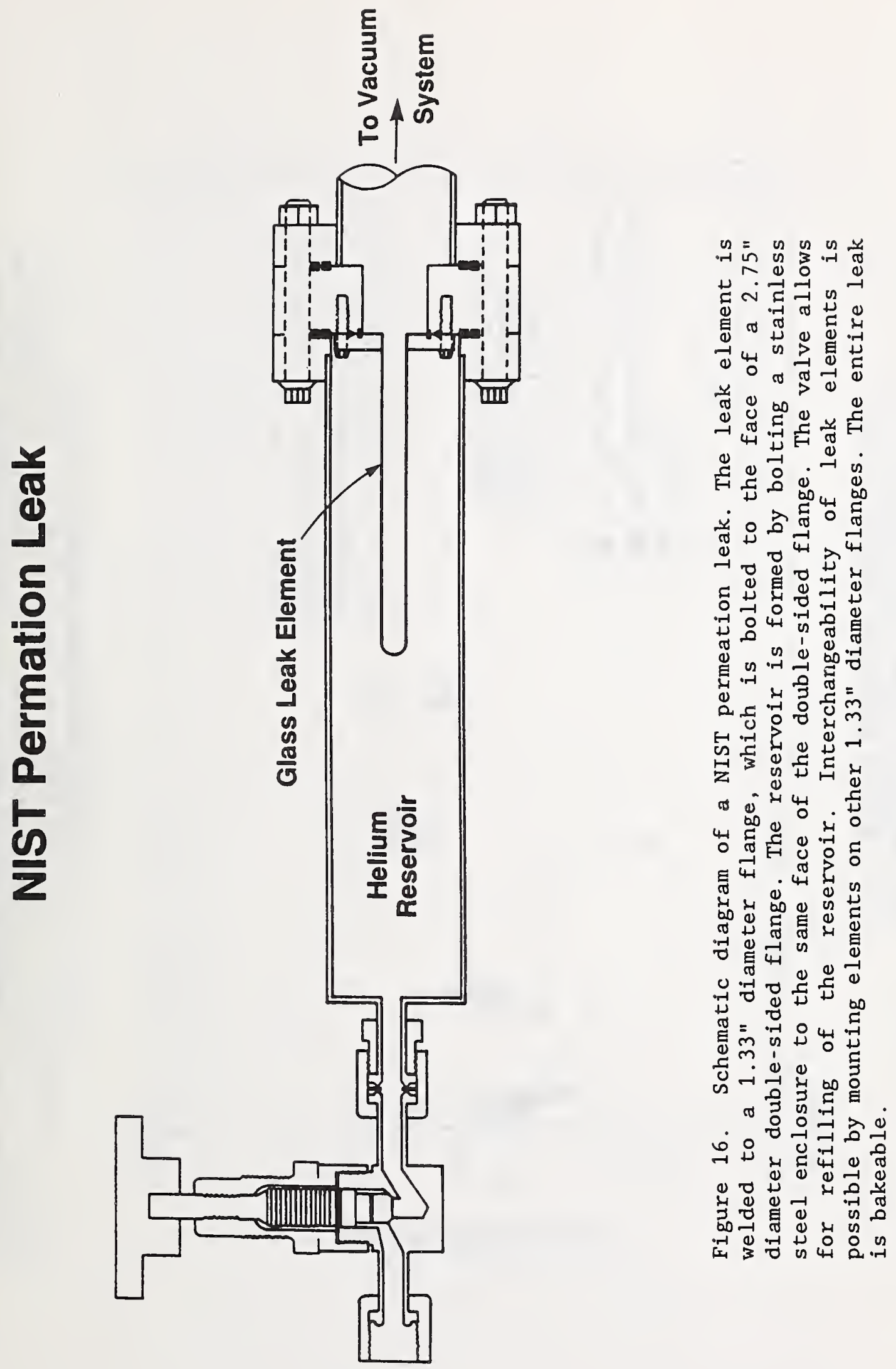




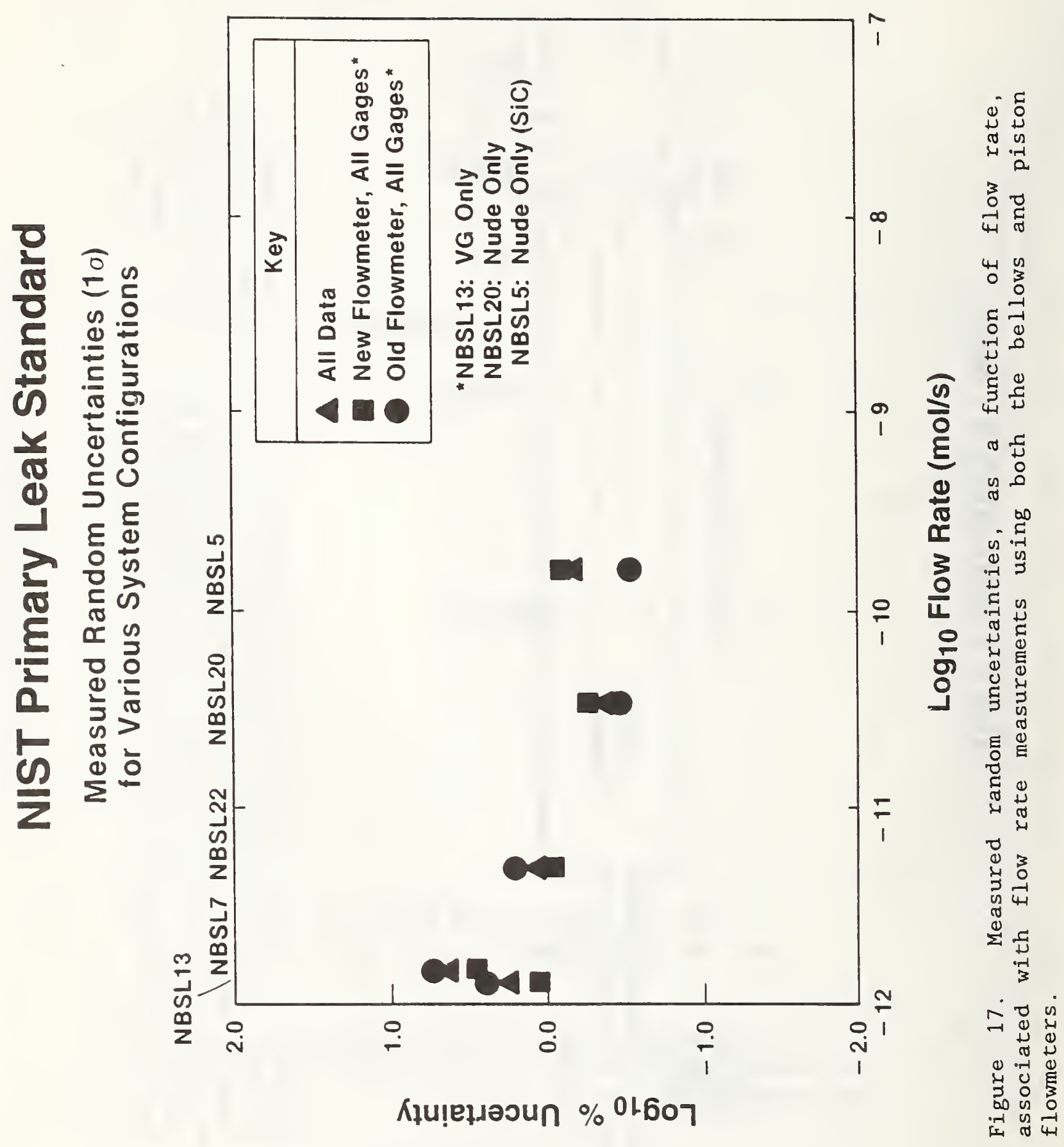




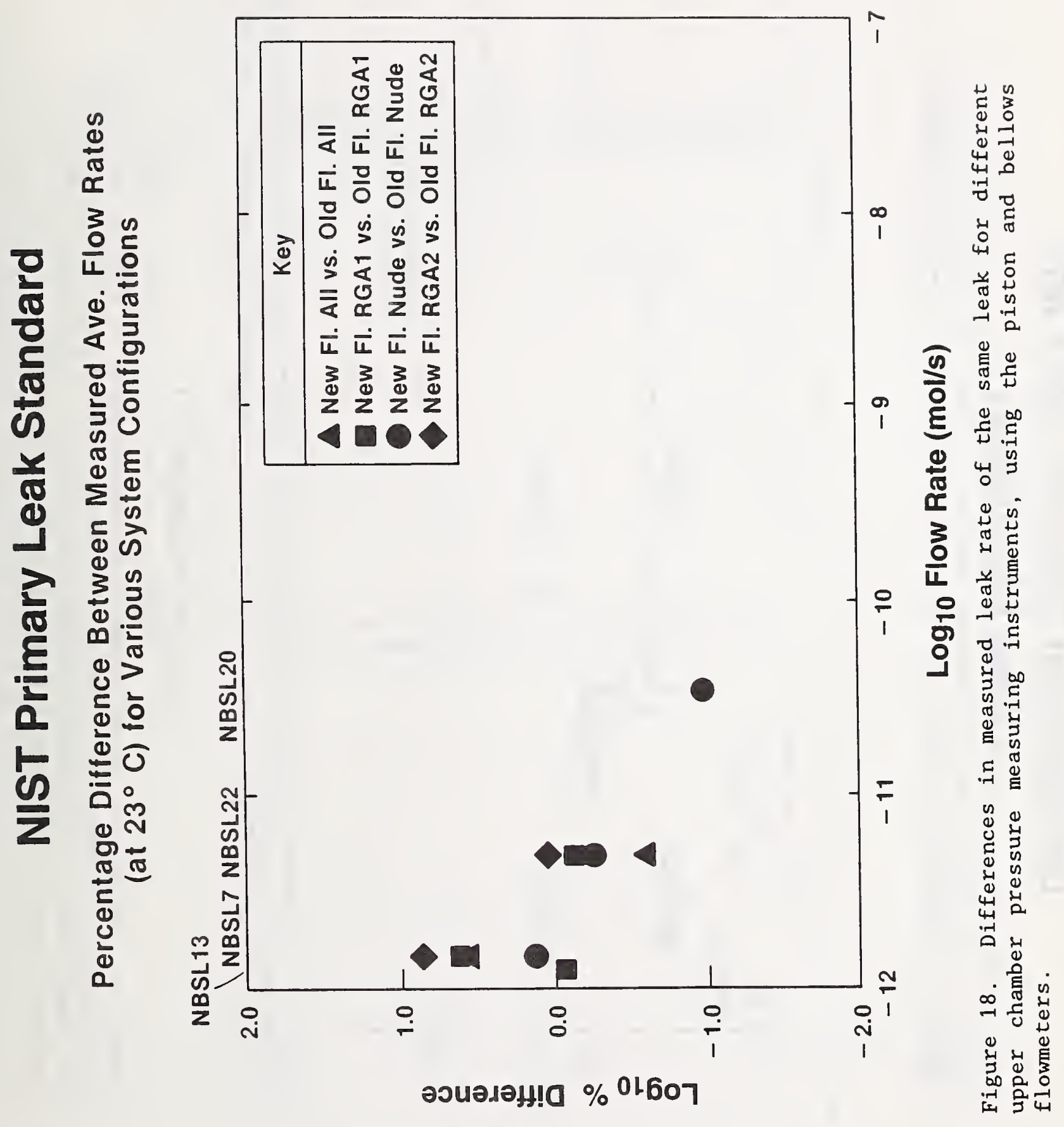




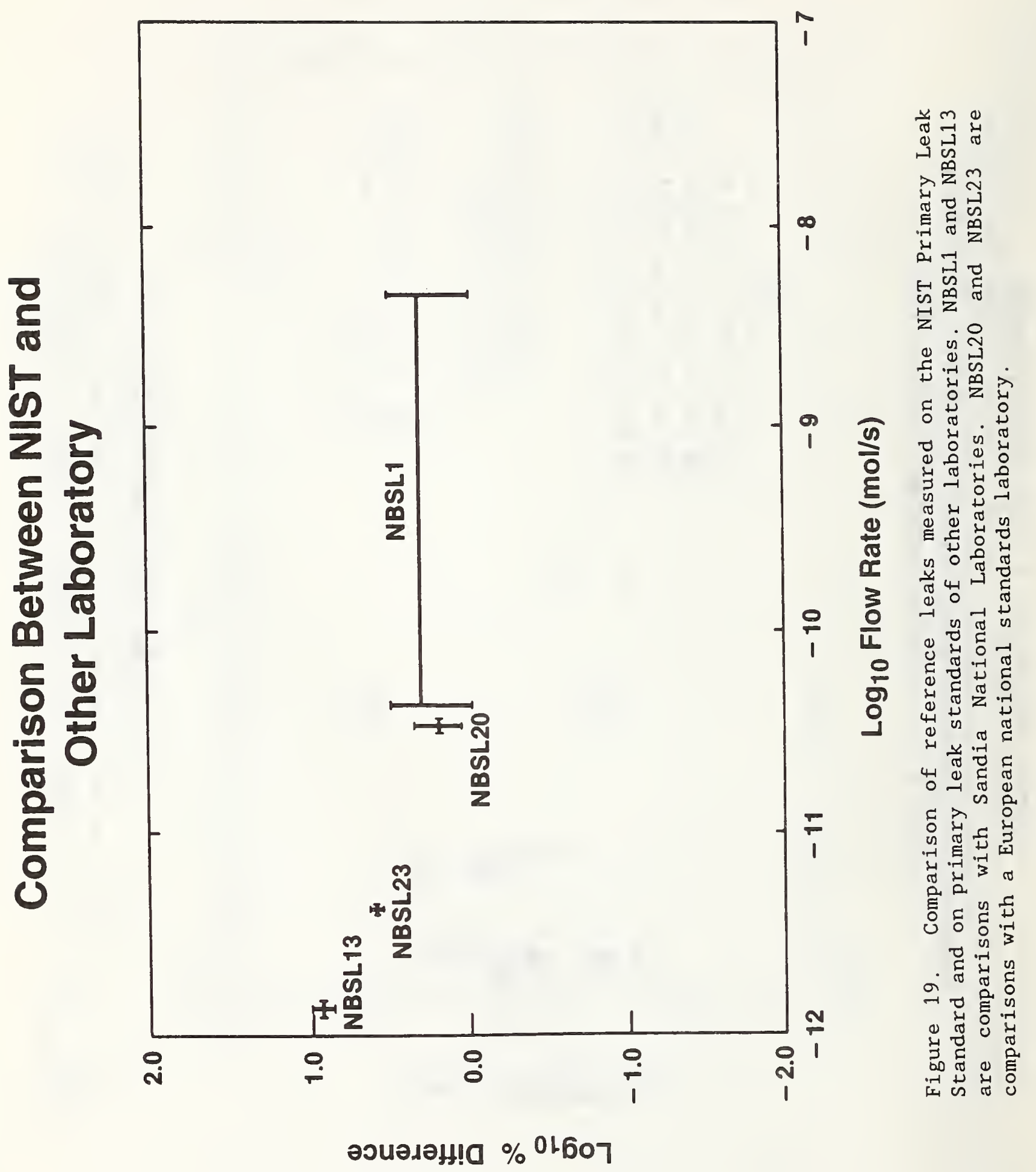




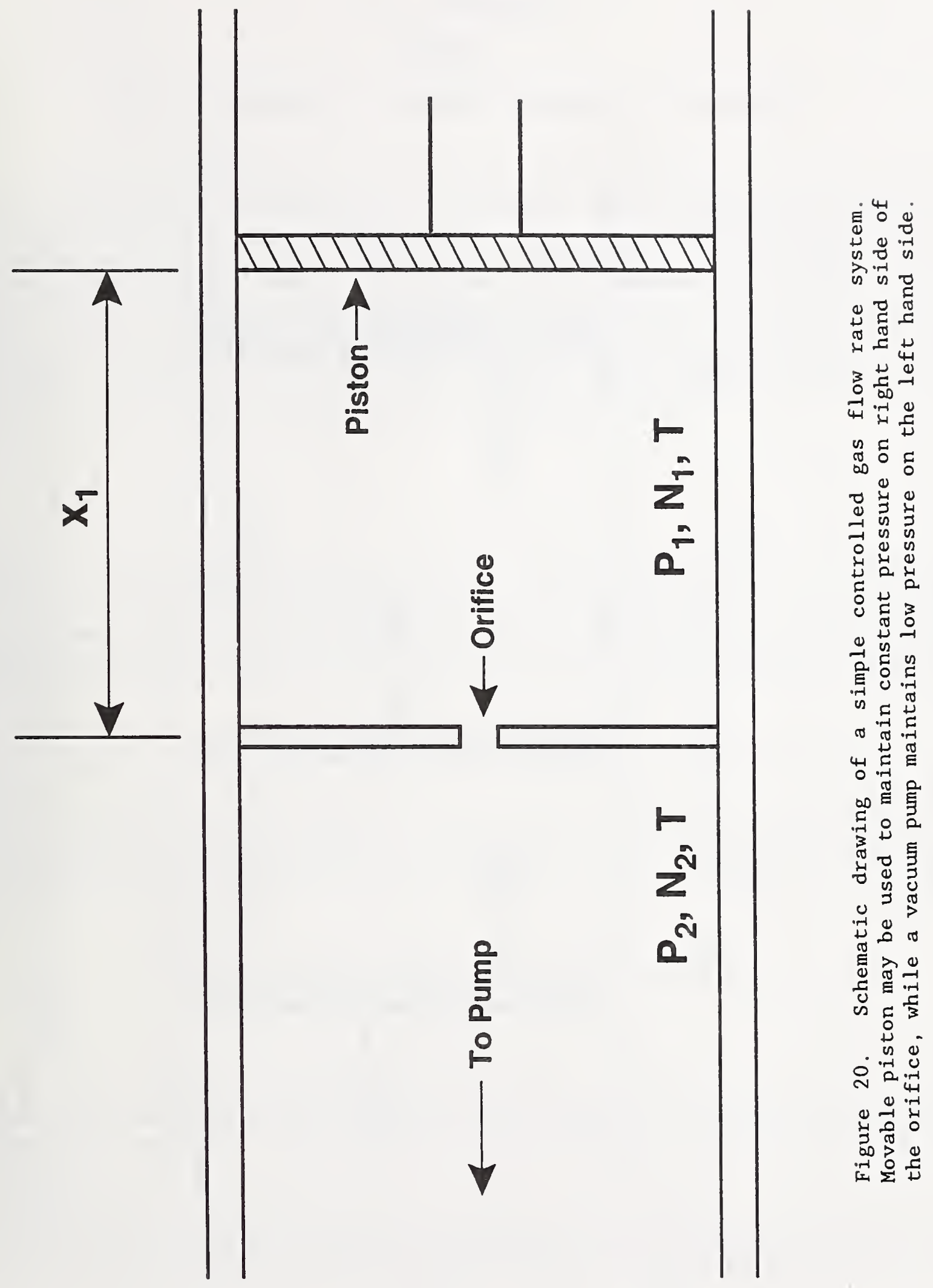




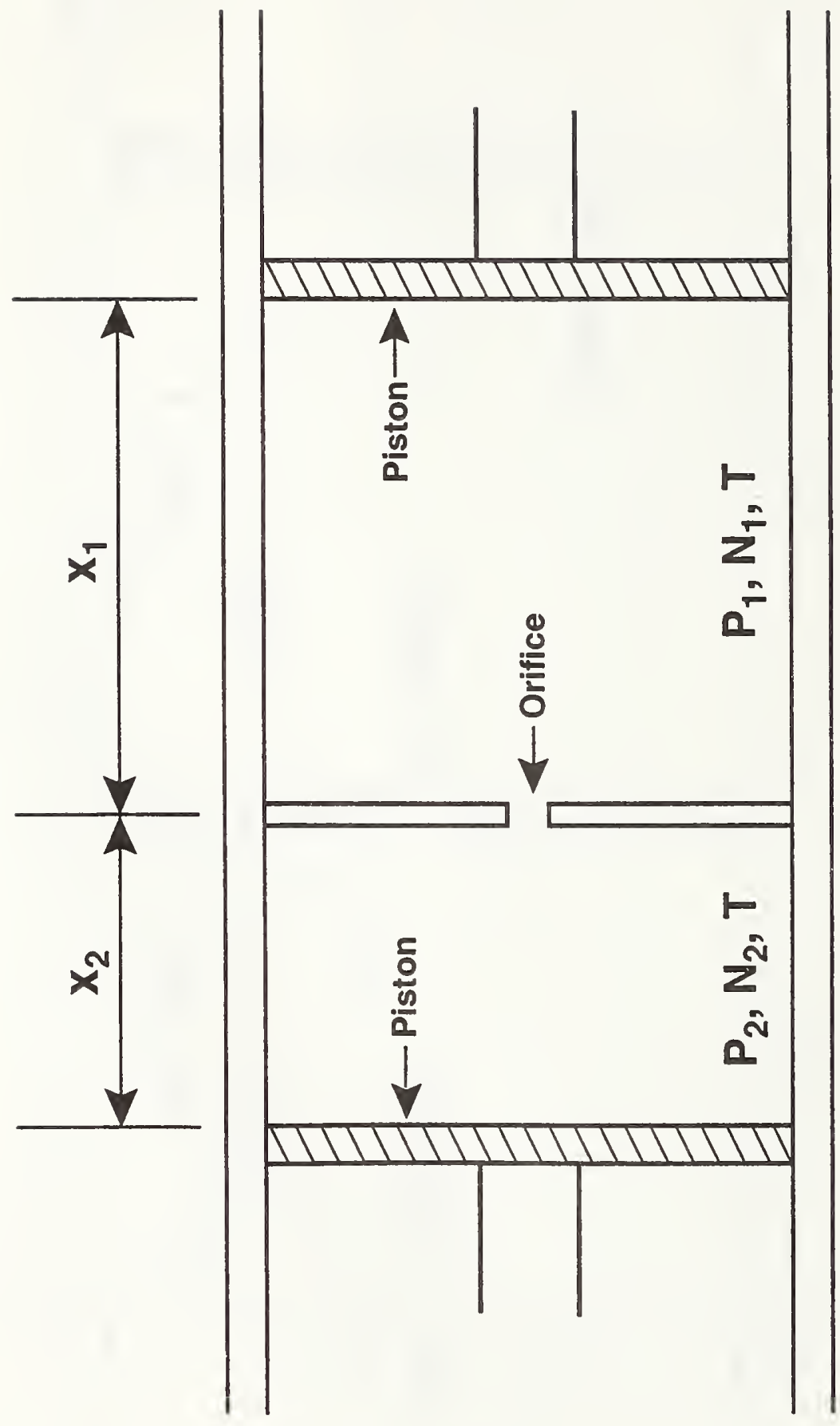

$\begin{array}{ll}: & 4 \\ 0 & 0 \\ \Delta & 0 \\ 0 & 0 \\ 0 & 0 \\ 0 & 0\end{array}$

㟧

م.

은

记

$\rightarrow 0$

चै ญ

$\exists$

닌

㟔

( )

을

祭

(1)

4

일

零

मै 3

อ อ

䒕 完

है

ज

。

in

$\therefore$

$\vec{\sim}$

(1)

눙

as $>0$

贸全 


\section{APPENDICES}

\section{APPENDIX A \\ USE AND CONVERSION OF UNITS OF FLOW RATE AND THROUGHPUT}

To discuss the differences between flow rate and throughput units, consider the simple experimental apparatus in figure 20, where a cylindrical volume is divided by a plate with a small orifice in it, a tightly-fitting piston is inserted in one end, and the other end is attached to a vacuum pump. While this system is quite simple, it can be used to discuss many of the factors which should be considered when performing gas flow rate measurements. Let an ideal gas at pressure $P$ and temperature $T$ fill the reservoir side of the cylinder. As gas effuses through the orifice and is pumped away, let the piston be moved at a rate that maintains the pressure in the reservoir at $P$. The equation of state of the gas at each instant of time is

$$
\mathrm{PV}=\mathrm{NRT} \text {, }
$$

where $\mathrm{N}$ is the number of moles of gas contained in the volume $\mathrm{V}$, and $\mathrm{R}$ is the universal gas constant (numerically equal to $8.31441 \mathrm{Joule}^{-1} \mathrm{~K}^{-1}$ or 82.057 atm $\mathrm{cm}^{3} \mathrm{~mol}^{-1} \mathrm{~K}^{-1}$ ). If $\mathrm{dN}$ moles of gas are passing through the orifice every dt seconds, giving the molar flow rate $Q_{m} \equiv d N / d t$, then, to keep $P$ constant, the piston must be moved at a rate such that the volume change per unit time is given by

$$
d V / d t=\left[\left(\begin{array}{ll}
R
\end{array}\right) / P\right](d N / d t) \equiv\left[\left(\begin{array}{ll}
R
\end{array}\right) / P\right] Q_{m} .
$$

It is assumed that the process is slow enough and that the heat capacity of the cylinder walls is great enough that the process is isothermal. Eq (A2) can be rewritten as

$$
\begin{gathered}
\mathrm{Q}_{\mathrm{m}} \equiv \mathrm{dN} / \mathrm{dt}=[\mathrm{P} /(\mathrm{RT})](\mathrm{dV} / \mathrm{dt})=[\mathrm{P}(\mathrm{dV} / \mathrm{d} t)] /(\mathrm{RT}) \\
\equiv \mathrm{Q} /(\mathrm{RT}),
\end{gathered}
$$

where $Q[=P(d V / d t)]$ is frequently called the "throughput" of the gas. Thus while the number of moles of gas passing through the orifice per unit time $\left(Q_{m}\right)$ is an explicit function of the gas temperature, the throughput (Q) is not.

For example, if the pressure $P$ is equal to one atmosphere ( $1 \mathrm{~atm}$ ) and the volume rate of change necessary to maintain that pressure is one cubic centimeter per second $\left(1 \mathrm{~cm}^{3} \mathrm{~s}^{-1}\right)$, then the gas throughput is equal to 


$$
\mathrm{Q}=\mathrm{P}(\mathrm{dV} / \mathrm{dt})=(1 \mathrm{~atm})\left(1 \mathrm{~cm}^{3} \mathrm{~s}^{-1}\right)=1 \mathrm{~atm} \mathrm{~cm}^{3} \mathrm{~s}^{-1}
$$

independent of the temperature of the gas. If the gas temperature is $273.15 \mathrm{~K}$ $\left(0{ }^{\circ} \mathrm{C}\right)$, the molar flow rate of gas can be computed using eq (A3) as

$$
\begin{aligned}
\mathrm{Q}_{\mathrm{m}} & =\mathrm{Q} /(\mathrm{R} \mathrm{T}) \\
& =\left(1 \mathrm{~atm} \mathrm{~cm} \mathrm{~s}^{-1}\right) /\left[\left(82.057 \mathrm{~atm} \mathrm{~cm} \mathrm{~mol}^{-1} \mathrm{~K}^{-1}\right)(273.15 \mathrm{~K})\right] \\
& =4.462 \times 10^{-5} \mathrm{~mol} \mathrm{~s}-1
\end{aligned}
$$

If the temperature of the gas is $296.15 \mathrm{~K}\left(23^{\circ} \mathrm{C}\right)$, then the molar flow rate of gas can again be computed, using eq (A3), as

$$
\begin{aligned}
\mathrm{Q}_{\mathrm{m}} & =\mathrm{Q} /(\mathrm{R} \mathrm{T}) \\
& =\left(1 \mathrm{~atm} \mathrm{~cm}^{3} \mathrm{~s}^{-1}\right) /\left[\left(82.057 \mathrm{~atm} \mathrm{~cm} \mathrm{~mol}^{-1} \mathrm{~K}^{-1}\right)(296.15 \mathrm{~K})\right] \\
& =4.115 \times 10^{-5} \mathrm{~mol} \mathrm{~s} \mathrm{~s}^{-1}
\end{aligned}
$$

Thus, while it is frequent practice to interchange the words "throughput" and "flow rate," this example illustrates clearly that, for the same throughput of $1 \mathrm{~atm} \mathrm{~cm}^{3} \mathrm{~s}^{-1}$, the actual flow rate of gas will have different values, depending on the temperature of the gas.

If throughput and flow rate are not the same quantity, we may ask if throughput has any physical significance. From the example above, we see that the quantity $Q$ called throughput is actually the amount of work per unit time (or power) that must be done by the piston on the gas to maintain constant pressure $P$ in the reservoir as gas effuses through the orifice, and that this quantity is independent of temperature. For isothermal conditions, this energy is transported across the orifice in the form of kinetic energy of the gas molecules.

Dual usage of the word throughput, on the one hand defined by $Q=d(P V) / d t$, and on the other hand meant to be synonymous with leakage rate, has caused considerable confusion in the literature over the years, and has led to the use of the words "throughput units" or "PV units" when the word throughput is meant to be synonymous with gas flow rate. The way that PV units or throughput units are associated with flow rates can be seen using the example above. For the conditions used to compute the flow rate in eq (A5), the throughput is $1 \mathrm{~atm} \mathrm{~cm} \mathrm{~s}^{-1}$, the temperature of the gas is $0{ }^{\circ} \mathrm{C}$, and the flow rate is $4.462 \times 10^{-5} \mathrm{~mol} \mathrm{~s} \mathrm{~s}^{-1}$. The PV unit or throughput unit that is associated with this flow is 1 atm $\mathrm{cm}^{3} \mathrm{~s}^{-1}$ @ $0{ }^{\circ} \mathrm{C}$. Similarly, for the conditions used to compute the flow rate in eq (A6), the throughput is still 1 atm $\mathrm{cm}^{3} / \mathrm{s}$, the temperature of the gas is now $23^{\circ} \mathrm{C}$, and the flow rate is now $4.115 \times 10^{-5} \mathrm{~mol} / \mathrm{s}$. The PV unit or throughput unit that is associated with 
this flow is 1 atm $\mathrm{cm}^{3} \mathrm{~s}^{-1}$ @ $23^{\circ} \mathrm{C}$. It is important to note that PV units or throughput units are not really units at all, in the sense that on their own they do not have clear dimensions: they are merely expressions of convenience that are, in fact, defined by the flow rates with which they are associated. Thus, an equivalence relationship can be established

$$
1 \text { atm } \mathrm{cm}^{3} \mathrm{~s}^{-1} \text { @ } 0{ }^{\circ} \mathrm{C}=4.462 \times 10^{-5} \mathrm{~mol} \mathrm{~s}^{-1} \text {. }
$$

From eqs (A5) and (A6) it can be seen that this definition can be extended to other PV units or throughput units at arbitrary temperature according to:

1 atm $\mathrm{cm}^{3} \mathrm{~s}^{-1} @ \mathrm{~T}_{1}(\mathrm{~K})=\left(273.15 / \mathrm{T}_{1}(\mathrm{~K})\right) \cdot 4.462 \times 10^{-5} \mathrm{~mol} \mathrm{~s}^{-1}$

Generalizing even further, then, to move from one PV unit or throughput unit to another, eq (or 'equivalence') (A8) can be used to derive the expression

1 atm $\mathrm{cm}^{3} \mathrm{~s}^{-1}$ @ $\mathrm{T}_{1}(\mathrm{~K})=\left[\mathrm{T}_{2}(\mathrm{~K}) / \mathrm{T}_{1}(\mathrm{~K})\right]$ atm $\mathrm{cm}^{3} \mathrm{~s}^{-1}$ @ $\mathrm{T}_{2}(\mathrm{~K})$.

Equations (A7), (A8), and (A9) then form the basis on which conversions to other PV units or throughput units, such as $\mathrm{Pa} \mathrm{m} \mathrm{s}^{-1} @ \mathrm{~T}_{3}(\mathrm{~K})$, atm $\mathrm{cm}^{3} \mathrm{~s}^{-1}$ @ $\mathrm{T}_{4}(\mathrm{~K})$, Torr $1 \mathrm{~s}^{-1}$ @ $\mathrm{T}_{5}(\mathrm{~K})$, etc., can be performed. Table A1 lists conversion factors for various units[9]. The following example illustrates such a conversion.

Let us say that for the gas flow rate measured under the conditions corresponding to eq (A5), we would like to know the flow rate in terms of the $\mathrm{PV} /$ throughput unit $\mathrm{Pa} \mathrm{m}^{3} \mathrm{~s}^{-1} @ \mathrm{~T}_{3}(\mathrm{~K})$. That is, we would like to find $A_{3}$ in

$$
\mathrm{A}_{3}\left\{\mathrm{~Pa} \mathrm{~m} \mathrm{~m}^{-1} @ \mathrm{~T}_{3}(\mathrm{~K})\right\}=1 \mathrm{~atm} \mathrm{~cm}^{3} \mathrm{~s}^{-1} \text { @ } 00^{\circ} \mathrm{C} \text {. }
$$

The first step is to perform the conversion between atm $\mathrm{cm}^{3} \mathrm{~s}^{-1}$ and $\mathrm{Pa} \mathrm{m} \mathrm{m}^{-1}$ which, from table A1, is

$$
1 \text { atm } \mathrm{cm}^{3} \mathrm{~s}^{-1}=0.101325 \mathrm{~Pa} \mathrm{~m}^{3} \mathrm{~s}^{-1}
$$

Note that table A1 must be used with some caution. The units in the top left quadrant, which is highlighted with a heavy black line, are all throughput units, and the conversions between them are independent of temperature. Alternatively, the units outside of the top left quadrant are all flow rate units, but are also independent of temperature (except for "ATM STP $\mathrm{cm}^{3} / \mathrm{s}^{\prime \prime}$, where the temperature is referred to in the unit). When the expression "@ $0{ }^{\circ} \mathrm{C}$ " is added to the throughput units in the upper left 
quadrant, as the Table Al caption indicates is intended, the throughput units can then be regarded as flow rate units, and conversion of flow rate units across the heavy black line is then allowed. Substituting eq (A11) into eq (A10) then gives

$$
\mathrm{A}_{3}\left\{\mathrm{~Pa} \mathrm{~m} \mathrm{~s}^{-1} @ \mathrm{~T}_{3}(\mathrm{~K})\right\}=\left(0.101325 \mathrm{~Pa} \mathrm{~m} \mathrm{~s}^{-1}\right) @ 0{ }^{\circ} \mathrm{C}
$$

The next step is to convert to the desired temperature $T_{3}(K)$ on the right hand side of eq (A12), using eq (A9) in the more generalized form

$$
\mathrm{Q} @ \mathrm{~T}_{1}(\mathrm{~K})=\left[\mathrm{T}_{2}(\mathrm{~K}) / \mathrm{T}_{1}(\mathrm{~K})\right] \mathrm{Q} @ \mathrm{~T}_{2}(\mathrm{~K}) \text {, }
$$

where $Q$ is any throughput unit, such as atm $\mathrm{cm}^{3} \mathrm{~s}^{-1}, \mathrm{~Pa} \mathrm{~m} \mathrm{~m}^{-1}$, etc. We get

$$
\mathrm{A}_{3}\left(\mathrm{~Pa} \mathrm{~m} \mathrm{~s}^{-1} @ \mathrm{~T}_{3}(\mathrm{~K})\right)=(0.101325) \cdot \mathrm{T}_{3}(\mathrm{~K}) / 273.15 \text {, }
$$

so that $A_{3}$ is

$$
A_{3}=(0.101325) \cdot\left[T_{3}(K) / 273.15\right]
$$

This example can then be taken one step further to handle the most general conversion from $\mathrm{Q}_{4} @ \mathrm{~T}_{4}$ to $\mathrm{Q}_{3}$ @ $\mathrm{T}_{3}$, that is

$$
A_{4}\left\{Q_{4} @ T_{4}\right\}=A_{3}\left\{Q_{3} @ T_{3}\right\},
$$

where $Q_{3}$ and $Q_{4}$ are any two throughput units, related by the temperatureindependent conversion factor $\mu_{4,3}$

$$
\mathrm{Q}_{4}=\mu_{4,3} \mathrm{Q}_{3}
$$

We wish to find $A_{3}$ in terms of the other known parameters. Following steps virtually identical to eq (A10) through (A15), we get

$$
A_{3}=A_{4} \mu_{4}, 3 T_{3}(K) / T_{4}(K)
$$

For example, suppose we wish to convert $1 \times 10^{-7} \mathrm{~atm} \mathrm{~cm}^{3} \mathrm{~s}^{-1}$ @ $0{ }^{\circ} \mathrm{C}$ to Torr 1 $s^{-1}$ @ $23{ }^{\circ} \mathrm{C}$ 


$$
1 \times 10^{-7} \mathrm{~atm} \mathrm{\textrm {cm } ^ { 3 }} \mathrm{s}^{-1} \text { @ } 0{ }^{\circ} \mathrm{C}=\mathrm{A}_{3} \operatorname{Torr} 1 \mathrm{~s}^{-1} \text { @ } 23^{\circ} \mathrm{C} \text {. }
$$

Then, in eq (A16), $\mathrm{A}_{4}=1 \times 10^{-7}, \mathrm{Q}_{4}=\mathrm{atm} \mathrm{cm}^{3} \mathrm{~s}^{-1}$, and $\mathrm{T}_{4}=0{ }^{\circ} \mathrm{C}=273.15 \mathrm{~K}, \mathrm{Q}_{3}$ $=\operatorname{Torr} 1 \mathrm{~s}^{-1}$, and $\mathrm{T}_{3}=23{ }^{\circ} \mathrm{C}=296.15 \mathrm{~K}$. From Table A1, the conversion factor in eq (A17) is 1 atm $\mathrm{cm}^{3} \mathrm{~s}^{-1}=(0.760)$ Torr $1 \mathrm{~s}^{-1}$, so that $\mu_{4,3}=0.760$. Using eq (A18) we obtain

$$
A_{3}=1 \times 10^{-7} \cdot(0.76) \cdot 296.15 / 273.15=8.24 \times 10^{-8}
$$

so that

$$
1 \times 10^{-7} \mathrm{~atm} \mathrm{~cm}^{3} \mathrm{~s}^{-1} \text { @ } 0{ }^{\circ} \mathrm{C}=8.24 \times 10^{-8} \text { Torr } 1 \mathrm{~s}^{-1} \text { @ } 23^{\circ} \mathrm{C} \text {. }
$$

From eq (A7), this is equivalent to $4.462 \times 10^{-12} \mathrm{~mol} \mathrm{~s}^{-1}$.

From this discussion it should be clear why a unit such as moles per second (mol $\mathbf{s}^{-1}$ ) is chosen as the recommended unit for flow rate or leakage rate, as opposed to a throughput unit. Other possibilities, such as kilograms per second, were also considered, but have the drawback that in comparing flow rates from leaks emitting different gas species or mixtures, it is necessary to know the relative molecular weights. Another popular leak rate unit is the standard atmosphere $\mathrm{cm}^{3} \mathrm{~s}^{-1}$. However, there is an opportunity for ambiguity in stating the standard conditions in temperature because of the availability of more than one accepted standard, with $0{ }^{\circ} \mathrm{C}, 25{ }^{\circ} \mathrm{C}, 20^{\circ} \mathrm{C}$, etc. in use. Since "standard atmosphere $\mathrm{cm}^{3} \mathrm{~s}^{-1}$ " requires knowledge of the "standard" temperature, the calibration temperature and the usage temperature, further confusion is possible[10]. Therefore, the recommendation of use of the unit moles per second is further strengthened. This use reduces the problems of ambiguity and confusion, since the originator of the measurements must immediately incorporate knowledge of the temperature $T$ into the appropriate equation in order to express the flow rate in mol $\mathbf{s}^{-1}$. Likewise, the user of a leak, given the temperature dependence of the leakage rate in mol $\mathrm{s}^{-1}$, can readily convert data to the applicable units during use knowing the temperature of the measurement process. 


\begin{tabular}{|c|c|c|c|c|c|c|c|c|c|}
\hline & 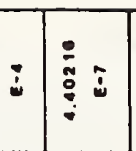 & 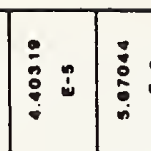 & 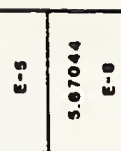 & 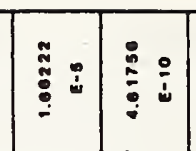 & & 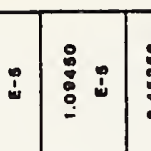 & & & \\
\hline 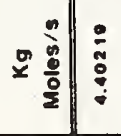 & 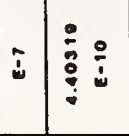 & $\mid$ & & 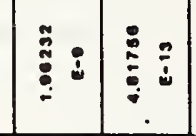 & & & & & \\
\hline 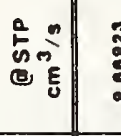 & ב⿱艹 & $\mid$ & & $\frac{1}{8}=$ & & $: \mid$ & & & : \\
\hline 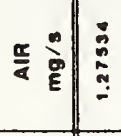 & $=$ & 离 & $\frac{2}{3}$ & $\mid$\begin{tabular}{l}
2 \\
\hdashline
\end{tabular} & 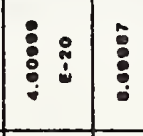 & $\vdots \mid$ & -1 & & 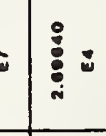 \\
\hline 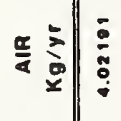 & & $\mid$ & $=2$ & 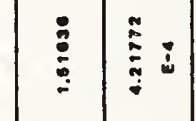 & $\mid$ & $\Sigma-$ & $=$ & & $=\frac{1}{30}$ \\
\hline 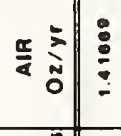 & & $=$ & $=0 \frac{8}{3}$ & 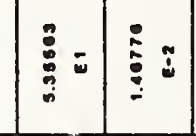 & 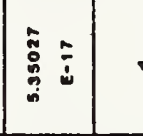 & - & 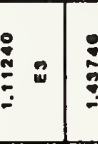 & & 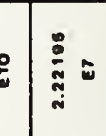 \\
\hline 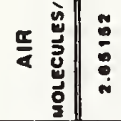 & 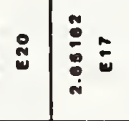 & 䒺: & 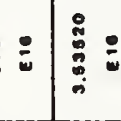 & $\mid$ & - & 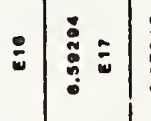 & : & & 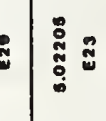 \\
\hline 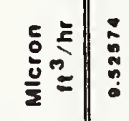 & 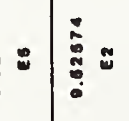 & 竞: & $=$ & 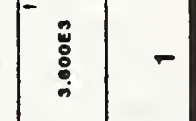 & |: & $=$ & 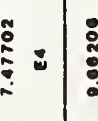 & & 13 \\
\hline 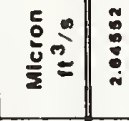 & 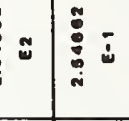 & 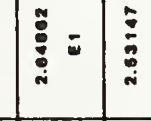 & $=5$ & & 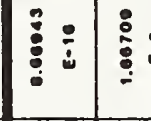 & 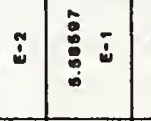 & : & & $=$ \\
\hline 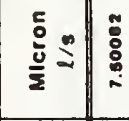 & $=:$ & 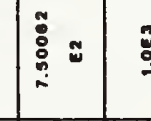 & $\vdots$ & 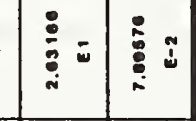 & 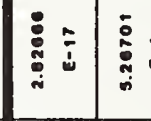 & 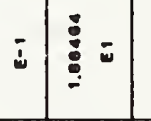 & 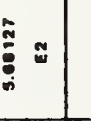 & & $=18$ \\
\hline 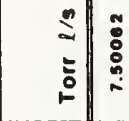 & ב⿱艹 & 然 & $-\quad$ & $\mid$ & $\mid$ & : & $\overline{\underline{u}}$ & & \\
\hline $\begin{array}{l}\mid \mathfrak{i} \\
\end{array}$ & 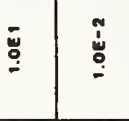 & - & 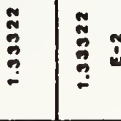 & 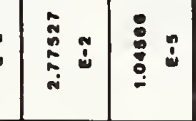 & 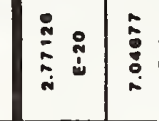 & $: \mid$ & 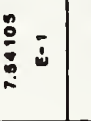 & & . \\
\hline 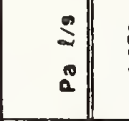 & $\vdots$ & 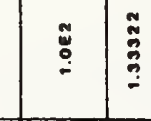 & & 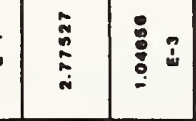 & 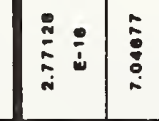 & $=\frac{a}{3}$ & $\begin{array}{l}\vdots \\
\vdots\end{array}=$ & & $1=$ \\
\hline 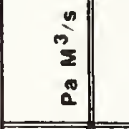 & $-\frac{\tilde{a}}{3}$ & 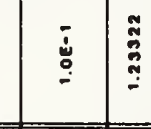 & 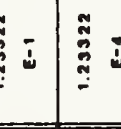 & 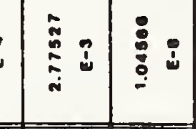 & 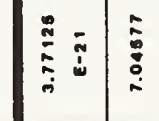 & $\mid$ & 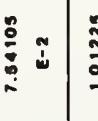 & & $\left.\right|^{*}$ \\
\hline & & 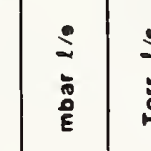 & 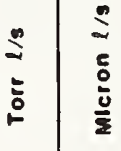 & $\frac{50}{\frac{5}{2}}=\frac{5}{\frac{5}{2}}=$ & & & & & \\
\hline
\end{tabular}

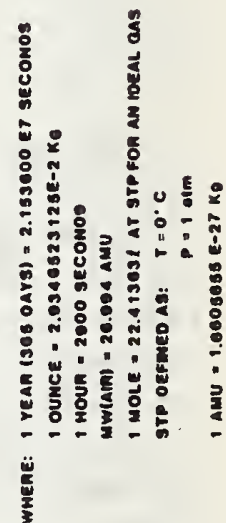




\section{APPENDIX B}

\section{GENERAL THEORY OF GAS FLOW IN VACUUM SYSTEMS}

The flow of highly rarefied gases through various components of a vacuum apparatus has been a topic of serious interest since the early 1900's. The works of Knudsen [11], Smoluchowski [12], Dushman [13] and Clausing [14] on the flow of such gases through tubes of various lengths and shapes are still of current interest and use today. Derivation of expressions which adequately quantify gas flow "rate in the "transition region" between molecular and viscous flow, based on first principles of the kinetic theory of gases, remain elusive. The need still exists to make accurate measurements of gas flow rates in these regions to better define and understand the physical parameters that are most important in describing this flow.

Fundamental to any understanding or measurement of the flow rate of gases is a clear definition of the system through which the gas will be moving, the forces (mechanical or otherwise) which cause the gas to move, the equation of state of the gas under conditions of equilibrium and the energy flow in the system. A system capable of controlled gas flow is shown schematically in figure 21, where a cylindrical volume is divided by a plate with a small orifice in it, and tightly-fitting pistons are inserted into either end. While this system is quite simple, it can be used to discuss many of the factors which should be considered when performing gas flow rate measurements.

Consider first the conditions where gas at pressure $P_{1}$ initially fills the right volume $V_{1}\left(=X_{1} \cdot A\right.$, where $X_{1}$ is the linear distance between the face of the piston and the plate with the orifice, and $A$ is the cross sectional area of the cylinder), the left volume $V_{2}$ is evacuated, and the entire system is maintained at temperature $T$. We wish to determine the net flow rate of gas through the orifice, as a function of time, when the pistons are first held in a fixed position. It is frequently the case that the equation of state of the gas under equilibrium conditions can be represented to sufficient accuracy by the ideal gas law:

$$
\mathrm{P} \cdot \mathrm{V}=\mathrm{N} \cdot \mathrm{R} \cdot \mathrm{T}
$$

where $\mathrm{P}$ is the equilibrium pressure of the gas, $\mathrm{V}$ is the volume in which the gas is contained, $\mathrm{N}$ is the number of moles of gas contained in the volume, $\mathrm{R}$ is the universal gas constant $\left(=8.31441 \mathrm{Joule}^{\mathrm{mol}} \mathrm{K}^{-1} \mathrm{~K}^{-1}\right.$, see table 1 for conversion to other units) and $\mathrm{T}$ is the absolute temperature of the gas and the walls of the containment volume. For the highest accuracy it is necessary to replace eq (B1) with a virial expansion:

$$
P /\left(k_{B} \cdot T\right)=n+B_{2}(T) \cdot n^{2}+B_{3}(T) \cdot n^{3}+\ldots
$$

where $\mathrm{n}\left(=\mathrm{N} \cdot \mathrm{N}_{\mathrm{A}} / \mathrm{V}\right)$ is the molecular density of gas, $\mathrm{k}_{\mathrm{B}}$ is the Boltzmann constant $\left(=\mathrm{R} / \mathrm{N}_{\mathrm{A}}=1.381 \mathrm{E}-23\right.$ Joule $\mathrm{K}^{-1}$ where $\mathrm{N}_{\mathrm{A}}$ is Avagadro's number $=6.022 \mathrm{E} 23$ 
$\left.\operatorname{mol}^{-1}\right)$, and the coefficients $B_{i}$ are the "virial coefficients", which are available in the literature for many gases (e.g., [15]). As an example, for helium at room temperature and atmospheric pressure, the correction term corresponding to the second virial coefficient is on the order of 10 to 100 parts per million. For all of the work done to date in conjunction with the NIST Leak Service, the accuracy afforded by eq (B1) is completely adequate, and virial corrections are ignored.

At time $t=0$, then, the molar density of gas in volume 1 can be calculated from the equation of state given in eq (B1):

$$
\frac{N_{1}(t=0)}{V_{1}}=\frac{P_{1}(t=0)}{R \cdot T} .
$$

As time progresses, gas atoms or molecules from volume 1 will pass through the orifice into volume 2 , and some may return from volume 2 into volume 1 . A good measure of the net rate of flow of molecules from volume 1 into volume 2 would then be the rate of change of the molecular (or molar) density of molecules in volume 1 or volume 2 (assuming insignificant adsorption of molecules to the walls). Since the total number of molecules must remain constant at each instant in time, $N_{1}+N_{2}=N_{1}(t=0)$, a measure of the density in one of the volumes is sufficient to determine the density in the other. The actual rate at which the gas densities change depends on several factors, such as the type of gas, the initial pressure $\left(P_{1}(t=0)\right)$, the temperature, and the size of the orifice. The first three factors determine the mean free path $(\lambda)$ of the gas:

$$
\lambda \approx 1 /(\mathrm{n} \cdot \sigma)
$$

where $\mathrm{n}$ is the molecular density of the gas and $\sigma$ is the "cross sectional area" of the atom or molecule. Comparison of $\lambda$ with the diameter of the orifice (D) gives an indication of the functional dependence of the net rate at which gas atoms or molecules will move from volume 1 to volume 2 ( $\lambda / D$ is sometimes referred to as the Knudsen number):

1) $\lambda / D \gg 1$ molecular flow The net flow rate is found to depend on the pressure differential across the orifice according to $(\mathrm{dN} / \mathrm{d} t)=[\mathrm{C} /(\mathrm{R} \cdot \mathrm{T})] \cdot\left(\mathrm{P}_{1}-\mathrm{P}_{2}\right)$, where $C$ is referred to as the conductance of the orifice, and is a function of the orifice geometry but not the gas pressure. For a particular model, such as the kinetic theory of gases, the value of $C$ can be calculated.

2) $\lambda / D \ll 1$ viscous flow

The net flow rate is in general a complicated function of pressure, gas type, etc., so that the conductance is highly pressure dependent. Hydrodynamic flow theory, utilizing the Navier-Stokes equations, is needed. For 
certain geometries other than an aperture it is possible to derive explicit expressions, such as Poiseuille flow through a 'long' pipe.

3) $\lambda / D \approx 1$ transition flow The net flow rate is in general a function of several parameters, and adequate theories are not well developed.

While no explicit formulas are presented here for viscous or transition flow (many widely available textbooks discuss such relationships for a variety of geometries [e.g., 16]), it is almost always the case that net flow rates are greater in these flow regimes than in the molecular flow regime, due to the higher pressures usually involved, and due to the mechanism of interaction of the gas molecules. It is worth noting that for purposes of estimation, the mean free path of many simple gases is on the order of $10^{-5} \mathrm{~cm}$ at atmospheric pressure.

Returning to our discussion of the system in figure 21, for sake of calculational simplicity we will assume that the diameter (D) of the orifice is such that the flow is molecular. Then the equation describing the net flow rate through the orifice, resulting in a loss of molar density in volume 1 and an increase in molar density in volume 2 is:

$$
\frac{d\left(N_{1}\right)}{d t}=-C \cdot\left(P_{1}-P_{2}\right) /(R \cdot T)
$$

and the equation representing the conservation of total number of molecules is:

$$
\mathrm{N}_{1}+\mathrm{N}_{2}=\text { constant }=\mathrm{N}_{1}(t=0) \text {. }
$$

Substitution of eq (B6) and eq (B1) into eq (B5) results in the equation:

$$
\frac{d\left(N_{1}\right)}{d t}=\frac{C}{V_{2}}\left[N_{1}(t=0)-N_{1} \frac{\left(V_{1}+V_{2}\right)}{V_{1}}\right]
$$

with solution:

$$
N_{1}(t)=\frac{N_{1}(t=0)}{\left(V_{1}+V_{2}\right)}\left[V_{1}+V_{2} e^{-t / \tau}\right]
$$

where

$$
\tau \equiv \mathrm{V}_{1} \mathrm{~V}_{2} /\left[\mathrm{C}\left(\mathrm{V}_{1}+\mathrm{V}_{2}\right)\right]
$$


The rate at which gas leaves volume 1 (or enters volume 2) is then:

$$
\frac{\mathrm{dN}_{1}}{\mathrm{dt}}=-\frac{\mathrm{dN}_{2}}{\mathrm{dt}}=-\frac{\mathrm{N}_{1}(t=0) \mathrm{C}}{\mathrm{V}_{1}} \mathrm{e}^{-\mathrm{t} / \tau}
$$

These results demonstrate that even for such a very simple gas flow system the flow rate of the gas through the orifice is constantly changing, making flow rate measurement generally complicated. However, by designing systems such that $V_{2}$ is large compared to $V_{1}$, or by measuring only over times that are short compared to the time constant $\tau$, it is possible to perform 'pressure rate of rise' measurements to determine either the 'instantaneous' or 'time averaged' gas flow rate to a reasonable degree of accuracy.

It is in general much more desirable, both for convenience in measurement and for achievable accuracy, to establish a steady-state gas flow past a particular region of a vacuum system, and measure the (constant) gas flow rate a multiple number of times. Returning to the system in figure 21 , this can be accomplished by now allowing the pistons to be moved while maintaining a constant pressure differential across the orifice. Assuming the same initial conditions as above $\left(\mathrm{dN}_{1} / \mathrm{dt}=\left[\mathrm{N}_{1}(t=0) \cdot \mathrm{C} / \mathrm{V}_{1}\right]\right)$, the piston on the right hand side must be moved at a rate:

$$
\frac{\mathrm{dX}_{1}}{\mathrm{dt}}=\frac{\mathrm{R} \cdot \mathrm{T}}{\mathrm{P}_{1} \mathrm{~A}} \cdot \frac{\mathrm{dN}_{1}}{\mathrm{dt}}
$$

in order to maintain constant pressure $P_{1}$. However, as the initial pressure on the left hand side was zero, the piston on that side would have to move at 'infinite' speed to maintain that condition. Since this is impossible, the next best solution is to provide a means of exhausting the gas from the region using a vacuum pump. Since vacuum pumps have finite pumping capabilities and are naturally limited by the gas dynamics, it is necessary to tolerate a slight pressure (and pressure differential) in the region to the left of the orifice. For a pumping system with pumping speed $S$ (with units of $l s^{-1}$ ) in the pressure region of interest, the pressure that will be developed in region 2 is given by:

$$
P_{2}=\frac{d N_{1}}{d t} \cdot \frac{R \cdot T}{S}
$$

Note that even if the pressure $P_{1}$ in eq $B 11$ is such that the flow through the orifice is not molecular, eqs B11 and B12 are still valid, but the conductance $C$ is then pressure dependent. 


\title{
A note on flow rate and leak rate units
}

\author{
Charles D. Ehrlich \\ Center far Basic Standards, Natianal Bureau af Standards. Gaithershurg. .Maryland 20899
}

(Received 31 October 1985; accepted 28 April 1986)

\begin{abstract}
The confusion in the literature and in the laboratory surrounding the terminology and units of gas flow rates, particularly as applied to calibrated leak artifacts, has prompted this discussion of leak rate units. Special attention is paid to conflicting usages of the term "throughput," and how this frequently leads to the loss of crucial information about the gas temperature and hence the true gas flow rate. The advantages of expressing leak rates in "mol/s," avoiding the complications of both the explicit mention of temperature in the unit and the need for agreement on "standard" temperature and pressure, are also discussed.
\end{abstract}

Upon initiation of a leak standards program at the National Bureau of Standards, we observed that the choice and proper use of units in which to express the fow of gas from a leak artifact and through a vacuum system are historically subjects of much confusion, stemming from problems with several of the definitions and usages of units in vacuum technology in general. While not attempting to cover the broader issues, we will discuss the various sources of confusion which apply to the immediate area of gas flow rate and leak rate units, and point out how use of the unit moles/second avoids most of the problems with the more commonly used units. We will show how different usages of the term "throughput" and its various associated units are ambiguous, frequently leading to loss of information about the gas temperature and hence, the gas flow rate. Other sources of confusion concerning leak rate and gas flow rate units, such as use of "standard" conditions in defining a unit, or the necessity to use multiple temperatures to characterize a leak artifact, will also be discussed. In many instances the errors caused by this confusion are inconsequential, but for high accuracy, high precision measurements the errors can be quite significant. The NBS Pressure and Vacuum Group intends to use the unit " $\mathrm{mol} / \mathrm{s}$ " (moles/second) to report leak rates of calibrated leak artifacts (with gas species and temperature of the leak artifact separately stated), and believes that the rest of the calibrated leak user community can benefit from using this unit as well. For calibrated leak artifacts containing gas mixtures, the unit will be " $\mathrm{mol} / \mathrm{s}$ " for each of the individual gas species.

Looking first at how the common usages of the term "throughput" lead to confusion in the expression of gas flow rate, consider the definition of "throughput" found in the American Vacuum Society Dictionary of Terms' (as well as numerous other places in the literature): "throughput-The quantity of gas in pressure-volume units, at a specified temperature, flowing per unit time across a specified open cross section." From this definition "throughput" and "gas flow rate" are inferred by some to be synonomous, and a typical "unit" of "throughput" is "atm $\mathrm{cm}^{3} / \mathrm{s}$ at $T_{1}{ }^{\circ} \mathrm{C}$." This is most likely the original intent of the word "throughput." However, the literature also abounds with equations of the type $^{2.3}$

$$
Q=d / d t(P V) \text {, }
$$

where $Q$ is referred to as the "throughput," $P$ is the gas pressure, $V$ is the containment volume, and $(d / d t)$ indicates the time derivative, but the temperature is not specified. There are those who argue that it is "understood" that there is an implicit "at $T_{1}{ }^{\circ} \mathrm{C}$." Some understand $T_{1}$ to be "room temperature," whatever that may be, others $0^{\circ} \mathrm{C}$. The point here is that use of the word "throughput," as it is commonly used to describe gas flow in such an ambiguous fashion, either results in an ill-defined, implied temperature in the "unit," or encourages the dropping of the temperature from the "unit" altogether, resulting in an incomplete description of the molar or mass flow rate. That the description is incomplete can be seen from the expression for the molar flow rate for an ideal gas under isothermal conditions:

$$
Q_{m}=Q /(R T) \text {, }
$$

where $Q_{m}$ is the molar flow rate, $Q$ is defined in Eq. (1), $R$ is the molar gas constant $\left(R=8.314 \mathrm{~J} \mathrm{~mol}^{-1} \mathrm{~K}^{-1}=82.06\right.$ atm cm $\mathrm{cm}^{3} \mathrm{~mol}^{-1} \mathrm{~K}^{-1}=62.36$ Torr $1 \mathrm{~mol}^{-1} \mathrm{~K}^{-1}$ ), and $T$ is the absolute temperature in Kelvins. Loss or misunderstanding of the temperature $T$ subsequently results in either the inability to calculate or the miscalculation of the molar fiow rate. The use of the unit " $\mathrm{mol} / \mathrm{s}$ " eliminates this problem, since the originator of the measurement, who knows the temperature $T$, must immediately incorporate this knowledge [using Eq. (2)] to express the flow rate in $\mathrm{mol} / \mathrm{s}$.

Even when properly used, "units" such as "atm $\mathrm{cm}^{3} / \mathrm{s}$ at $T_{1}{ }^{\circ} \mathrm{C}$ " can be a source of confusion if used to describe leak artifacts. In addition to the $T$, in the unit required to calculate mass or molar flow rate, the temperature $T_{2}$ at which the leak was calibrated and the temperature $T_{3}$ at which it is being used must also be known. Under such circumstances it is very easy for the three different temperatures to become confused. By expressing the flow rate in $\mathrm{mol} / \mathrm{s}$, the possibil- 
ity for confusion is greatly reduced.

Another common practice with leak rate units is to express the leak rate in terms of "standard" conditions, such as "standard $\mathrm{cm}^{3} / \mathrm{s}$ " or " $\mathrm{cm}^{3} / \mathrm{s}$ STP." Unfortunately, there exist several different usages of "standard conditions." If both the "standard pressure" and "standard temperature" are not explicitly stated, the units are ambiguous. Occasionally ${ }^{4}$ a temperature and/or pressure range will be given for "standard" conditions. The consequences are not trivial for a helium diffusion leak, where a few degrees change in tentperature can result in a few percent shift in the leak ratc. Since it is quite unlikely that everyone will suddenly agree on what "standard" conditions are, we suggest that these units be dropped in favor of $\mathrm{mol} / \mathrm{s}$, which avoids the problem altogether.

To further demonstrate how the term "througliput" causes widespread confusion, note that the dimensions of Eq. (1) are those of [ (force/area $) \times($ volume $) /($ time $)]$, or power, which are not the same dimensions as flow rate dimensions ( $\mathrm{mol} / \mathrm{time}$ ). Accordingly, one occasionally sees in the literature the dimensions of power explicitly ascribed to the word "throughput,"5 illustrating that not everyone automatically infers an implied temperature associated with Eq. (1). Strictly speaking, the quantity $Q$ in Eq. (1) is the power that is required to move a gas at constant flow rate and temperature across a specified cross section of a vacuum system, and can be of interest in certain areas of vacuum equipment design. ( It is not the additional power that is carried by the gas across the cross section except in cases of adiabatic flow.) Thus, for those who use the word "throughput" to mean $Q$ in Eq. (1) at face value, the dimensions of power are appropriate. For those who use the word "through put" to mean Eq. (I) "at a temperature," the dimensions of flow rate are appropriate. However, it is obviously not appropriate to use the word "throughput" to mean both of these quantities, since their dimensions are different, a point not generally recognized. Note that the "unit" "atm $\mathrm{cm}^{3} / \mathrm{s}$ at
$T_{1}{ }^{\circ} \mathrm{C}$ " is an unorthodox unit in the strictest physical and mathematical sense. since it does not have any well-defined dimensions on its own. It should perhaps be regarded instead as an expression whose meaning is given by a relationship such as Eq. (2), which has well-defined dimensions of molar flow rate. Use of $\mathrm{mol} / \mathrm{s}$ at the outset indicates to the reader that if the word "throughput" is being used, it is being used in the sense of a flow rate.

Another important consideration is that the unit "mole" is recognized as the "amount of substance" in the SI system of units, so that $\mathrm{mol} / \mathrm{s}$ is the natural SI unit of flow rate.

In summary, there are several reasons for preferring the unit $\mathrm{mol} / \mathrm{s}$ over several other popular units for leak rate and gas flow rate. Foremost is that it avoids errors resulting from the failure to properly specify the temperature in "throughput" units, it also lessens the confusion of multiple temperatures associated with leak artifacts, and it avoids the confusion that sometimes exists with the term "standard" tenupcrature and pressure. It also clarifies which usage of the word "through put" is being used. Finally, $\mathrm{mol} / \mathrm{s}$ is in accordance with the SI sustem of units.

Acknouledgments: I would like to thank Richard Hyland and Charles Tilford for their constructive reading of this note. I would also like to acknowledge the support of the NBS Office of Nondestructive Evaluation.

'Dichionary' of Terms for I'acuum Science ond Technology. Surfoce Science, Thin Film Technology. Vacuum Metallurgy, Electronic Moteriols, edited by M. Kaminsky and J. Lafferty (A.P. New York, 1980), p. 69.

'L. Holland. IN Steckelmacher, and J. Yarwood, Vocuum .Monuol (E. \& F. N. Spen1. London, 1974), p.18.

'A. Roth, I becuum Technology' (North-Holland, Amsterdam, 1982), p. 67.

American Vac!num Socicty Standards AVS 2.1, 1963 and AVS 2.2, 1968.

'J. F.O'Han]on. I User's Guide to Vacuum Technology (Wiley, New York. 1980), Р 22. 


\title{
APPENDIX I)
}

\section{Low-range flowmeters for use with vacuum and leak standards}

\author{
K. E. McCulloh, C. R. Tilford, C. D. Ehrlich, and F. G. Long

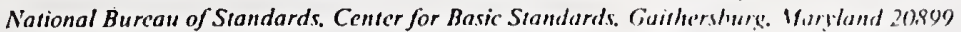

(Rcceived 20 Octobcr 1986; accepted 28 Dccinbcr 1986)

\begin{abstract}
Vacuum prcssure standards of the orifice-flow type requirc known gas flows of 10 " $\mathrm{mol} / \mathrm{s}(10$ ) 2 atm $\mathrm{cm}^{3} / \mathrm{s}$ at $0{ }^{\circ} \mathrm{C}$ ) and less. Known gas flows can also be uscl to calibratc "standard" leaks by comparing the pressurcs generatcd when flows from the lcak and the flownctcr arc alternately passed through a constant conductance. Two constant-prcssurc, piston displatcomcnt flow-mcters developed at the National Bureau of Standards arc describcl that can gencratc flows between $10^{-6}$ and $10^{-10} \mathrm{~mol} / \mathrm{s}$ with an estimatcd unccrtainty of $0.8 \%$ to $2 \%$. Comparisons of the flowmeters with alternate calibration techniques, and rcpcatcl lnw-range leak and vacuum gauge calibrations, have been used to confirm the cstimated uncertainty and random errors of the flowmeter.
\end{abstract}

\section{INTRODUCTION}

Two areas of vacuum standards require the generation of very low flows: orifice-flow pressure standards and leak standards. The orifice-flow technique gcnerates a calculable pressure differential by passing a measured flow of gas through a calculated conductance. Reference I describcs one such standard. The nominal $10 \mathrm{l} / \mathrm{s}$ conductance used is typical for this type of device, as is the working range of 10 ' $\mathrm{Pa}\left(10^{-3}\right.$ Torr $)$ and helow. This requires flow moasurements for different gases with a range starting at $5 \times 10^{\text {. ? }}$ $\mathrm{mol} / \mathrm{s}\left(10^{-2} \mathrm{~atm} \mathrm{~cm}^{3} / \mathrm{s}\right.$ at $\left.0^{\circ} \mathrm{C}\right)$, and extending down three or more decades. Leak measurements cover an even wider range, and Refs. 2 and 3 describe how the flow from a "standard" leak can be measured by direct comparison with that from a flowmeter.

Gas flow rate is defined as the number of molecules or moles of a particular gas species passing through a system per unit time. A basic gas flow measurement must start with the equation of state; for the level of accuracy required for these applications the ideal gas law suffices:

$$
P V=N R T
$$

with the usual couvention of $P$ as the pressure, $V$ as the volume, $N$ the number of moles, $R$ the ideal gas constant, and $T$ the absolute temperature. As a practical matter, primary flowmeters are generally realized by varying only the pressure or volume, i.e., the molar flow rate is

$$
d N / d t=(V / R T)(d P / d t)
$$

or

$$
d N / d t=(P / R T)(d V / d t) .
$$

We have chosen to use the latter, "constant pressure" technique as the basis for our design. A constant pressure flowmeter was first used with an orifice-flow pressure standard by Hayward and Jepsen ${ }^{4}$ and subsequently by several other experimenters. Their use has been reviewed by Peggs. ${ }^{5}$ Basically, constant pressure flowmeters regulate the flow of gas from a small volume through a leak valve into the vacuum system. The pressure and temperature of the gas in the volume are measured and the gas volume is decreased at a rate sufficient to maintain a constant pressure. The columc change is generally accomplished by driving a piston of known cross scction into the gas volume through sliding scals. The volume change and flowrate can then be derived from the rate of advance of the piston. A variant of this tccliniquc employs a welded bellows as the variable volumc elemcnt.

We describe herc two constant pressure flowmeters. The first employs a piston with sliding seals and has been in use at the National Bureau of Standards (NBS) for several years over the range from $10^{-6}$ to $10^{-11} \mathrm{~mol} / \mathrm{s}\left(2 \times 10^{-2}-2 \times\right.$ 10. 7 at $\mathrm{cm}^{2} / \mathrm{s}$ at $0{ }^{\circ} \mathrm{C}$ ). The second uses an all-netal gas system enploying a hydraulically driven welded bellows as a variable volume. Its range extends at least two decades lower than that of the first although its performance at the lowest flows has not yet bcen fully analyzed.

\section{DESCRIPTION AND OPERATION OF PISTON FLOWMETER}

The piston and sliding seal ("piston") flowmeter is presented schenatically in Fig. I, and an enlargement of a piston asscmbly is shown in Fig. 2. The two pistons of different cliameter ( $\mathrm{l}$ in. and $1 \mathrm{cms}$ ) allow for a wider range of flow ratcs than a single piston. The pistons are tungsten carbide or chromium plated steel wire gauges, supplied with a dimensional tolerance of $0.0005 \%$ along their lengths. They are sealed by Teflon rings with an L-shaped cross section, backed up by rubber $\mathrm{O}$ rings, as shown in Fig. 2. All other seals in the system are metal, including the vacuum valve closurcs. The $\mathrm{O}$ ring behind the Teflon acts solely as an elastic element to maintain the critical sealing force-the seal must have a minimal leakage but still allow free passage of the piston. A second ring of the same design, the top one in Fig. 2, serves to maintain the alignment of the piston along its axis of motion. A bypass channel vents the volume bctween rings to the ballast volume. This minimizes the effects of seal leakage by maintaining a guard pressure on the back side of the seal close to the operating pressure of the flowmeter. A clamp at the end of the piston and a coupling rod, which allows for radial misalignment, connect the piston to an external micrometer screw through a welded bellows. The bellows serves to seal the guard pressure. The micrometcr screw is connected to the linkage by a bearing 


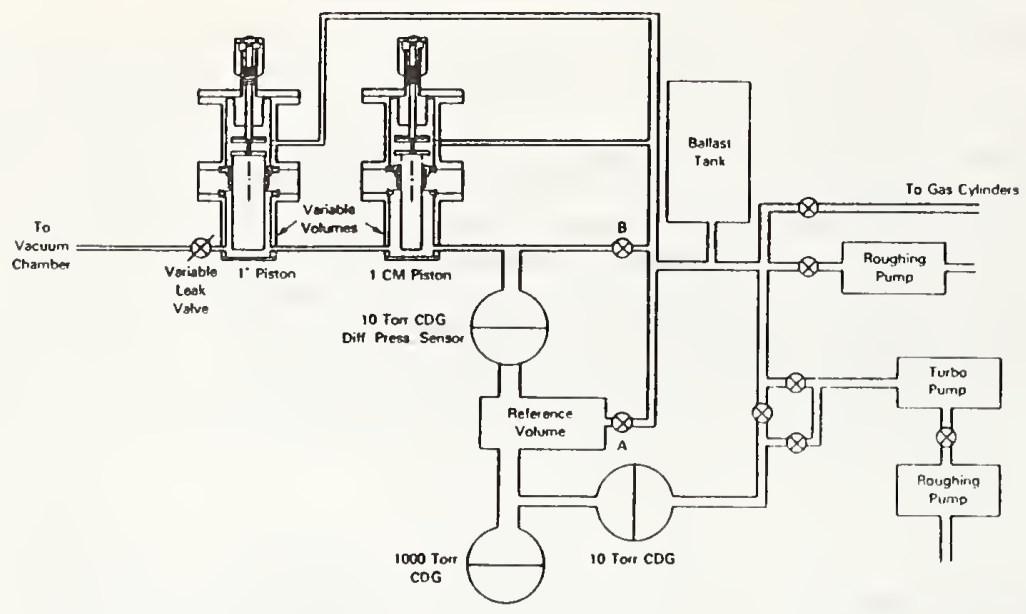

Fig. I. Schematic of the conslanl pressure pislon flowmeler. Two differenl size pislons are included to extend the range. The lurbomolecular pump provides a tow ref. erence pressure for the 10 -Torr differential capacitance diaphragm gauge.

NBS Gas Piston Flowmeter

which allows free rotation of the screw but maintains a tight axial coupling.

During operation the micrometer screw for the piston in use is advanced by a stepping motor at a rate that maintains a constant pressure in the flowmeter. A feedback circuit operating on the output of the 10-Torr differential capacitance

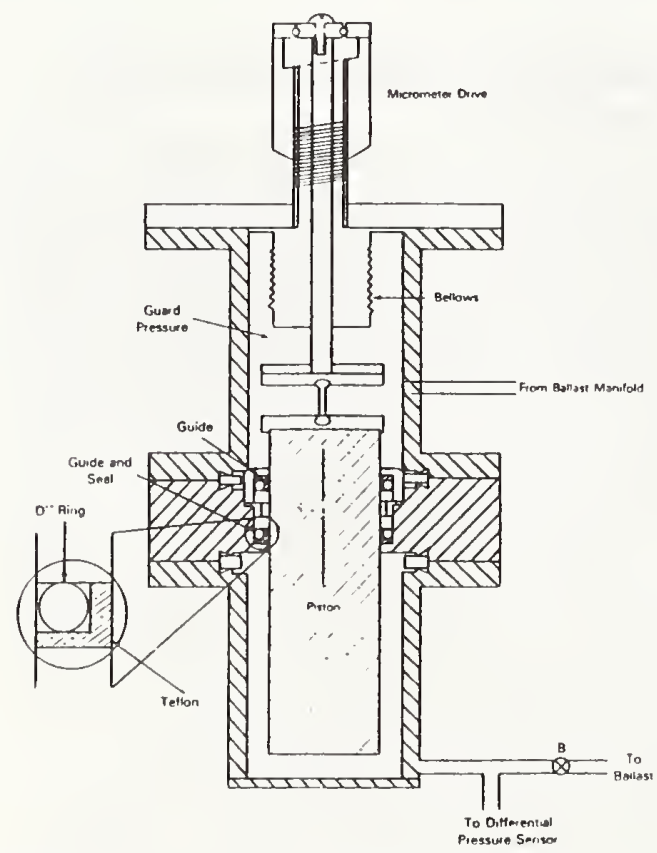

FIc. 2. Delail of the variable volume, includiug piston seal design and trise mechanism. All seals are metallic except for the stiding seal. To minimize leak inge past the seal, a guard pressure close to the pressure in the ariathle volume is maintained on the back side of the seal by the tine connected to the hallası manifold. diaphragm gauge (CDG) connected between the reference volume and the variable volumes controls the motor. The variable volumes, reference volume, and $C D G$ are contained in a common thermally insulated area to minimize temperature induced pressure changes.

The pressure in the reference volume is measured with 10 and 1000-Torr CDG's calibrated against a primary standard. ${ }^{6}$ As discussed below, instabilities in these gauges constitute the largest single source of error.

Gas flow to the vacuum chamber is regulated by an allmetal variable leak valve selected for stability and cleanliness. A $8000-\mathrm{cm}^{3}$ ballast tank allows a stable flow to be maintained for extended periods so that pressures in the vacuum chamber can be stabilized to within $0.1 \%$ before the flow is measured. After equilibration the pressure drops at a rate of $0.3 \% / \mathrm{h}$ or less. Gas purity is monitored with a residual gas analyzer in the vacuum chamber. At the highest flowrates the indicated concentrations of residual gases are less than $0.01 \%$ of the test gas. It has not been determined whether these indicated impurities are in the original gas source or are generated in the gas analyzcr ion source. In either case, they are below the level of concern. At lower flow rates residual gases become more important, presumably because of outgassing. In particular, at the lowest flows the indicated concentration of hydrogen, probably evolving from stainless-steel components, may exceed that of the test gas.

A trapped mechanical rough pump and a $50 \mathrm{l} / \mathrm{s}$ turbomolecular pump allow the system to be evacuated before the test gas enters the system. The flowmeter is not baked for fear of damaging the elastomer sliding seals. The turbopump also providcs an absolute reference pressure for the 10-Torr CDG and permits the zero setting of the 1000-Torr CDG.

Before each use, the system is pumped with the turbomolecular pump to a pressure $<10^{-4} \mathrm{~Pa}$, measured with a hot filament ionization gauge. The piston that is not being used is driven fully irto the flowmeter to minimize the variable volume. The turhopump is then valved from the system and gas of the desired species is adnitted to the variable volumes, 
ballast tank, and rcfercnce volunc. The fiowncters liave bcen operated with hydrogen, helium, ncon, nitrogen. and argon. The system pressure is brought up to thc valuc required to gencrate the desired flow in the vacuum systcm. Typical fill pressurcs vary from $10^{5} \mathrm{~Pa}$ for a $10^{-6} \mathrm{~mol} / \mathrm{s}$ fow to $10 \mathrm{~Pa}$ for $10^{-11} \mathrm{~mol} / \mathrm{s}$. The variable leak valve is picset so that about $1000 \mathrm{~s}$ is rcquired for the piston to advance over its $2.5-\mathrm{cm}$ rangc. This procedure is found to give the smoothest operation of the piston drive system. The variablc lcik valve is typically set at least $5 \mathrm{~h}$ before operation to allow any crcep in the valve to settle out. After filling the fownctcr with gas, the gas flow to the vacuum chamber is maintained until the pressure in the vacuum chamber and thc absorption of gas in the sliding seals have equilibrated. Equilibration times of 30 to $60 \mathrm{~min}$ are typical.

When equilibrium is achieved, valve $A$ between the rcference volume and the ballast tank is carefully shut so that ihere is negligible pressure differential across the CDG between the reference volume and the variable volumes. $V$ alve $B$ between the variable volumes and the ballast tank is then shut, and the pressure in the variable volumes starts to drop as gas flows only from this relatively small volume. The drop in pressure in the variable volumes with respect to the reference pressure is detected by the CDG, whose output voltage is sent to a proportional motor control unit, which causes the stepping motor to turn, advancing the piston. The servo system maintains the differential pressure at less than $0.1 \%$ of the reference volume pressure for the lowest flow rates, and considerably lower at higher flow rates. The nicrometer screw is allowed to travel 20 revolutions, advancing the piston $2.54 \mathrm{~cm}$, with the elapsed time being logged after each revolution. After each run the variable volumes are again connected to the ballast volume, the piston retracted, and the cycle is ready to begin again.

\section{I. DESCRIPTION AND OPERATION OF THE BELLOWS FLOWMETER}

The hydraulically driven bellows ("bellows") flowneter is shown schcmatically in Fig. 3. The basic principle of operation and mucll of the design are the same as those of the piston flowmcter. However, in this case the variable volume is a welded bellows, providing a bakable all-metal gas system that is virtually frcc of leaks and adsorption effects. Base pressures after baking are about $10^{-6} \mathrm{~Pa}$. This permits operation at lower fill prcssures and correspondingly lower fow rates. However, the volume change of the bellows is in all likclihood not linear with displacement. This problem is overcome with a technique used at the Electro Technical Laboratory in Japan. ${ }^{7}$ The bellows is coupled to a piston by a scaled hydraulic reservoir surrounding the bellows. Care is taken to eliminate gas from the hydraulic reservoir so that as the piston is advanced through a sliding seal into the reservoir the volume of the bellows must decrease by a corresponding amount. Two pistons are used of the same size and type as in the other flowmeter. The sliding seals are of the same design but now must only seal oil. The bellows has a nominal cross section of $13 \mathrm{~cm}^{2}$ and stroke of $2 \mathrm{~cm}$.

Tlie variable volumes, reference volume, and oil reservoir are contained in a common insulated aluminum block to minimizc temperature gradients. The "dead" volumes in both the variablc volumes and oil reservoir have been minimizcd.

A spinning rotor gaugc (SRG) thimble and ball are conrectcd to the variable volumes in anticipation of possible use for fowmeter control at very low fill pressures.

As shown in Fig. 3, the bellows is extended by a variable weight connected to the bellows through a small-diameter sliding seal. The weight used is such that an oil pressure

\section{NBS OIL/BELLOWS FLOWMETER}

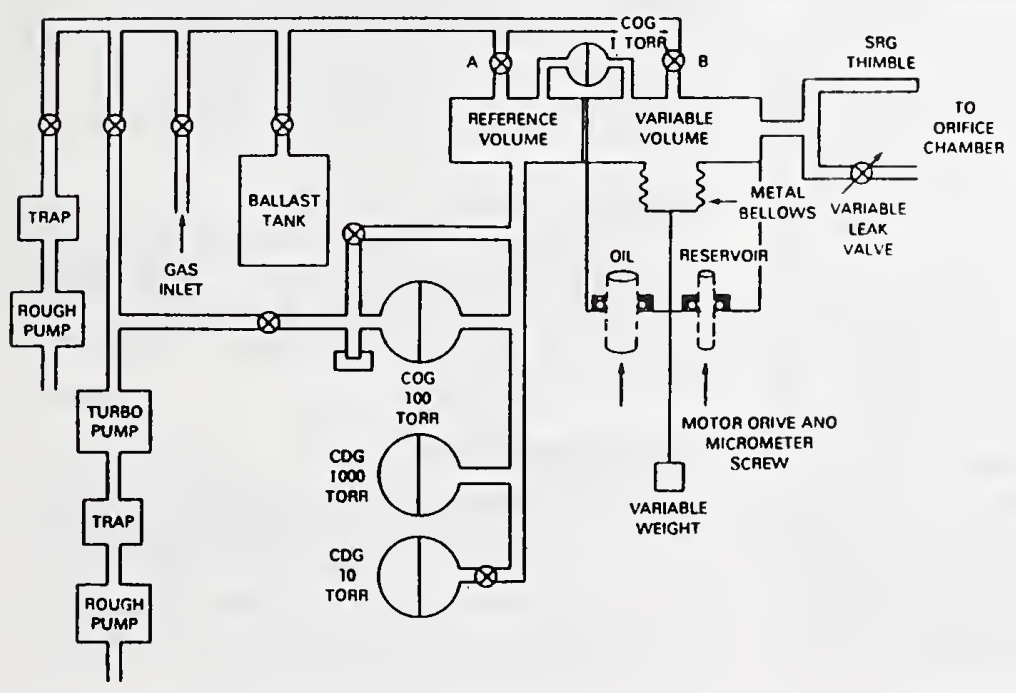

FIG. 3. Schematic of the constanl pressure bellows flowmeler. The variable volume is a welded bellow's coupled 10 two different diamejer pislons by a seated oit reservoir. The pisIons are advanced by a micromeler screw and mechanism simitar to that used in the piston flowmeter. All seals in the gas system are meIallic. 
slightly above atmospheric will be required to compress the bellows. This will minimize leaks, in particular, leakage of air into the oil, which would cause significant errors, and maintain positive contact between the piston and the drive mechanism. Procedures for the use of the bellows flowmeter are the same as those for the piston flowmeter.

\section{ESTIMATED FLOWMETER UNCERTAINTIES}

The piston flowmeter has been in regular use for vacuum gauge and leak calibrations since 1984 and the bellows flowmeter since late 1985. During this time data have been collected on the uncertainties contributed by individual components of the flowmeters as well as on the overall performance. These data can be used to assess the probable errors of both flowmeters between $10^{-6}$ and $10^{-11} \mathrm{~mol} / \mathrm{s}$. The flowmeters have been operated at lower flows, particularly the bellows flowmeter, but further data are required to fully assess the uncertainties below $10^{-11} \mathrm{~mol} / \mathrm{s}$. The total uncertainty can be estimated by summing component errors.

From Eq. (1), the instantaneous flow rate can be derived as

$$
d N / d t=d / d t[(P V) /(R T)] \text {. }
$$

In practice an average flow rate $\overline{d N / d t}$ over a time $\Delta t$ is measured:

$$
\overline{d N / d t}=\left[\left(P_{1} V_{1}\right) /\left(R T_{1}\right)-\left(P_{2} V_{2}\right) /\left(R T_{2}\right)\right] / \Delta t,
$$

where the subscript 1 indicates the respective measurement at the beginning of the time interval, and the subscript 2 indicates the respective measurement at the end of the time interval. In the case of the piston flowmeter this equation must be modified to allow for the possibility of gas leakage $L$ past the sliding seal, and gas absorption or desorption $D$ at the seal:

$$
\begin{aligned}
\overline{d N / d t}= & {\left[\left(P_{1} V_{1}\right) /\left(R T_{1}\right)-\left(P_{2} V_{2}\right) /\left(R T_{2}\right)\right] / } \\
& \Delta t-L-D .
\end{aligned}
$$

$D$ and $L$ are not known and cannot be corrected for, although their magnitude can be estimated and limits placed on the related errors.

Defining

$$
\begin{aligned}
& \Delta T=T_{2}-T_{1}, \\
& \Delta V=V_{1}-V_{2},
\end{aligned}
$$

and

$$
\Delta P=P_{2}-P_{1},
$$

Eq. (6) can be rewritten, to first order in $\Delta P$ and $\Delta T$, as

$$
\begin{aligned}
\overline{d N / d t}= & {\left[\left(P_{1} \Delta V\right) /\left(R T_{1} \Delta l\right)\right]\left\{1-\left(V_{2} / \Delta V\right)\right.} \\
& \left.\times\left[\left(\Delta P / P_{1}\right)-\left(\Delta T / T_{1}\right)\right]\right\}-L-D .
\end{aligned}
$$

In the constant pressure mode the measured flowrate is obtained from the first term of this equation, $P_{1} \Delta V / R T_{1} \Delta l$. and the remaining terms are regarded as sources of error.

\begin{tabular}{|c|c|c|c|c|}
\hline & & \multicolumn{3}{|c|}{ Flowrase $(\mathrm{mol} / \mathrm{s})$ and piston size } \\
\hline & & $\begin{array}{c}10^{-6}-10^{-9} \\
1 \mathrm{in} .\end{array}$ & $\begin{array}{l}10^{-10} \\
1 \mathrm{cr.1}\end{array}$ & $\begin{array}{l}10^{-11} \\
1 \mathrm{~cm}\end{array}$ \\
\hline$\delta P_{1} / P_{1}$ & $\begin{array}{l}\text { systematic } \\
\text { random }\end{array}$ & $\begin{array}{l}0.50 \\
0.01\end{array}$ & $\begin{array}{l}0.50 \\
0.01\end{array}$ & $\begin{array}{l}0.52 \\
0.10\end{array}$ \\
\hline$\delta\left(\Delta J^{\circ}\right) / \Delta V^{\prime}$ & $\begin{array}{l}\text { area systematic } \\
\text { length syctematic }\end{array}$ & $\begin{array}{l}0.001 \\
0.10\end{array}$ & $\begin{array}{l}0.001 \\
0.10\end{array}$ & $\begin{array}{l}0.001 \\
0.10\end{array}$ \\
\hline$\delta 7_{1} / T_{1}$ & $\begin{array}{l}\text { systcmatic } \\
\text { random }\end{array}$ & $\begin{array}{l}0.003 \\
0.01\end{array}$ & $\begin{array}{l}0.003 \\
0.01\end{array}$ & $\begin{array}{l}0.003 \\
0.01\end{array}$ \\
\hline$\delta(\Delta t) / \Delta r$ & random & 0.01 & 0.10 & 0.10 \\
\hline$\frac{V_{2}}{\Delta V} \frac{\delta P_{1}}{P_{1}}$ & systematic & 0.20 & 1.30 & 1.30 \\
\hline$\frac{V_{2}}{\Delta V} \frac{\delta T_{1}}{T_{1}}$ & sysjematic & 0.006 & 0.04 & 0.04 \\
\hline Leakage & sy'stcmatic & 0.01 & 0.06 & 0.06 \\
\hline $\begin{array}{l}\text { Systematic } \\
\text { (Linear sum) }\end{array}$ & & 0.82 & 2.00 & 2.02 \\
\hline $\begin{array}{l}\text { Random } \\
\text { (rms sum) }\end{array}$ & & 0.02 & 0.10 & 0.14 \\
\hline Total & & 0.84 & 2.10 & 2.16 \\
\hline
\end{tabular}
The estimated errors in the first term as well as those due to the other terms arc tabulated at different flowrates for the piston flowmeter in Table I. The basis for these cstimates is discusscd below.
Tallt. I Uncertainties of the pistun flow meter in percenl. The uncerlaintics of the bellows flowmelcr are the same excepl at the lowest ubulated fowrale. where they are marginally smaller. Random errors are evalualed at three limes die standard devialious or maximum observed devialions.

\section{A. Initlal fill pressure: $\delta \boldsymbol{P}_{1} / \boldsymbol{P}_{1}$}

The systematic uncertainties are due almost entirely to observed long-term instabilities in the calibration of the capacitance diaplıragm gauges used to measure the flowmeter fill pressure. Our experience with gauges used in the flowmeters has been consistent with our experiences with a larger group of gauges. ${ }^{R}$ At the lowest flows there is an additional contribution due to a systematic offset in the servo system advancing the piston. The estimated random errors are due to randon reading errors in the CDG's and the inability of the servo loop to maintain zero differential pressure between the reference and variable volumes. Modification of the servo system may reduce this error.

\section{B. Volume change: $\delta(\Delta \eta / V$}

The uncertainties in piston cross-sectional areas are based on the spccifications for the wire gauges. The uncertainties in the litear displacements are hased on the maximum nonlincaritics in the micrometer screws observed when checked against a standard length.

\section{Initial temperature: $\delta T_{1} / T_{1}$}

Systenatic unccl lainties are based on a maxinum $10-\mathrm{mK}$ cror in the calibtation of the curartz and platinum resistance thermutucts used in the flowmeters. The random errors arc based on observel temperature changes over 20-30 min periosls, which are indicativc of possible temperalure differences betwecu the gas and the thermometers. 


\section{TIme Interval: $\delta(\Delta t) / \Delta \ell$}

The clapsed time is recorded for each turn as lise micrometer screw advances. Tine intervals are calculated fion the differences of successive elapsed times. The first few of these 20 time differences may be excluded from the data analysis as they may be perturbed by small differential pressures generated during the closing of valve $A$ and initial oscillations of the servo system driving the stepping inotor. The times per turn exhibit randon and sy'stematic variations from turn to turn that depend on the fill pressure, and hence the flowrate. At higher fill pressures the times do not exhibit a systematic trend but have a random variation due to the 0.1 -s resolution of the timing circuit. As the fill pressures are decreased the instabilities of tlie differential CDG and servo system become significant and the random variations in the time increase. The time interval $\Delta t$ is an average of the individual times. However, with the piston flowmcter a systematic trend in the times becomes evident at $10^{-11} \mathrm{~mol} / \mathrm{s}$ and becomes larger at lower flows. The times progressively decrease from the initial values towards an asymptotic value. The magnitude of the initial offset from the asymptotic value is roughly inversely proportional to the flowrate. This effect is substantially reduced for the beliows flowmeter. We believe this effect is caused by gas desorbed from the sliding seal as the piston moves through it. Therefore, we ignore those time intervals indicating a systematic trend and estimate an asymptotic value of the time interval from the remaining measurements. The probable error in estimating this asymptotic value is largely determined by the random variations of the individual times and the decreased number of "stable" time intervals that can be used in the estimate. Systematic errors in the timing circuitry are negligible.

\section{E. Changes in the pressure during operation: $\left(V_{2} / \Delta \eta\left(\delta P_{1} / P_{1}\right)\right.$}

We observe unexplained changes in the indicated pressure of the reference volume from the beginning to the end of the piston advancement. Their relative magnitude increases with decreasing fill pressures to a maximum of $0.1 \%$ at $10^{-11} \mathrm{~mol} / \mathrm{s}$. We do not believe these changes can be due to short-term CDG instabilities or temperature changes. We treat them as a possible additional error in the measured pressure of the variable volume. Their effect is multiplied by the ratio of the final or "dead" volume of the variable volumes to the volume change. This factor $V_{2} / \Delta V$ is 2 for the larger piston and 13 for the smaller. These pressure changes are almost always a pressure increase, therefore the associated uncertainty has been listed as systematic and evaluated on the basis of the maximum observed changes.

\section{F. Temperature changes: $\left(V_{2} / \Delta \eta\left(\delta T_{1} / T_{1}\right)\right.$}

Observed maximum 10-mK changes in the measured temperature are treated as possible changes in the gas temperature during the piston advancement. Again, the effect is larger for the smaller piston.

\section{G. Leakage: $L$}

Errors due to seal leakage in the piston flowmeter are esti- mated by deliberately establishing a large pressure dilferential across the seal and observing the rate of pressure cliange in the known variable volume. This observed leakage is scaled down to correspond to the small differential pressures across the sliding seal during operation.

\section{H. Desorption: $D$}

As noted earlier there is evidence at very low fowrates of gas desorption from the sliding seals in the piston flowneter Compensation is made for this effect by using asymptolic values of the time per revolution of the micrometer screw used to advance the piston. We believe the errors associated with this procedure are included in the increased randorn errors in the measurement of the time interval. Therefore, no separate uncertainty contribution for desorption is included in Table I.

Fron Table I it is apparent that improved accuracies for the flowmeters will largely depend on improvements in the pressure measurements. It is also important to minimize the dead or minimum volume $V_{2}$ of the variable volume. A large dead volume magnifies the effects of pressure or temperature instabilities.

In this same range the uncertainties of the bellows flowmeter will be substantially the same except that errors due to leakage or desorption have been eliminated.

The random errors listed in Table I are based on maximum observed errors. Therefore, the total error is computed from a linear sum of the systematic uncertainties plus a root sum of the squares of the random errors, with no multiplicative factor for the latter.

\section{OBSERVED FLOWMETER PERFORMANCE}

The validity of the uncertainty estimates in Table I can be experimentally checked to a certain extent. The estimated random error can be compared with observed random variations in the calibration of vacuum gauges or leak artifacts. Since the only errors common to both flowmeters are minor compared to the total, the errors of the two flowmeters are essentially independent of one another. Therefore, observed differences in the calibration of vacuum gauges or leak artifacts using the two flowmeters should be less than the linear sum of the errors of the two flowmeters. Finally, results obtained with these flowmeters can be compared with tlıose obtained using other standards. In all cases the experinsental dat a will include the random errors of the rest of the callibration system and the effects of instabilities inherent in the gauge or leak, and therefore, must be considered as an upper bound on the random errors of the flowmeters. This is particularly true of the low-range leak measurements. In these cases the pressures generated by the small helium flows are comparable to changes in the hydrogen background pressure in the vacuum chamber. This precludes the use of ion gauges to determine pressure equivalence of the flows from the leaks and the flowmeter. The quadrupole residual gas analyzers used at the low flows are significantly less stable than the ion gauges, shifts of several percent in sensitivity are not uncommon, and the random errors of the leak measurements are correspondingly higher. 


\section{A. Pandom errors}

The measured random errors during gauge and leak calibrations differ with flowrate and type of device calibrated. The pooled standard deviation about the mean for six molecular drag gauges repeatedly calibrated over a two-month period using the piston flowmeter and flows between $2.2 \times 10^{-9}$ and $1.3 \times 10^{-7} \mathrm{~mol} / \mathrm{s}$ did not exceed $0.3 \%$ for the piston flowmeter. ' For flows of $10^{-9} \mathrm{~mol} / \mathrm{s}$ the pooled standard deviation increased to $0.4 \%$, but in this case the results are clearly limited by the imprecision of the molecular drag gauge. Repeated calibrations of helium diffusion leak it $5 \times 10^{-11} \mathrm{~mol} / \mathrm{s}$, using both flowmelers, gave a standard deviation about the mean of $0.4 \%$ for six calibrations with the piston flowmeter and $0.5 \%$ for five calibrations with the bellows flowmeter. Repeated calibrations of a helium diffusion leak at $5 \times 10^{-12} \mathrm{~mol} / \mathrm{s}$ had standard deviations about the mean of $1.7 \%$ for 10 calibrations with the piston flowmeter and $1.0 \%$ for 17 calibrations with the bellows flowmeter.

These random errors clearly exceed those listed in Table I, but, as noted, they include instabilities of the leaks and gauges and random errors due to other parts of the calibration system.

\section{Comparlsons between flowmeters and with other standards}

The means of molecular drag gauge calibrations performed with the piston and bellows flowmeter at $2 \times 10^{*}$ $\mathrm{mol} / \mathrm{s}$ differed by $0.7 \%$. The means of leak calibrations performed using the two flowmeters at $5 \times 10^{-11}$ and $5 \times$ $10^{-12} \mathrm{~mol} / \mathrm{s}$ differed by less than the standard deviations of the individual flowmeter measurements so that any difference between flowmeters at this level is masked by the random errors of the individual flowmeters. The piston flowmeter has been used to calibrate molecular drag ganges that were calibrated using a "quantity" meter. "The results for four gauges differed by $0.1 \%$, the results for a fifth gatige differed by $0.5 \%$. This does not indicate a significant difference between calibrations performed using the piston flowmeter and those made using the quantity meter.
Calibrations of a sintered metal leak by the NBS and the Sandia National Laboratory Primary Standards Laboratory differed by no more than $1.5 \%$ between $10^{-8}$ and $10^{-6}$ $\mathrm{mol} / \mathrm{s}^{2}$ There was evidence of a drift in the transfer leak, but the differences are, in any case, well within the combined uncertainties of the leak calibration standards of the two laboratories.

\section{SUMMARY}

Two low-range. constant-pressure, piston displacement flowmeters have been developed at the NBS. The uncertainlies have becn evaluated in the flow range $10^{-6}-10^{-11} \mathrm{~mol} /$ s. and comparisons made with measurements performed on other systems or using other techniques in this same range. The cstimated errors in the flow range $10^{-6}-10^{-9} \mathrm{~mol} / \mathrm{s}$ of $0.8 \%$, increasiug to about $1.3 \%$ at $10^{-11} \mathrm{~mol} / \mathrm{s}$, appear consistent with the experimental results. Investigations are currently under way to assess the uncertainties at lower flowrates.

\section{ACKNOWLEDGMENTS}

We would like to acknowledge the support of the NBS Officc of Nondestructive Evaluation, and the Transportation Systems Technology and Analysis Division and the Prinary Standards Laboratory of the Sandia National Laboratory:

' $K$ E. Mic Cullol, C R. Tilford. S.D. Wond, and D.F. Martin, J. Vac. Sci Jechimel A $4.362(1986)$.

'R Il, laird, C D. Ehrlich, C. R. Tilford, and S. Thornberg, J. Vac. Sci Technol. A 4. 334 (1986).

C. D. Ehrlich, J. Vac. Sci. Technol. A 5. 125 (1987)

'W' Ilayward and R. Jepsen, in Transactuons of the 9 th American Vacuum Socut: licuum Symposium (American Vacuum Snciety, New York, 196.3). r. 450

G.N. Peggs, Vacmom 26. 321 (1976)

"P. I.. M Ileydem:mn, C. R. Tilford, and R. W. Hytand, J. Vac. Sci. Technol. 14. 597 (1977).

H. Hojo, M. Ono, and K. Nakayama, in Proceedings of the Seventh Internotional Jicum Conpress (International Union for Vacuum Science, Technique and Applications, Vienna, 1977). p. 117.

R. W. Ilyland and C. R. Tilford. J. Vac. Sci. Technol. A 3. 1731 (1986).

"K. E. MeCulloh. J. Vac. Sci. Technol. A 1, 168 (1983). 


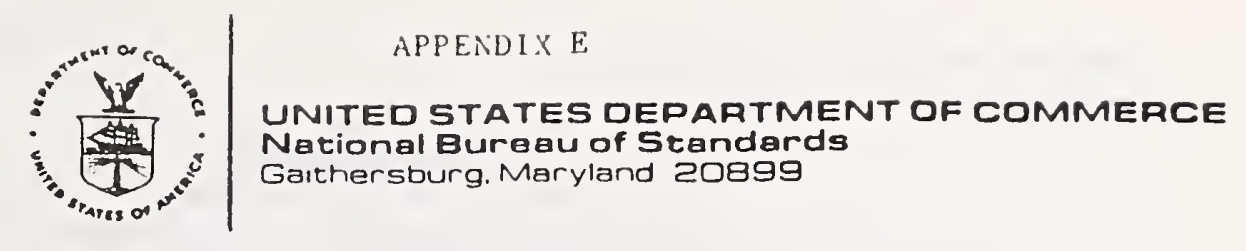

\section{SAMPLE CALIBRATION REPORT}

Report Date: February 1, 1988

LEAK ARTIFACT

Submitted by

Name of Company, Inc.

Anywhere, USA

Test performed January 1988

NBS Test Number : $\underline{\text { L12 }} \angle 240840$

NBS Leak Identification Number: NBSLC9

Leak Manufacturer: Leak Maunfacturer, Inc.

Manufacturer Serial Number: MFG-\#

Customer Property Number: S/N CUSTOMER\#

Leak Type: Fixed reservoir, glass permeation

Gas: Helium

Measured Leak Rate (over temperature range $0-50{ }^{\circ} \mathrm{C}$ ):

Leak Rate $(T)=A$ T e

where $T$ is the absolute temperature in kelvins,
$A=\underline{4.8708} \times \underline{10}^{-10} \mathrm{~mol} \mathrm{~s} \mathrm{~s}^{-1} \mathrm{~K}^{-1}$ and $\mathrm{B}=\underline{3012.46} \mathrm{~K}$

This equation gives a leak rate of $5.51 \times 10^{-12} \mathrm{~mol} / \mathrm{s}$ when the leak artifact is equilibrated at $23^{\circ} \mathrm{C}$.

${ }^{*}$ See Table I and Measurement Uncertainties 


\section{PROCEDURES}

This leak artifact was calibrated near $23{ }^{\circ} \mathrm{C}$ by comparison with Flowmeter \#2 of the NBS Primary Leak Standard, using the upper to lower chamber flow division technique. The temperature dependence was determined by varying the temperature of the leak between 0 and $50{ }^{\circ} \mathrm{C}$ and comparing its flow rate with a fixed-temperature leak artifact.

\section{MEASUREMENT UNCERTAINTIES}

The present estimate of the total uncertainty in the measured leak rate of this artifact at $23^{\circ} \mathrm{C}$ at the time of test is \pm 7.98 . This includes a systematic uncertainty of \pm 3.08 in Flowmeter $\# 2$ of the NBS Primary Leak Standard, \pm 2.38 random error in the measurement of the upper to lower chamber flow ratio, and \pm 2.68 random errors in the measured leak rate of this artifact. The latter two errors represent three standard deviations. Between 0 and $50{ }^{\circ} \mathrm{C}$, there is an additional uncertainty of \pm 0.0378 per ${ }^{\circ} \mathrm{C}$ temperature difference from $23{ }^{\circ} \mathrm{C}$.

Note that under conditions of normal usage and storage at room temperature, the leak rate from an artifact of this type can be expected to decay by as much as several percent over the course of a year. There is insuffi. cient data provided with this artifact to determine what this decay rate is.

In order to optimize the overall accuracy in the use of this artifact, it should be stored with any shutoff valve open (a dust cover can be used to protect the vacuum port), it should be stored at the temperature at which it will be used for at least 24 hours and pumped for at least 3 hours prior to use. Sufficient time should also be allowed for the system on which the leak artifact is to be used to come to equilibrium with the environment. Confidence in the stability of this artifact can be maintained by periodic comparisons of its leak rate with leak rates of other stable, well-characterized leak artifacts.

\section{COMMENTS}

\section{1) THIS ARTIFACT IS FRAGILE, HANDLE WITH CARE}

For the Director

National Measurement Laboratory

Arthur 0. McCoubrey, Acting Chief

Temperature and Pressure Division

Center For Basic Standards

National Bureau of Standards 
REPORT OF TEST (continued)

Page 3

\author{
"REPORT OF TEST" \\ NBS Test \# L12/240840 \\ Report Date : February 1, $1988^{+}$ \\ LEAK RATE VS. TEMPERATURE
}

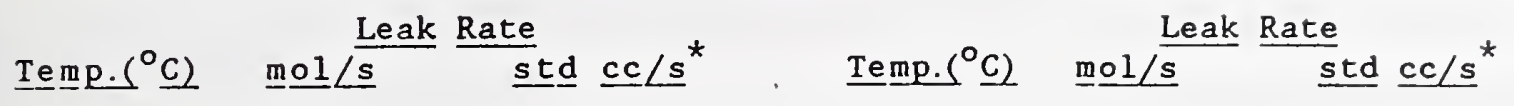

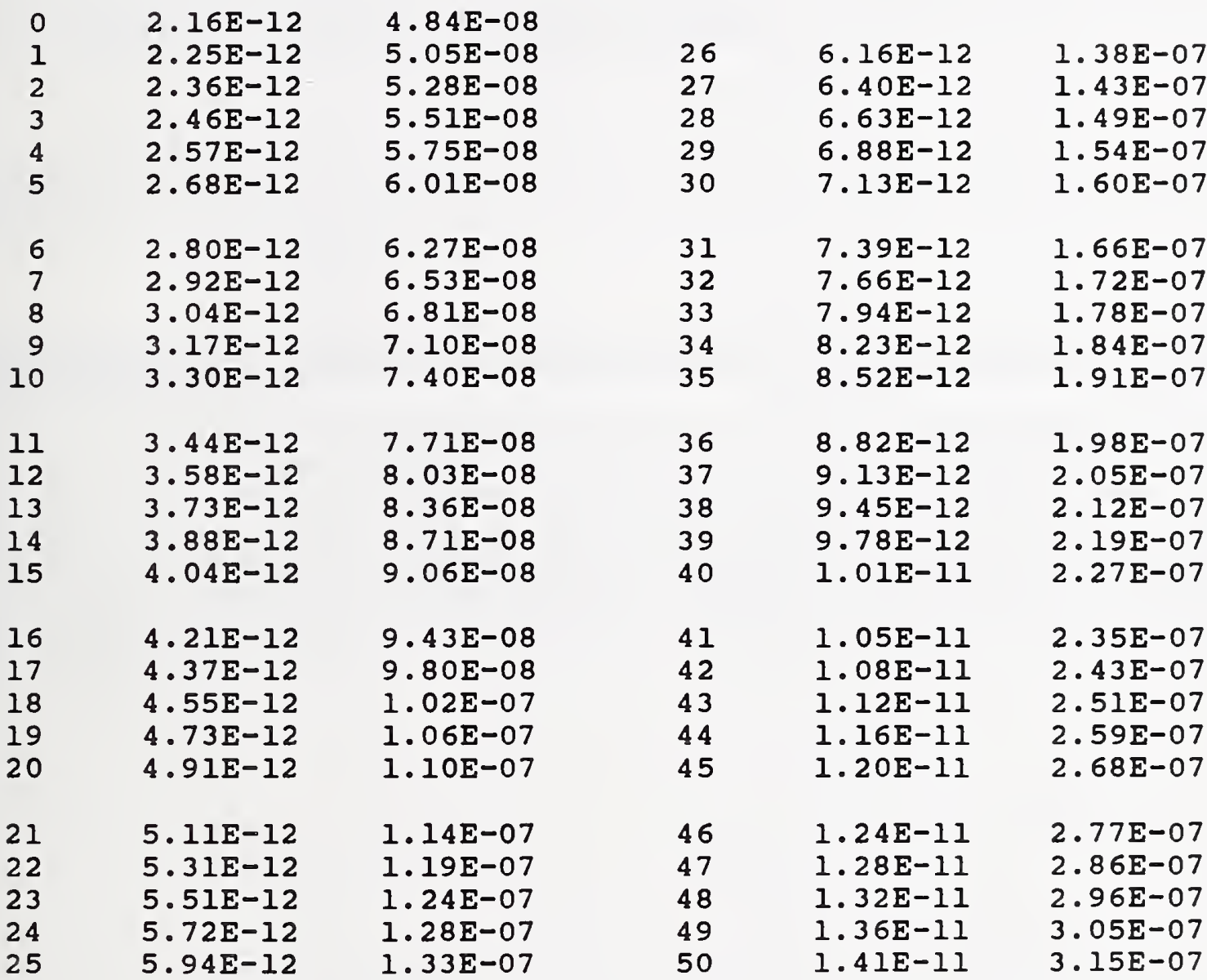

*std cc/s refers to conditions of 1 atmosphere (atm) absolute pressure $(101.325 \mathrm{kPa})$ and $273.15 \mathrm{~K}\left(0^{\circ} \mathrm{C}\right)$. $1 \mathrm{std} \mathrm{cc} / \mathrm{s}=4.46 \times 10^{-5} \mathrm{~mol} / \mathrm{s}$.

${ }^{+}$As noted on page 2, under normal conditions of storage and use the leak rate will decay from the values 1 isted here at an undetermined rate.

Table I

* U.S. G.P.0.1991-311-891/40067

E-3 



\section{BIBLIOGRAPHIC DATA SHEET}

3. PUBLCATION DATE

January 1992

4. TITLE AND SUBTITLE

NIST Leak Calibration Service

5. AUTHOA(S)

Charles D. Ehrlich

Stuart A. Tison

6. PERFORMING ORGANIZATION (IF JOINT OR OTHER THAN NIST, SEE INSTRUCTIONS)

U.S. DEPARTMENT OF COMMERCE

NATIONAL INSTITUTE OF STANDARDS AND TECHNOLOGY

GAITHERSBURG, MD 20899

7. CONTRACT/GRANT NUMBER

8. TYPE OF REPORT AND PEAIOD COVERED Final

9. SPONSORING ORGANIZATION NAME AND COMPLETE ADDRESS (STREET, CITY, STATE, ZIP)

NIST

10. SUPPLEMENTARY NOTES

11. ABSTRACT (A 200-WORD OR LESS FACTUAL SUMMAAY OF MOST SIGNIFICANT INFORMATION. IF DOCUMENT INCLUDES A SIGNIFICANT BIBLOGRAPHY OR UTERATURE SURVEY, MENTION IT HERE.)

This NIST Special Publication describes the recently offered Leak Calibration Service. A description of the services provided is followed by a discussion of the design philosophy and theory, and a description of the total Leak Calibration System. Uncertanties associated with the Primary Leak Standard and Leak Comparator System are discussed in detail. Important properties of helium permeation leaks, especially the temperature dependence, are also discussed. Sections on Quality Control and Future Directions are followed by appendices discussing general theory of gas flow in vacuum systems, and proper use and conversion of flow rate units.

12. KEY WORDS (6 TO 12 ENTAIES; ALPHABETICAL ORDER; CAPITALZE ONLY PROPER NAMES; AND SEPARATE KEY WORDS BY SEMICOLONS) Calibrated leak; helium permeation leak; leak; leak calibration; leak calibration service; leak rate units; leak standards

\section{AVAILABIUTY}

\section{$\mathrm{X}$ UNLMITED}

FOR OFFICIAL DISTRIBUTION. DO NOT RELEASE TO NATIONAL TECHMICAL INFORMATION SERVICE (NTIS).

ORDER FROM SUPERINTENDENT OF DOCUMENTS, U.S. GOVERNMENT PRINTING OFFICE, WASHINOTON, DC 20402.

OADER FROM WATIOWAL TECHWCAL WFOAMATION SERVICE (NTIS, SPRWGFIELD, VA 22161.
14. NUMBER OF PRINTED PAGES

$$
89
$$

15. PRICE 

SP 250-1 Spectral Radiance Calibrations PB87179883

SP 250-2 Far Ultraviolet Detector Standards PB87227609

SP 250-3 Radiometric Standards in the Vacuum Ultraviolet PB87227625

SP 250-4 Fricke Dosimetry in High-Energy Electron Beams PB88110374

SP 250-5 Alpha-Particle Calibrations PB88168620

SP 250-6 Regular Spectral Transmittance PB88108550

SP 250-7 Radiance Temperature Calibrations PB88123674

SP 250-8 Spectral Reflectance PB88109905

SP 250-9 Calibration of Beta-Particle-Emitting Ophthalmic Applicators PB88108535

SP 250-10 Radioactivity Calibrations with the " $4 \pi$ " Gamma lonization Chamber and Other Radioactivity Calibration Capabilities PB88123708

SP 250-11 Dosimetry for High Dose Applications PB88201587

SP 250-12 Neutron Personnel Dosimetry PB87227617

SP 250-13 Activation Foil Irradiation with Californium Fission Sources PB88217443

SP 250-14 Activation Foil Irradiation by Reactor Cavity Fission Sources PB88217435

SP 250-15 Photometric Calibrations PB88153747

SP 250-16 Calibration of X-Ray and Gamma-Ray Measuring Instruments PB88211826

SP 250-17 The NBS Photodetector Spectral Response Calibration Transfer Program PB88201595

SP 250-18 Neutron Source Strength Calibrations PB88211818

SP 250-19 Calibration of Gamma-Ray-Emitting Brachytherapy Sources PB89193858
SP 250-20 Spectral Irradiance Calibrations PB88123781

SP 250-21 Calibration of Beta-Particle Radiation Instrumentation PB88201579

SP 250-22 Platinum Resistance Thermometer Calibrations PB88138367

SP 250-23 Liquid-in-Glass Thermometer Calibration Service PB89128888

SP 250-24 Standard Cell Calibrations PB88123690

SP 250-25 Calibration Service for Inductive Voltage Dividers

SP 250-26 NBS Phase Angle Calibration Services PB88225636

SP 250-27 AC-DC Difference Calibrations PB892222616

SP 250-28 Solid-State DC Voltage Standard Calibrations PB88168703

SP 250-29 Traceable Frequency Calibrations PB88168364

SP 250-30 GOES Satellite Time Code Dissemination: Description and Operation PB88168760

SP 250-31 Mass Calibrations PB89153894

SP 250-32 A Calibration Service for $30 \mathrm{MHz}$ Attenuation and Phase Shift PB88238324

SP 250-33 A Calibration Service for Voltage Transformers and High-Voltage Capacitors PB882252903

SP 250-34 High Vacuum Standard and Its Use PB89193841

SP 250-35 The Calibration of Thermocouples and Thermocouple Materials PB89209340

SP 250-36 A Calibration Service for Current Transformers

SP 250-38 NIST Leak Calibration Service

SP 250-40 Absorbed-Dose Calibration of Ionization Chambers in a ${ }^{80} \mathrm{Co}$ Gamma-Ray Beam SN003-003-03034-1 \$2.00

* Entries Entries containing a stock number (SN003-003-) and price can be purchased from the Superintendent of Documents, U.S. Government Printing Office, Washington, DC 20402. GPO will accept checks, money orders, VISA, and MasterCard. For more infomation, or to place an order, call (202) 783-3238. Be sure to cite the stock number on all orders.

Entries containing PB numbers can be purchased from the National Technical Information Service, Springfield, VA 22161. NTIS will accept American Express in addition to the payment methods listed for GPO. For more information call (703) 487-4650; to place an order call $(800) 336-4700$. Be sure to cite the PB number on all orders.

Entries without stock or PB numbers are in preparation. 


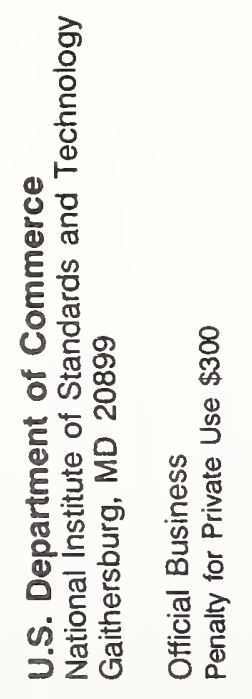

